University of Louisville

ThinkIR: The University of Louisville's Institutional Repository

Electronic Theses and Dissertations

$5-2012$

\title{
Of mice and sigma : conferred antibiotic resistance in the Salmonella enterica serovar Typhimurium murine model.
}

Rena Margaret Wallen 1981-

University of Louisville

Follow this and additional works at: https://ir.library.louisville.edu/etd

\section{Recommended Citation}

Wallen, Rena Margaret 1981-, "Of mice and sigma : conferred antibiotic resistance in the Salmonella enterica serovar Typhimurium murine model." (2012). Electronic Theses and Dissertations. Paper 1503. https://doi.org/10.18297/etd/1503

This Master's Thesis is brought to you for free and open access by ThinkIR: The University of Louisville's Institutional Repository. It has been accepted for inclusion in Electronic Theses and Dissertations by an authorized administrator of ThinkIR: The University of Louisville's Institutional Repository. This title appears here courtesy of the author, who has retained all other copyrights. For more information, please contact thinkir@louisville.edu. 
OF MICE AND SIGMA:

CONFERRED ANTIBIOTIC RESISTANCE IN THE SALMONELLA ENTERICA SEROVAR TYPHIMURIUM MURINE MODEL

By

Rena Margaret Wallen

B.Sc., University of Louisville, 2009

\begin{abstract}
A Thesis
Submitted to the Faculty of the

College of Arts and Sciences of the University of Louisville in Partial Fulfillment of the Requirements

for the Degree of
\end{abstract}

\author{
Masters of Science \\ Department of Biology \\ University of Louisville \\ Louisville, Kentucky
}

May 2012 
OF MICE AND SIGMA:

Conferred Antiobiotic Resistance in the Salmonella enteric serovar Typhimurium Murine Model

By

Rena Margaret Wallen

B.Sc., University of Louisville, 2009

A Thesis Approved on

April 6, 2012

By the following Thesis Committee:

Michael Perlin, Thesis Director

Micah Worley

James Graham 


\section{ACKNOWLEDGEMENTS}

I would like to thank Dr. Michael Perlin for his mentorship, patience, and guidance throughout my research process. I would also like to thank the members

of my committee, Dr. James Graham and Dr. Susanna Remold, for their thoughtful insight and constructive comments. A special thanks is extended to Dr. Micah Worley for jumping in to save the day at the end of the process due to unforeseen circumstances. I would like to thank my fellow Goat Lab Members, Su San Toh, Janhavi Chatterjee, Michael Cooper, Seth Adams, and Kavita Aulakh for their constant support and laughs. Thanks to Josh Thornbrough for teaching me the finer points of mouse gavage.

On a more personal note, thank you to my parents, Ed and Rena Wallen, for their belief in me, even when I doubted. Special appreciation to my brother, Matthew Wallen, for reading countless rough drafts and now knowing more about Salmonella than most people would care to know. And finally, thanks to my husband, Matthew Ashby, for tolerating the long nights and short tempers and for always being my strongest supporter. 


\section{ABSTRACT \\ OF MICE AND SIGMA: \\ CONFERRED ANTIBIOTIC RESISTANCE IN THE \\ SALMONELLA ENTERICA SEROVAR TYPHIMURIUM MURINE MODEL}

\section{Rena Margaret Wallen}

April 6, 2012

Salmonella enterica serovar Typhimurium is an enteric pathogen capable of infecting a wide range of hosts. The manner in which this pathogen is able to interact with its host is difficult to define, as is the case with most microbes. Through the use of alternate sigma factors and other regulatory processes, $S$. Typhimurium is able to invade host cells to establish systemic infections, and survive the assaults of the host immune system. While most strains of $S$. Typhimurium are typically ampicillin sensitive, within the host, survival inside host cells may provide an escape from many antibiotics. Previous research demonstrated that co-culture with ampicillin resistant strains of Escherichia coli is able to provide protection for sensitive $S$. Typhimurium. The current study was an attempt to model this relationship within the host. While $S$. Typhimurium was able to grow within murine hosts in the presence of ampicillin, it is unclear whether this resistance is from coinfection with a resistant strain of $E$. coli or from the ability of $S$. Typhimurium to avoid destruction by antibiotics by invading host cells. 


\section{TABLE OF CONTENTS}

Acknowledgements ..................................................................................................... iii

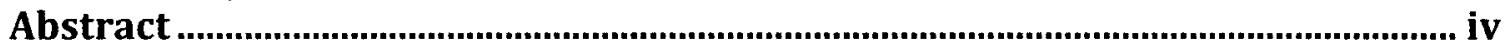

List of Figures ................................................................................................................... vii

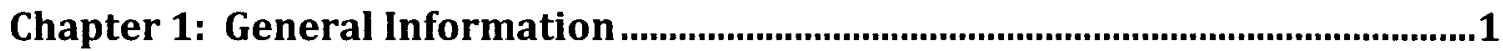

Chapter 2: In Vivo Experiments with Selected Bacterial Strains and

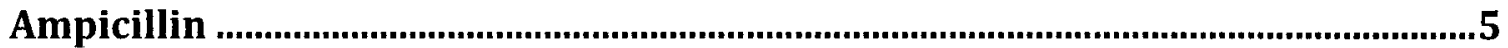

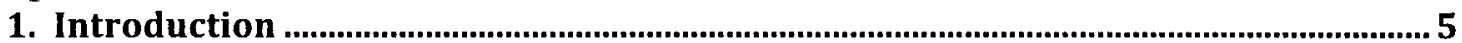

2. Materials and Methods ……........................................................................................5

2.1 Plasmids and Host Bacteria ..................................................................................................... 5

2.2 Mouse Strains ....................................................................................................................

2.3 Innoculation with Bacterial Strains .......................................................................................

2.4 Preparation and Administration of Ampicillin .................................................................... 10

2.5 Sample Collection and Preparation .......................................................................................... 10

3. Results ............................................................................................................... 11

3.1S. Typhimurium grew with resistant strains of $E$. coli in presence of ampicillin..... 11

3.2 S. Typhimurium was not cleared from gut during ampicillin treatment...................... 13

3.3 Sensitive E. coli strains are protected when grown with resistant strains ................. 17

4. Discussion .......................................................................................................................... 19

Chapter 3: In Vitro Studies of the Pharmakinetics of Ampicillin and In Vivo Attempts to Clear $S$. Typhimurium Infection ............................................................22

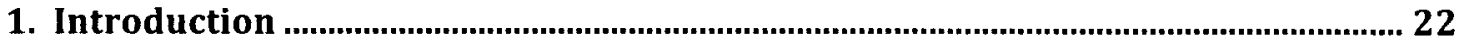

2. Materials and Methods ……………………………………………………………... 24

2.1 Plasmids and Host Bacteria ........................................................................................................ 24

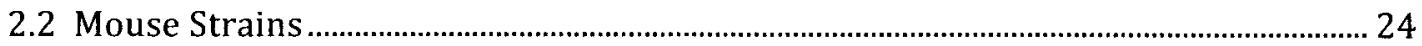

2.3 Innoculation with Bacterial Strains .................................................................................. 24

2.4 Preparation and Administration of Ampicillin .............................................................. 25

2.5 Minimum Inhibitory Concentration of Ampicillin............................................................. 25

2.6 Evaluation of Ampicillin Stability at different $\mathrm{pH}$ and Temperature .............................2.25

2.7 Measurement of bacterial sensitivity when grown in culture .........................................2 26

2.8 Collection and Preparation of Fecal Samples .......................................................................... 27

3. Results ...................................................................................................................... 27

3.1 Temperature and $\mathrm{pH}$ affect bactericidal properties of ampicillin ................................. 27

3.2 Salmonella demonstrates a range of sensitivities to ampicillin ......................................2 29

3.3 S. Typhimurium is ampicillin sensitive at low levels when grown in culture ........... 29

3.4 Attempts to clear $S$. Typhimurium from mouse gut were unsuccessful ...................... 30

4. Discussion .................................................................................................................. 39

Conclusions from In Vivo Modeling ............................................................................43

Chapter 4: The Best of Times and the Worst of Times...........................................46

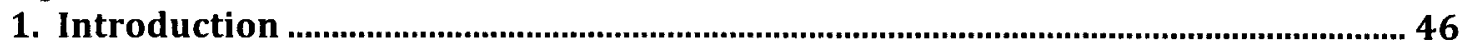


2. Early Virulence-Related Genetic Studies ......................................................................... 49

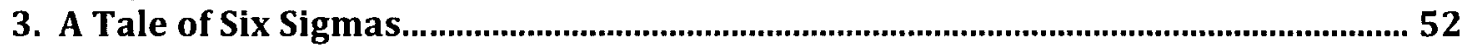

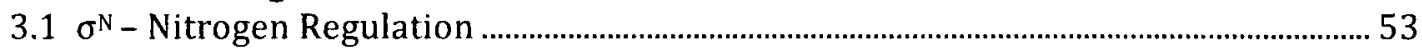

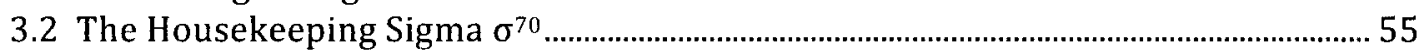

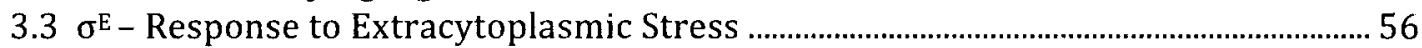

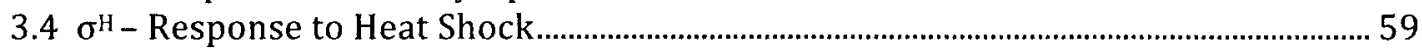

$3.5 \sigma^{\mathrm{S}}$ - Stationary Phase Growth, Response to Stress and Starvation ................................ 61

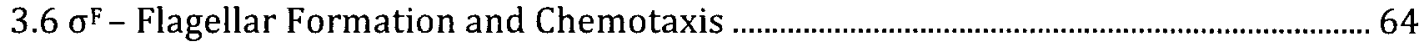

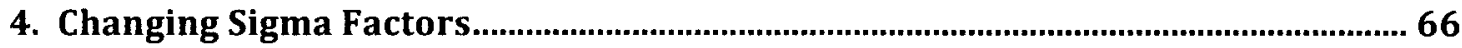

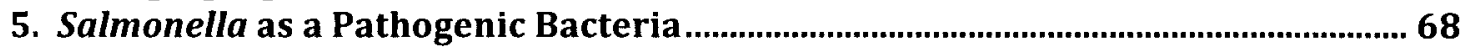

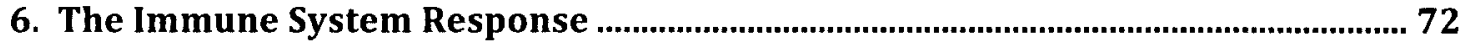

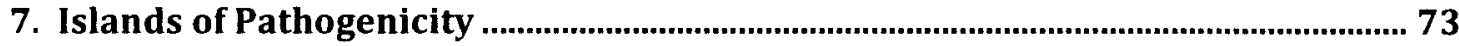

8. Regulation of Salmonella Pathogenicity Islands by Sigma Factors.......................... 76

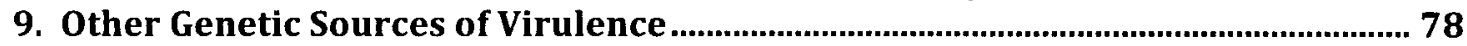

10. A Sigma Factor Cascade Contributes to Survival in Phagocytic Cells ................... 79

11. Sigma Factors Coordinate Gene Expression Together .............................................. 80

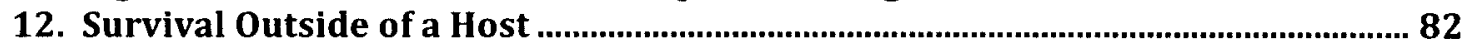

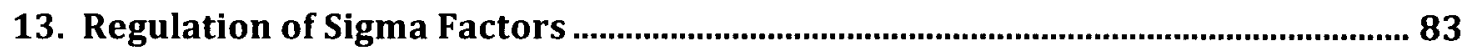

14. Sigma Factors and Other Regulatory Mechanisms .............................................. 85

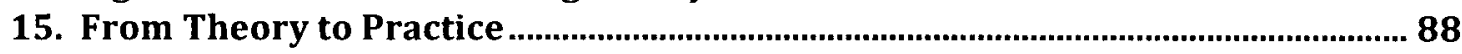

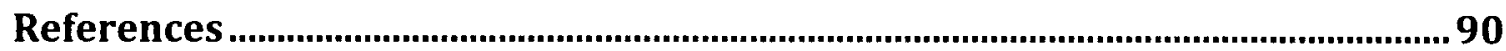

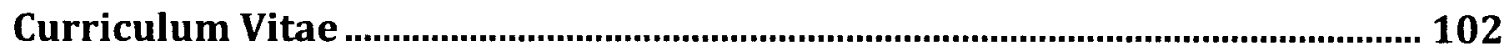




\section{LIST OF FIGURES}

Figure 1: The return of $S$. Typhimurium following ampicillin treatment when grown with a) E. coli Lu53 (pBR322) and b) E. coli 6925 (pSLAR).

Figure 2: Salmonella Typhimurium CFUs observed in cohorts treated with ampicillin $(200 \mu \mathrm{g} / \mathrm{mL})$ for a period of 11 days grown with a) E. coli 6925, b) $E$. coli 6925 (pBR322), c) E. coli 6925 (pSAR), and d) E. coli 6925 (pSLAR).

Figure 3: $S$. Typhimurium was detectable again in the fecal samples from all four cohorts following the removal of ampicillin.

Figure 4: Percentage of sensitive E. coli surviving treatment with ampicillin when grown with $E$. coli (pSAR).

Figure 5: CFUs of a) E. coli 6925, b) S. Typhimurium, and c) E. coli 6925 (pBR322) over the course of 36 hours following inoculation into LB broth containing lethal dosages of ampicillin. For c), the CFUs at 0 hours following inoculation was approximately $3 \times 10^{4}$, similar to the other two strains..

Figure 6: CFUs of $S$. Typhimurium from samples in Cohort 4 following bolus administration.

Figure 7: CFUs of $S$. Typhimurium from samples in Cohort 1 a) during ampicillin treatment (The inset graph is an enlargement of days 2 through 12 where it is apparent that the detectable level of S. Typhimurium did not stay at zero.) and b) following removal of ampicillin.

Figure 8: CFUs of $S$. Typhimurium from samples in Cohort 2 a) during ampicillin treatment (The inset graph is an enlargement of days 2 through 12 . Bacterial load dropped dramatically and then decreased gradually to 0 for the last five days of treatment.) and b) following removal of ampicillin.

Figure 9: CFUs of $S$. Typhimurium from samples in Cohort 3 a) during ampicillin treatment (The inset graph is an enlargement of days 2 through 12 . Bacterial load dropped decreased to undetectable with a few spikes of detectability during treatment.) and b) following removal of ampicillin.

Figure 10: CFUs of $S$. Typhimurium from samples in Cohort 5 a) during ampicillin treatment and b) following removal of ampicillin treatment. 


\section{CHAPTER 1}

\section{GENERAL INFORMATION}

The emergence of antibiotic resistance in bacteria has caused many concerns in the sanitation and health care industries. Most of this resistance seems to be the result of transfer of genetic information between the same or closely related species. However, this may not be the only way that antibiotic susceptible bacteria are able to survive in the presence of bactericidal agents. Previous work has demonstrated that bacteria that do not possess genetic information to produce enzymes conferring resistance may be able to survive in the presence of other bacteria that do, even in the presence of lethal dosages of antibiotics.

The specific antibiotic examined in these studies was ampicillin. Ampicillin is a member of the $\beta$-lactam family of antibiotics that includes amoxicillin and penicillin. This family of antibiotics binds to and prevents the action of transpeptidases that are important in constructing the peptidoglycan layer of the bacterial cell well [1]. Blocking the activity of these transpeptidases renders the bacterium unable to complete its cell wall and results in a loss of osmotic stability and eventually cell death [1]. Sensitivity to this mechanism of action requires the bacteria to be growing and making new cell wall elements. $\beta$-lactam antibiotics are therefore only effective against dividing cells, i.e., not those in stationary phase that are not rearranging and reforming their cell walls. 
One way that bacteria are able to survive ampicillin treatment typically is by producing the enzyme $\beta$-lactamase which modifies with the antibiotic's physical structure and activity. $\beta$-lactamase cleaves the functional ring of $\beta$-lactam antibiotics, rendering them unable to bind to transpeptidases and blocking the activity of the antibiotic. Because this mode of resistance is the production of an enzyme that breaks down the antibiotic, it has been theorized that bacteria producing $\beta$-lactamase may be able to provide some protection for typically sensitive strains colonizing the same system. If this is the case, bacteria may be able to survive antibiotic treatment without acquiring the ability to produce the enzyme. In vitro studies co-culturing ampicillin resistant strains of bacteria with ampicillin sensitive strains in the presence of the drug has produced interesting results. In these studies, the $\beta$-lactamase gene was carried on a plasmid by Escherichia coli. Multiple strains of ampicillin-resistant E. coli were engineered, each producing $\beta$-lactamase from a plasmid introduced into the cell and each demonstrating resistance to high levels of ampicillin treatment. All of the resistant strains in these studies contained the bla $_{\text {тем. }}$ gene, encoding a class A TEM-1 $\beta$ lactamase [2]. Two types of strains were engineered, one in which the $\beta$-lactamase remained inside the bacterial cell producing it and the other that was able to release the enzyme into the extracellular space. Six times more $\beta$-lactamase was found in the media where growing cells releasing the enzyme than in those engineered to keep it inside [3]. Carrying the plasmid did result in some cost to the bacteria [2], as non-plasmid bearing bacteria of the same species were able to outcompete plasmid bearing bacteria in the absence of ampicillin [3]. 
However, in the presence of ampicillin, despite the metabolic cost, carrying the plasmid containing $\beta$-lactamase produced a selective advantage. Moreover, in some cases, typically sensitive bacteria were able to survive when grown in culture with their resistant cousins. The same phenomenon was not observed equally amongst the two different types of strains. When co-cultured with the strain that kept the $\beta$-lactamase within the producing cell, sensitive E.coli were unable to survive; however, in the presence of cells secreting $\beta$-lactamase into the extracellular space, sensitive E.coli were able to survive, albeit at lower level than their resistant benefactors [2]. In a similar study, sensitive $E$. coli were able to survive at only about $3 \%$ of the original population when grown with E. coli releasing $\beta$-lactamase [4]. A considerable amount of $\beta$-lactamase was found in the media where these resistant bacteria had grown [3].

E. coli tend to be commensal species so antibiotic resistance does not present health complications to host organisms. However, species like Salmonella enterica serovar Typhimurium, which are typically pathogenic, may be offered the same protection as their commensal relatives in the presence of antibiotic resistant bacteria. In fact, $S$. typhimurium was observed to survive despite ampicillin treatment in the presence of $E$. coli releasing $\beta$-lactamase. After an initial period of apparent elimination of $S$. Typhimurium lasting about 12 hours, survival of the pathogen was observed after 24 hours grown with $\beta$-lactamase producing $E$. coli and continued to increase through the duration of the experiment [4]. Additionally, unlike the $E$. coli that were not protected by strains retaining $\beta$-lactamase inside the producing cell, $S$. typhimurium when competed against such resistant $E$. coli strains, 
was, able to survive at approximately the same rate as it was able to persist when $\beta$ lactamase was released into the extracellular space [4]. Further analysis of these competitions revealed that no transfer of genetic information had occurred nor did the resistant $E$. coli and sensitive $S$. typhimurium have to be grown in physical contact for the protection to be provided [4]. Moreover, while the $\beta$-lactamase activity in this strain was confined to the producing cell, $\beta$-lactamase was found within the supernatant, indicating cell lysis [4], potentially due to S. typhimurium activity against other bacterial strains. 


\section{CHAPTER 2}

IN VIVO EXPERIMENTS WITH SELECTED BACTERIAL STRAINS AND AMPICILLIN

\section{Introduction}

The current research is an attempt to model the competition between ampicillin resistant and sensitive strains within a host organism, specifically the mouse. Bacterial strains were introduced and monitored in the presence of antibiotic treatment to determine if similar results [4] could be observed within a live host. In vivo modeling provides environments not encountered within an in vitro setting. Inside a host, bacteria interact with host cells and any other bacteria present within the system. The microorganisms must compete for nutrients with the host as well as other bacteria, and the availability of nutrients is limited by the food intake of the host. In the case of the enteric bacteria, consumed food moving through the gastrointestinal tract presents a dynamic environment through which bacteria must negotiate. An attempt to model bacterial competitions within a host must consider these varied conditions.

\section{Materials and Methods}

\subsection{Plasmids and Host Bacteria}

In these studies, $E$. coli strains were competed against other strains of $E$. coli and against $S$. Typhimurium, specifically strain 14028 S. This $S$. Typhimurium strain 
has a functional type three secretion system, necessary for establishing systemic infections, but does not carry any genetic antibiotic resistance.

Three types of plasmids were used to model bacterial competitions in mice, the same three that had been used in previous studies leading to the in vivo model. All of these plasmids were derivatives of pCR2.1 TOPO (Invitrogen, Carlsbad, CA) and were nonconjugative plasmids [3]. Two of these plasmids were constructed by investigators in previous research leading to this work. The SAR plasmid, an acronym for Shared Antibiotic Resistance, carried a copy of the bla TEM-1 gene attached to the $5^{\prime}$ end of a region of DNA containing ompA and Ipp [2]. Along with OmpA and Lpp, $\beta$-lactamase produced from the gene on this SAR plasmid is carried to the outer membrane but in theory remains attached to the cell, extending into the extracellular space where it is able to destroy ampicillin in the vicinity [2]. As noted earlier, because a substantial amount of $\beta$-lactamase was found in the supernatant in which the bacterial strains were grown [3], it is likely that some portion of the $\beta$ lactamase is released from the cell, broken from its tether to the outermembrane, or released into the extracellular milieu upon lysis of the cell.

The SLAR plasmid (Self-Limited Antibiotic Resistant) carries the same $b a_{T E M}$ 1 gene but a mutation in the coding region for the signal peptide prevents the protein from being transported completely into the periplasm [2]. As such, the protein is attached to the cytoplasmic membrane facing the periplasm, and in theory should only provide protection for the cell expressing the gene [2]. Both SLAR and SAR plasmids were introduced into E. coli 6925 , a typical strain used in lab work (F-, relA1, rpsL254(strR), spoT1, metB1, LacZ+, E. coli Stock Center, CGSC, Yale 
University). Without the plasmid, E. coli 6925 is sensitive to ampicillin treatment. These strains will be referred to as (pSAR) and (pSLAR) respectively.

A third plasmid, (pBR322), is a commonly used ColE1-derivative bearing the bla $a_{T E M-1}$ gene, as well as a tetracycline resistance gene [5]. B-lactamase produced from this cell also remains inside the bacterial cell, not released to the extracellular milieu. The plasmid was originally in an E. coli Lu53 background (F-, lacl22(Lacl-), proC43, D(kdpC-kdpA)18, LAM-, lysA28, rpsL139(strR), glpR7(glpn)?, glpR8(glpc), rha-4, thi-1, E. coli Stock Center, CGSC, Yale University). There did not appear to be any differences between the 6925 and Lu53 strains that would influence the outcome of this study. However, later this plasmid was also introduced into the $E$. coli 6925 background to ensure that any differences observed were due to the plasmids and the resulting difference in $\beta$-lactamase localization, not the background strain.

\subsection{Mouse Strains}

Inadvertently, two different strains of mice were used. Originally, the protocol was designed to use only one as the model organism, the $129 \mathrm{xl} / \mathrm{svJ}$ strain from Jackson Laboratories. This mice strain is Nramp1 $+/+[6]$. This gene has been found to be essential in preventing the development of systemic infections in mice. It encodes an integral membrane protein that is recruited to the phagosome containing $S$. Typhimurium within macrophages [7]. This strain of mice will develop an acute infection but it will not become systemic because the pathogen is not able to travel inside cells of the immune system to be transported to other parts of the body. 
Due to a clerical error, a second strain of mice was also used, DBA/2J from Jackson Laboratories as well. Despite this error, fortunately the later strain had been used also for $S$. Typhimurium studies previously. While far more susceptible than $129 \mathrm{xl} / \mathrm{svJ}$ mice in terms of systemic infections, potentially due to a different genotype for the two Nramp1 alleles, these mice develop infections that show intermediate symptoms between extremely susceptible mice strains, like BALB/c and resistant strains like $129 x \mathrm{x} / \mathrm{sv}$ [ [8], indicating that they do not typically succumb quickly to acute infections but succumb quickly to systemic infections when they develop.

Mice were housed in cohorts of 3 to 4 and each cage was treated as one experimental unit. Fecal samples were collected daily from the bottom of the cage. Cage bottoms were then cleaned, sterilized, and returned to the cage. When innoculations were done or treatment was changed (ampicillin to no ampicillin in drinking water, or vice versa), mice were moved to clean and sterile cages with fresh food and water to avoid reexposure from the cage, food, or water.

All mice were handled and cared for in the manner dictated by the Institutional Animal Care and Use Committee in accordance with IACUC protocol \#10019.

\subsection{Innoculation with Bacterial Strains}

Before inoculation with a given bacterial strain, all mice were treated with $500 \mu \mathrm{g} / \mathrm{mL}$ streptomycin, either in sterilized drinking water or by gavage of $100 \mu \mathrm{L}$ of the same concentration, to reduce native microbiota and thereby provide a suitable environment for colonization with the administered bacteria. Drinking 
bottles were sterilized before being filled with streptomycin-containing drinking water. Fecal samples were collected daily and plated on Hektoen agar plates to asses gut microbiota. Streptomycin was administered fresh daily when administered in drinking water.

Each bacterial strain was streaked from frozen stock onto Hektoen agar plates. For strains bearing the plasmid, over night growth was done on plates containing ampicillin at $100 \mu \mathrm{g} / \mathrm{mL}$. The following day, strains were inoculated into and grown overnight in Lysogeny broth (LB). If the strain was supposed to carry a plasmid rendering it resistant to ampicillin, the LB was supplemented with ampicillin at $100 \mu \mathrm{g} / \mathrm{mL}$ to ensure the bacteria administered to the mice contained the plasmid. Samples $(2 \mathrm{~mL}$ ) from the overnight cultures were spun at $20,000 \mathrm{rpm}$ for 10 minutes. The supernatant was removed and the pellets were resuspended in $667 \mu \mathrm{L}$ phosphate buffered saline (PBS) (Invitrogen). From this solution, $100 \mu \mathrm{L}$ was administered to each mouse by gavage.

Prior to gavage, food and water were removed from the mice for 4 hours to ensure no regurgitation during the procedure. A different sterilized gavage needle was used for each cohort. Mice were then monitored for several hours following the procedure to ensure that esophageal tearing had not occurred. For ampicillin resistant strains, mice were pretreated with ampicillin for at least a day prior to infection. The metabolic cost for the bacteria of carrying the plasmid made it difficult to colonize these strains without establishing an artificial selective advantage. 


\subsection{Preparation and Administration of Ampicillin}

Ampicillin was prepared in a concentrated stock, frozen, then thawed and diluted to the appropriate concentration for both agar plates and administration to the animals. Individual aliquots of the concentrated solution were only thawed once to reduce ampicillin degradation due to freezing and thawing repeatedly.

All Hektoen plates with ampicillin contained the antibiotic at a concentration of $100 \mu \mathrm{g} / \mathrm{mL}$. For administration to the mouse cohorts in drinking water, ampicillin from the concentrated stock was diluted into sterilized water and given to the mice in drinking bottles. In most cases, ampicillin was administered at 200 $\mu \mathrm{g} / \mathrm{mL}$. In other cases, the dosage was increased to determine if higher dosage would result in complete clearing of infection. These bottles were cleaned and sterilized following streptomycin treatment. Ampicillin in drinking water was replenished every 24 hours.

\subsection{Sample Collection and Preparation}

Fecal samples were collected daily using tweezers to gather pellets from the bottom of specially designed cages with a mesh wire to catch pellets. The freshest samples were collected to ensure a sample most reflective of the current state in the mouse gut and because they were the easiest samples to process.

Using an adapted protocol [9], fecal samples were weighed prior to processing. Samples were processed fresh or frozen and no difference existed in the data produced comparing frozen vs. fresh fecal samples(data not shown). Into each collection tube, $1000 \mu \mathrm{L}$ of sterilized $\mathrm{dH}_{2} \mathrm{O}$ was added. The pellets were broken up using a small plastic pestle with a blunt end and then vortexed vigorously to ensure 
the pellets were as macerated as possible. These samples were then centrifuged for 10 minutes at $800 \mathrm{rpm}$. The supernatant was removed and transferred to clean microcentrifuge tubes. The supernatant was then centrifuged for 5 minutes at 6000 rpm. The supernatant from this centrifugation was then removed and the pellet containing bacteria was resuspended in $200 \mu \mathrm{L}$ sterile $\mathrm{dH}_{2} \mathrm{O}$. This sample was either used to plate undiluted samples or to serially dilute samples so that it was possible to count colony forming units (CFUs). Dilutions were plated until CFUs on one plate were between 20 and 200 colonies to ensure accurate count. All samples were plated on Hektoen agar plates, with ampicillin $(100 \mu \mathrm{g} / \mathrm{mL})$ to determine if the strains growing were ampicillin resistant or without antibiotic.

Plated samples were grown overnight at $37^{\circ} \mathrm{C}$ and CFUs counted following 24 hours of growth. In some cases, samples were retained and if plated dilutions could not be counted accurately, further serial dilutions were performed and plated.

\section{Results}

\subsection{S. Typhimurium grew with resistant strains of $E$. coli in presence of ampicillin.}

$S$. Typhimurium was able to colonize DBA/2J mice first cleared of gut flora by gavage with $100 \mu \mathrm{L}$ of $500 \mu \mathrm{g} / \mathrm{mL}$ streptomycin and then inoculated with $E$. coli strains carrying plasmids rendering them resistant to the bactericidal activity of ampicillin. E. coli strains carrying pBR322 or pSLAR plasmids were first inoculated into the mouse. Once the colonization of these strains was verified, ampicillin treatments at $200 \mu \mathrm{g} / \mathrm{mL}$ were begun, and the colonies obtained from fecal samples were able to persist indicating that the inoculum had contained plasmid-bearing bacteria. After ampicillin was removed, each cohort was then inoculated with $S$. 
Typhimurium, which was allowed to colonize for several days. Summarily, ampicillin treatment was restarted to determine if $S$. Typhimurium was able to persist. After 4 days ( 96 hours) of growth treatment with ampicillin when $S$. Typhimurium was grown alone, the bacteria were not detectable from fecal samples (data not shown).

When grown the E. coli Lu53 (pBR322), 24 hours after treatment with ampicillin, $S$. Typhimurium dropped to an almost undetectable level. However, after 48 hours, the pathogen had begun to recolonize and grew steadily over the next few days (Figure 1a). Prior to treatment with ampicillin, S. Typhimurium grew at approximately $3.99 \times 10^{4} \mathrm{CFU}$ per milligram fecal sample, although it did not displace Lu53 (pBR322) and they were growing in an essentially 50:50 ratio within the mouse gut based on fecal samples. 24 hours after the ampicillin regiment was begun, the $S$. Typhimurium detectable growth dropped to $409 \mathrm{CFU}$ per milligram fecal sample, a reduction of $98.98 \%$. At the peak of growth during ampicillin treatment, when grown with Lu53 (pBR322), $S$. Typhimurium was able to return to a level of $8.8 \times 10^{3} \mathrm{CFU}$ per milligram fecal sample, $22 \%$ of the original growth without ampicillin present. This pattern was similar to results observed in a similar in vitro model (Perlin 2009), with an initial period of $S$. Typhimurium near disappearance followed by recolonization.

When grown with E. coli 6925 (pSLAR) strain, different results for $S$. Typhimurium were observed. When initially grown with E. coli 6925 (pSLAR) without ampicillin, $S$. Typhimurium grew at the rate of $3.88 \times 10^{4}$, a comparable rate as that observed with Lu53 (pBR322). However, after 24 hours of treatment with 
ampicillin, the observable number of CFUs for $S$. Typhimurium remained high, roughly the same for the first 24 hours and then dropping off to undetectable after 48 hours. After 72 hours, $S$. Typhimurium began to show signs of recolonization, but only at very low levels, the maximum CFU count being $3.07 \times 10^{3}$ per milligram sample, $7.9 \%$ of the growth observed without ampicillin.

\subsection{S. Typhimurium was not cleared from gut during ampicillin treatment}

A replication of the previous study was again attempted in DBA/2J mice. In this case, streptomycin was administered at a concentration of $500 \mu \mathrm{g} / \mathrm{mL}$ in drinking water, rather than by gavage. Clearing of the gut was observed before bacterial inoculation occurred. Inoculation with bacterial strains was quickly followed by treatment with ampicillin for cohorts infected with resistant strains to assist in colonization of the gut. Once the $E$. coli infection was confirmed, $S$. Typhimurium 14028 was added to all four cohorts.

When grown with E. coli 6925 not carrying a plasmid and therefore sensitive to ampicillin, $S$. Typhimurium completely displaced the well-established $E$. coli within 48 hours. Unexpectedly, when ampicillin treatment began at $200 \mu \mathrm{g} / \mathrm{mL}$, while clearance had been observed previously when $S$. Typhimurium growing alone, the bacteria survived at a low rate throughout 11 days of treatment (Figure 2a), reaching a maximum of $754 \mathrm{CFU}$ per milligram fecal sample. After an initial period of apparent clearing, $S$. Typhimurium was able to recolonize despite continued ampicillin treatment.

When grown with E. coli 6925 (pBR322), S. Typhimurium was not able to displace the E. coli 6925 (pBR322) but grew with it. With ampicillin treatment, 
a)

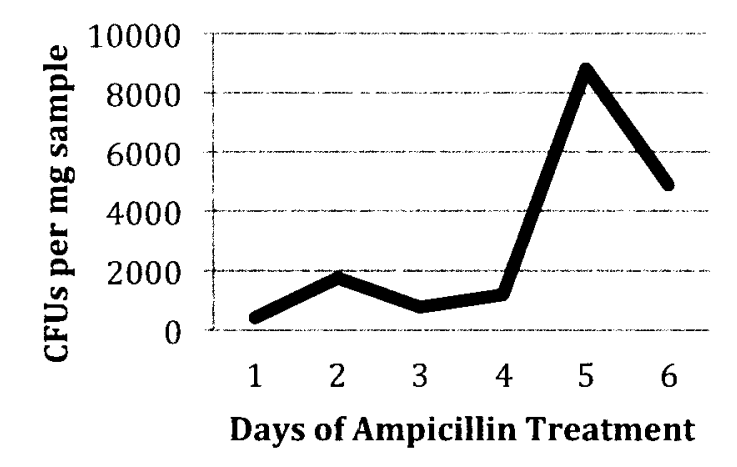

b)

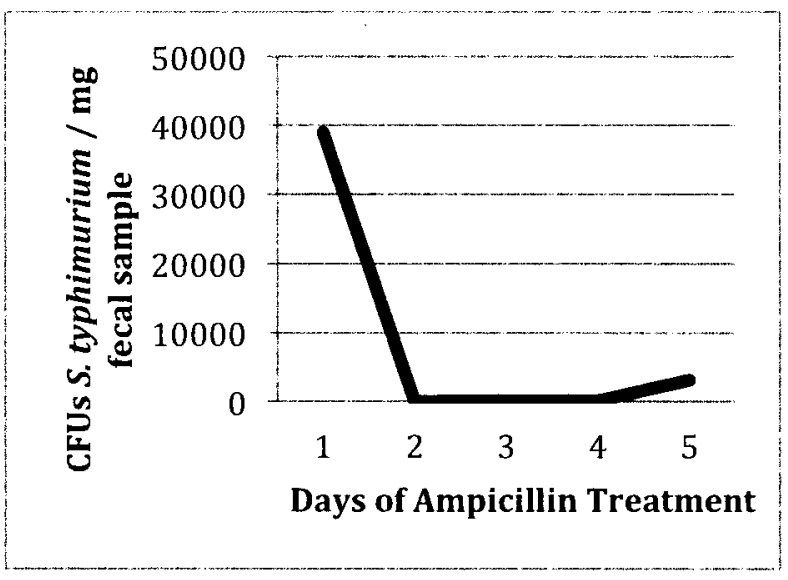

Figure 1: The return of $S$. Typhimurium following ampicillin treatment when grown with a) E. coli Lu53 (pBR322) and b) E. coli 6925 (pSLAR).

$S$. Typhimurium was able to persist but at much lower levels than observed with $E$. coli 6925 (Figure 2b), reaching only a maximum of $66 \mathrm{CFU}$ per milligram fecal sample. After 9 days of ampicillin treatment, no colonies of $S$. Typhimurium were detected in fecal samples from this cohort with continued antibiotic administration. When grown with E. coli 6925 (pSAR), again $S$. Typhimurium was not able to displace the originally established bacteria but instead grew with it. Upon initiation of ampicillin treatment, after a few days of what seemed to be elimination of the pathogen, $S$. Typhimurium returned and was observed at a level higher than 
observed with the $E$. coli 6925 cohort, reaching a maxium of $1.5 \times 10^{3} \mathrm{CFU}$ per milligram fecal sample (Figure 2c), although the concentration appeared to drop after 10 days of treatment.

When grown with E. coli 6925 (pSLAR), S. Typhimurium grew along with the commensal species until the introduction of ampicillin. Upon initiation of the ampicillin regiment, the $S$. Typhimurium seemed to be eliminated. However, 8 days into treatment, $S$. Typhimurium colonization was again observed at reasonably high levels, 727 CFU per milligram fecal sample (Figure 2 d). This level of colonization was, however, comparable to levels $S$. Typhimurium was able to achieve when grown without a protective resistant $E$. coli strain. On day 11 of ampicillin treatment, all cohorts showed complete clearing of $S$. Typhimurium. Unlike the other three cohorts, this was the only day of total clearing observed for this cohort from fecal samples.

After 11 days of treatment with ampicillin at $200 \mu \mathrm{g} / \mathrm{mL}$, the dosage was increased to $400 \mu \mathrm{g} / \mathrm{mL}$ to determine if the $S$. Typhimurium could be cleared completely and for multiple days at a higher dosage. For the two days this level of ampicillin treatment continued, no $S$. Typhimurium CFUs were observed in the fecal samples from all four cohorts. After two days of treatment with ampicillin at 400 $\mu \mathrm{g} / \mathrm{mL}$ in drinking water, ampicillin treatment was removed from all four cohorts to determine if $S$. Typhimurium was able to recolonize. One day following the removal of ampicillin treatment, no CFUs appeared in any of the four cohorts. However, 48 hours following the removal of ampicillin treatment all cages had returned to levels of $S$. Typhimurium colonization similar to those prior to initial treatment (Figure 3). 
Thus, in only 48 hours without treatment, the few bacterial cells able to survive the increased level of antibiotic treatment, $S$. Typhimurium was able to reestablish colonization of the gut detectable in fecal samples as if treatment with ampicillin had never occurred.

Attempts to use a similar infection model in $129 \mathrm{xl} / \mathrm{svJ}$ mice failed, primarily due to the lack of establishment of the desired bacteria. The guts were cleared by the streptomycin but verifying the establishment of the inoculated strains was never determined from fecal samples.

a)

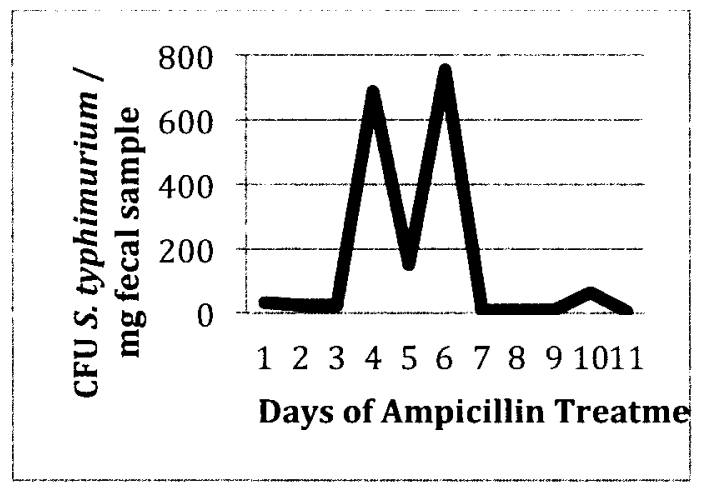

c)

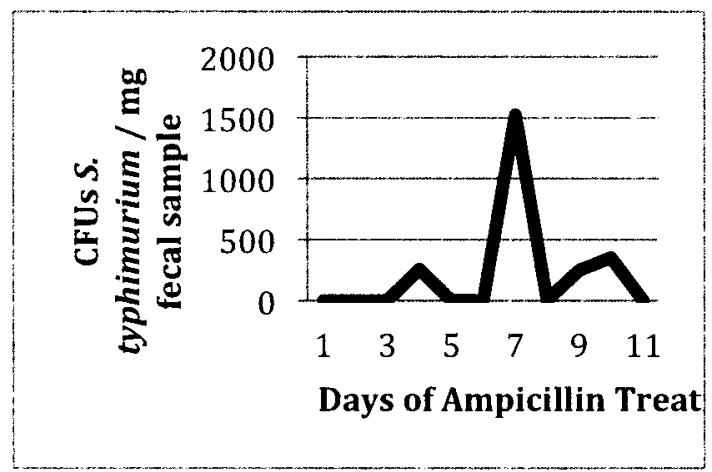

b)

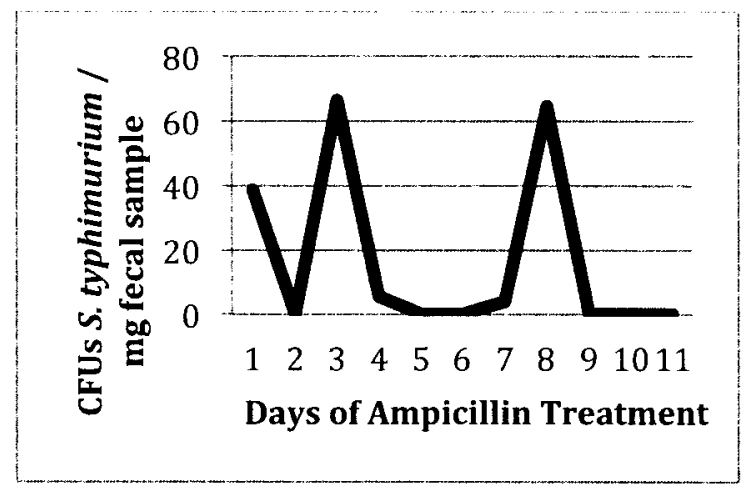

d)

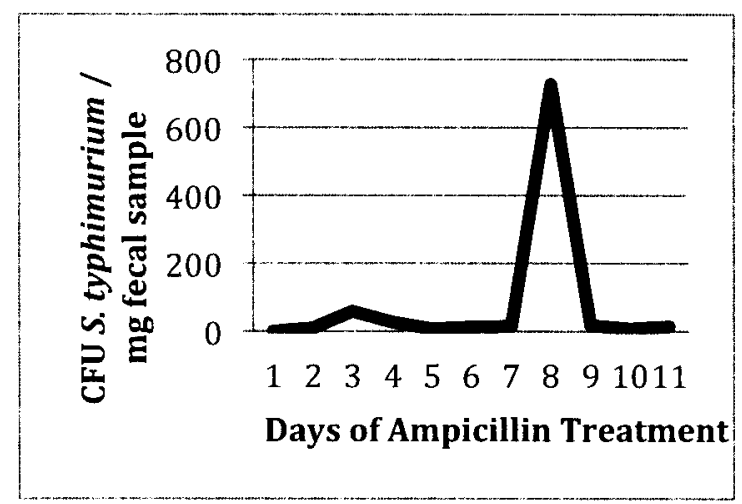

Figure 2: Salmonella Typhimurium CFUs observed in cohorts treated with ampicillin $(200 \mu \mathrm{g} / \mathrm{mL})$ for a period of 11 days grown with a) E. coli 6925 , b) E. coli 6925 (pBR322), c) E. coli 6925 (pSAR), and d) E. coli 6925 (pSLAR). 


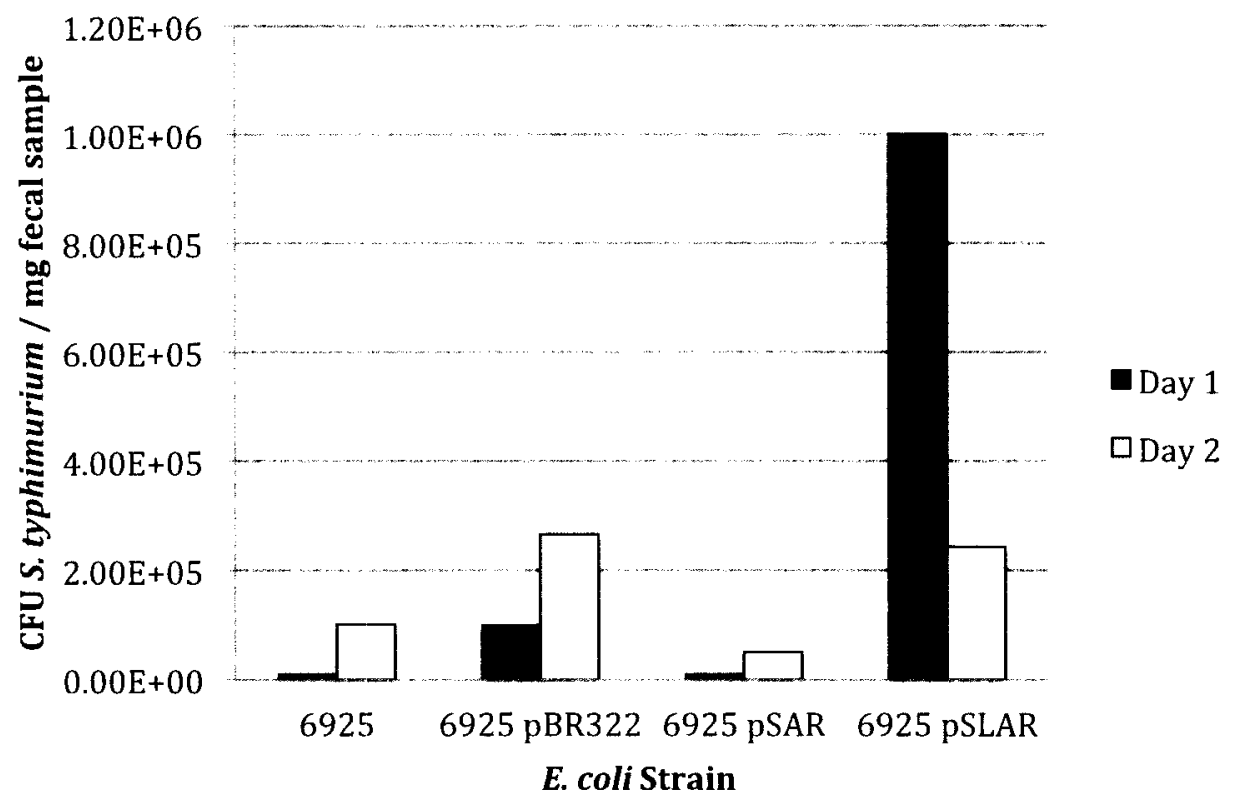

Figure 3: $S$. Typhimurium was detectable again in the fecal samples from all four cohorts following the removal of ampicillin.

\subsection{Sensitive E. coli strains are protected when grown with resistant strains}

Using DBA/2J mice, three cohorts originally inoculated with each of the three resistant strains of E. coli, E. coli (pBR322), E. coli (pSAR), and E. coli (pSLAR), while being treated with ampicillin to provide a selective pressure for the strains to retain their plasmids. After confirmation that the inoculated strains were established, ampicillin treatment was removed and $E$. coli 6925 was added. After giving the bacteria 24 hours to colonize the gut in absence of antibiotic treatment, ampicillin was returned to the cohorts in drinking water at $200 \mu \mathrm{g} / \mathrm{mL}$.

Because it was impossible on Hektoen plates to distinguish $E$. coli carrying the plasmid from plasmid-free cells, replicating plating was done to determine what portion of CFUs represented those with or without the plasmid. Cells from each sample were diluted and plated until individual cells could be counted. Individual 
colonies were then streaked onto drug-free plates. The same colonies were then replica streaked on agar containing ampicillin to determine if any non-plasmid carrying colonies survived treatment with ampicillin. Since plasmid loss is possible given the metabolic cost of carrying it, it is not beyond the realm of possibility that some of the sensitive colonies are the result of cells losing plasmids. However, if these bacteria were still able to survive in the presence of ampicillin, they would still be considered protected.

After 8 days of treatment, ampicillin sensitive $E$. coli were able to survive in the presence of $E$. coli (pSAR) and $E$. coli (pSLAR). In the presence of $E$. coli 6925 (pBR322), no sensitive E. coli were observed to have survive (data not shown). When grown with E. coli 6925 (pSAR), an average of $31.7 \%$ of cells screened were sensitive over three days of treatment (Figure 4). In the cohort originally inoculated with $E$. coli (pSAR), all of the colonies screened were sensitive to ampicillin when streaked on drug plates.

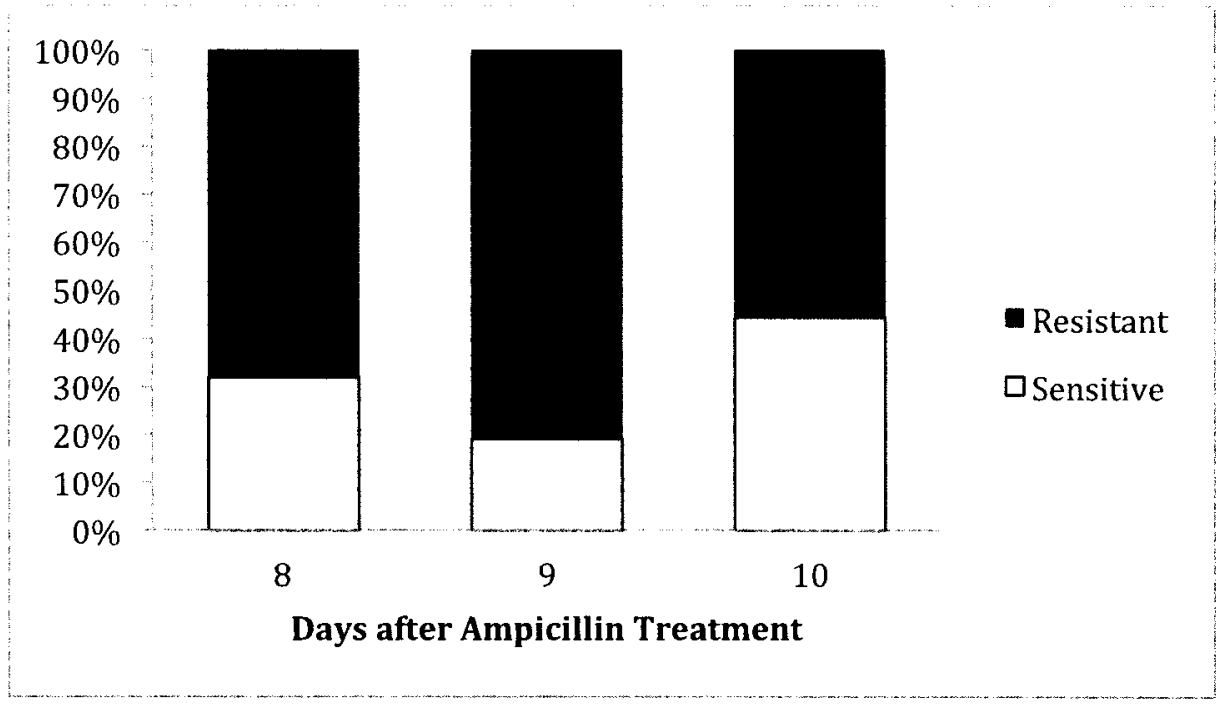

Figure 4: Percentage of sensitive $E$. coli surviving treatment with ampicillin when grown with E. coli (pSAR). 
Attempts to replicate this model in $129 \mathrm{xl} / \mathrm{svJ}$ mice also failed due to similar problems with establishing administered bacteria strains as discussed above. Streptomycin pretreatment followed by inoculation resulted in clear fecal samples.

\section{Discussion}

Previous in vitro models had demonstrated that ampicillin-resistant $E$. coli strains were able to provide protection for sensitive strains of both $E$. coli and $S$. Typhimurium when grown together in media as bacteria cultures. This protection was a function of the ability of the $\beta$-lactamase produced by ampicillin-resistant strains to destroy enough ampicillin to allow these sensitive strains to grow without acquiring the ability to produce the enzyme themselves or other resistance mutations.

When an in vivo model was attempted using mice, mixed results were observed. In the mouse, similar protective effects were observed for sensitive strains of E. coli, similar to results from in vitro studies [2], [3]. Because these sensitive strains were cleared easily when grown alone and treated with ampicillin, it is likely that this model did demonstrate the ability of resistant $E$. coli to protect their sensitive relatives. It was impossible to determine if the sensitive strains were actually the E. coli 6925 introduced or members of the originally resistant strain who had lost their plasmids, so called cheaters [2], but it was clear that sensitive and resistant strains of $E$. coli were growing within the same mouse gut environment during ampicillin treatment.

The proportion of sensitive to resistant $E$. coli growing together was consistent with what was expected given the location of the $\beta$-lactamase within the 
resistant cells. $E$. coli (pBR322) provided no detectable protection for sensitive $E$. coli, consistent with the ability to maintain $\beta$-lactamase inside the resistant cell. $E$. coli 6925 (pSAR) provided almost complete protection for sensitive bacteria, with the majority of the bacteria persisting in the mouse after several days of treatment with ampicillin being sensitive. E. coli 6925 (pSLAR) produced intermediate results, as expected, since in this case, the $\beta$-lactamase protein is tethered to the periplasmic membrane and is acting upon ampicillin but not in the extracellular space. A substantial proportion of sensitive $E$. coli were able to survive despite treatment with a typically lethal dosage of ampicillin.

However, $S$. Typhimurium presented the interesting case. At first it appeared that resistant $E$. coli were able to offer protection to ampicillin sensitive $S$. Typhimurium when grown inside the mouse simultaneously, similar to results previously observed [4]. However, it later became apparent that the dosage of ampicillin being administered was not sufficient to eliminate the $S$. Typhimurium infection alone. As such, it was impossible to determine if protection was actually occurring or if the $S$. Typhimurium infection was able to sustain because the dosage of ampicillin was not sufficient to eliminate the pathogen. It was apparent that the bacteria were not eliminated because upon the removal of ampicillin treatment, $S$. Typhimurium was able to recolonize the mouse gut.

These inconsistent results prompted further investigation into the pharmokinetics of ampicillin, particularly the ampicillin as used in the manner prepared for these in vitro studies. Experiments were also designed to determine the effect of $\mathrm{pH}$ and temperature inside the mouse on the effectiveness of ampicillin 
as an antibacterial agent. Moreover, it was pertinent to determine at what dosage of ampicillin $S$. Typhimurium was no longer able to survive inside the mouse gut when grown without ampicillin-resistant E. coli. 


\section{CHAPTER 3}

\section{IN VITRO STUDIES OF THE PHARMAKINETICS OF AMPICILLIN AND IN VIVO ATTEMPTS TO CLEAR S. TYPHIMURIUM INFECTION}

\section{Introduction}

Ampicillin has been widely used to treat both Gram negative and Gram positive bacterial infections. However, even among the family of $\beta$-lactams, it is not the most effective. While other $\beta$-lactams like amoxicillin showed a measurable therapeutic effect at dosages as low as $20 \mathrm{mg} / \mathrm{kg}$, ampicillin only had limited effectiveness at $200 \mathrm{mg} / \mathrm{kg}$ [10]. In humans, ampicillin has a low oral bioavailability, approximately 30 to $40 \%$ [11]. The serum half-life of ampicillin in humans is 1.8 hours [12], indicating that it is quickly degraded at physiological conditions. This may have contributed to results observed previously in in vivo models of $S$. Typhimurium and $E$. coli infections.

For ampicillin like other antibiotic drugs to be effective, it must be able to penetrate the tissue in which the bacteria is found or survive the $\mathrm{pH}$ of the gastrointestinal tract to reach bacteria growing in the luminal space of the small intestines [12]. The low bioavailability of ampicillin is a product of its hydrophilicity and mechanisms of absorption when administered orally [11]. There is some evidence that ability to enter into infected tissues is decreased at decreasing $\mathrm{pH}$, such as is found in the gastrointestinal tract [11]. If the ampicillin is able to survive the low $\mathrm{pH}$ conditions of the stomach, the $\mathrm{pH}$ within the intestine is near 
neutral and entrance may be easier, although the effective dosage will be dramatically reduced. Even once the antibiotic survives physiological conditions to reach the site of infection, it still must be able to interact with the bacteria in a specific way to cause cell death. In the case of $E$. coli, ampicillin must traverse the outer membrane to reach its target, which is typically done through general diffusion porins within the bacterial cell [13].

In early murine models of $S$. Typhimurium infection, treatment of a $S$. Typhimurium infection for three days with subcutaneous injections of ampicillin at a dosage of $64 \mathrm{mg} / \mathrm{kg}$ mouse weight prevented an increase of bacteria in the blood and spleen but did not eliminate the infection [12]. In the same study, significant decrease in bacterial load in the blood was found with dosages as low as $16 \mathrm{mg} / \mathrm{kg}$ while reduction of mortality was observed at dosages greater than $64 \mathrm{mg} / \mathrm{kg}$ [12]. These results indicate that ampicillin may be able to control the increase of a $S$. typhimuium infection but not necessarily eliminate it completely. Moreover, these measures are of a systemic infection, not infection only within the gastrointestinal tract, and ampicillin treatment may be different within this system.

Our previous attempts to model the ability of ampicillin resistant $E$. coli to provide protection for typically sensitive $S$. Typhimurium may have been complicated by the inability of ampicillin to effectively eliminate the pathogen infection. As such, the protection observed may be a result of ineffective dosage rather than the $\beta$-lactamase produced by the resistant strains eliminating enough ampicillin within the system to allow some of the sensitive bacteria to survive. The following set of experiments was a means of examining both the pharmokinetics of 
ampicillin as it was prepared for the murine model in Chapter 2 and attempting to find the dosage at which the $S$. Typhimurium infection could be eliminated.

\section{Materials and Methods}

\subsection{Plasmids and Host Bacteria}

E. coli and $S$. Typhimurium strains were the same as used previously: E. coli 6925, E. coli 6925 (pSAR), E. coli 6925 (pSLAR), and S. Typhimurium. Before each experiment, strains were streaked from pure frozen stock. LB broth was then inoculated with the bacterial strains and grown overnight.

For in vitro work, overnight cultures were diluted by 100 and then grown until the cell densities measured spectophotometrically indicated logarithmic growth.

\subsection{Mouse Strains}

For in vivo models, both mouse strains previously described (Chapter 2) were used: DBA/2J and 129xl/svJ. In vivo murine models were an attempt to determine the dosage of ampicillin to clear $S$. Typhimurium infection. Mice lived in cohorts of two.

\subsection{Innoculation with Bacterial Strains}

Before inoculation, mice were again treated with $500 \mu \mathrm{g} / \mathrm{mL}$ streptomycin in drinking water from sterilized bottles to render the gut clear for establishing $S$. Typhimurium infection. Food and water were removed for 4 hours prior to inoculation. Each mouse was administered by gavage $100 \mu \mathrm{g}$ of bacterial suspension prepared as described previously. Mice were again monitored for 
several hours following the procedure to determine if esophageal tearing had occurred during gavage.

\subsection{Preparation and Administration of Ampicillin}

Ampicillin was prepared as before, diluted from a concentrated stock for each administration to the mice cohorts. Five cohorts of mice were used, each receiving a different dosage of ampicillin, either in a single dosage or in drinking water: $200 \mu \mathrm{g} / \mathrm{mL}$ as previously used, $400 \mu \mathrm{g} / \mathrm{mL}, 600 \mu \mathrm{g} / \mathrm{mL}$, a single bolus of 100 $\mu \mathrm{L}$ of $500 \mu \mathrm{g} / \mathrm{mL}$ ampicillin, and a single bolus of $100 \mu \mathrm{L}$ of $500 \mu \mathrm{g} / \mathrm{mL}$ followed by $200 \mu \mathrm{g} / \mathrm{mL}$ in drinking water. For administration in drinking water, fresh ampicillin was made daily.

\subsection{Minimum Inhibitory Concentration of Ampicillin}

Hektoen and LB agar plates were prepared containing decreasing concentrations of ampicillin: $800,400,200,100,50,12.5,6.25,3,12$, and 1.56 $\mu \mathrm{g} / \mathrm{mL}$. All five strains of bacteria, E. coli 6925, E. coli 6925 (pSAR), E. coli 6925 (pSLAR), and $S$. Typhimurium, were grown to mid-logarithmic growth phase as confirmed by optical density. $15 \mu \mathrm{L}$ of bacterial suspension was spotted onto each plate and plates were grown for 24 hours, incubated at $37^{\circ} \mathrm{C}$. Statistical analyses of growth/inhibition were done using 1-tailed t-tests.

\subsection{Evaluation of Ampicillin Stability at different $\mathrm{pH}$ and Temperature}

Ampicillin was prepared at a concentration of $200 \mu \mathrm{g} / \mathrm{mL}$ and then subjected to different conditions for 24 hours, with measurements taken ever 6 hours. These conditions were meant to simulate those found within the mouse and during the 
administration of the drug as part of the experiment. As the ampicillin administered to mouse cohorts was left at room temperature, degradation of ampicillin at room temperature may have dramatically decreased. Ampicillin was left at room temperature, as well as stored at $37^{\circ} \mathrm{C}$ at the approximate at a $\mathrm{pH}$ of 4 , the approximate $\mathrm{pH}$ of the murine and human stomach in a fasted condition; $\mathrm{pH}$ was maintained at $\mathrm{pH} 4$ in acetate buffer. Sterilized $\mathrm{dH}_{2} \mathrm{O}$ at room temperature and the acetate buffering solution at $37^{\circ} \mathrm{C}$ were used as controls to determine if $\mathrm{pH}$ alone had an effect on bacterial viability.

The $\mathrm{pH}$ of each solution was measured at 0 hours and again at 24 hours to determine if the $\mathrm{pH}$ of any of the solutions changed over time. Samples were taken every six hours and frozen until all samples had been collected. Discs made using a standard hole punch from filter paper were impregnated with $10 \mu \mathrm{L}$ of each solution and allowed to dry before being placed on bacterial plates.

Sensitive strains of bacterial, E. coli 6925 and S. typhimuium, and resistant $E$. coli 6925 (pBR322) were grown in LB to mid-logarithmic phase as confirmed by measuring optical density. $150 \mu \mathrm{L}$ of each bacterial suspension were spread onto LB agar and Hektoen agar plates. Impregnated disks were placed on the plates and plates were incubated for 24 hours at $37^{\circ} \mathrm{C}$.

\subsection{Measurement of bacterial sensitivity when grown in culture}

Three strains of bacteria, one known to be ampicillin sensitive, E. coli 6925 , one known to be ampicillin resistant, E. coli 6925 (pBR322), and $S$. Typhimurium were grown in LB overnight from pure frozen stock. After growing overnight, all 
three cultures were diluted by 100 fold into LB broth and grown to mid-logarithmic phase, as measured spectophotometrically.

$100 \mathrm{~mL}$ of LB broth containing ampicillin at 50,100 , and $200 \mu \mathrm{g} / \mathrm{mL}$ in 500 $\mathrm{mL}$ flasks were inoculated with $100 \mu \mathrm{L}$ of the bacterial suspension. Samples were taken every 12 hours. Measurements of bacterial growth and/or survival were made spectophotometrically and by plating.

\subsection{Collection and Preparation of Fecal Samples}

Fecal samples were collected daily and processed as described in Chapter 2 .

\section{Results}

\subsection{Temperature and $\mathrm{pH}$ affect bactericidal properties of ampicillin}

For the control strain, resistant E. coli (pBR322), no difference was observed in the inhibitory properties of ampicillin regardless of time, temperature, or $\mathrm{pH}$ at which the ampicillin was stored for 24 hours; i.e., all measured zones of inhibition were 0 . The $\mathrm{pH}$ of the ampicillin solution was 7.0 at 0 and 24 hours and the $\mathrm{pH}$ of the buffered solution alone and containing ampicillin was 4.1 at 0 and 24 hours.

For sensitive E. coli 6925, when grown on Hektoen plates, no inhibitory properties of sterilized water or the $\mathrm{pH}$ buffering system were observed. The zone of inhibition around the impregnated disc was significantly smaller after 6 hours of $200 \mu \mathrm{g} / \mathrm{mL}$ ampicillin at room temperature than immediately after the ampicillin was prepared ( $\mathrm{p}<0.05)$, and continued to decrease over the course of 24 hours, indicating that the ampicillin was degrading at room temperature and therefore was less able to eliminate the sensitive bacteria. When plated on LB agar, a significant 
difference was not observed from the initial zone of inhibition until the 24 hour sample $(\mathrm{p}<0.005)$, but differences at 12 and 18 hours showed trends toward significance $(p=0.058$ and $p=0.018$ respectively $)$.

For ampicillin $200 \mu \mathrm{g} / \mathrm{mL}$ stored at $37^{\circ} \mathrm{C}$ and $\mathrm{pH} 4$ to simulate physiological conditions, the impregnated disks had significantly smaller zones of inhibition around them for E. coli 6925 grown on Hektoen after 24 hours ( $\mathrm{p}<.05$ ), and though not significant, a similar trend was observed after 18 hours $(p=0.18)$. When grown on LB plates, no significant decrease in zone of inhibition was observed over 24 hours, potentially due to different agar properties.

For $S$. Typhimurium 14028S, no differences in zone of inhibition were observed for $200 \mu \mathrm{g} / \mathrm{mL}$ at room temperature or stored at $37^{\circ} \mathrm{C}$ and $\mathrm{pH}$ when grown on Hektoen. However, when grown on LB plates, after 12 hours, the zone of inhibition around impregnated disks containing $200 \mu \mathrm{g} / \mathrm{mL}$ stored at room temperature was significantly smaller $(\mathrm{p}<.01)$ and continued to get smaller over the course of he 24 hour experiment. For the $200 \mu \mathrm{g} / \mathrm{mL}$ ampicillin stored at $37^{\circ} \mathrm{C}$ and $\mathrm{pH}$, a significantly smaller zone of inhibition was observed after 6 hours $(\mathrm{p}<0.05)$ and over the 24 hour observation period, the observed zones of inhibition continued to decrease.

The difference between the two sensitive strains may be a result of their different sensitivities to ampicillin. Moreover, $S$. Typhimurium was at a higher optical density (and therefore more cells were growing) at the time of plating than either $E$. coli strain. Either way, it is clear that the bactericidal properties of ampicillin decrease at room temperature and at physiological temperature and $\mathrm{pH}$ 
over 24 hours. As such, the effective dosage the mice were receiving was not constant between changes of the ampicillin.

\subsection{Salmonella demonstrates a range of sensitivities to ampicillin}

When plated on Hektoen and LB plates containing various concentrations of ampicillin, $S$. Typhimurium was for the most part eliminated at fairly low concentrations but a few cells in each sample were able to persist across a range of concentrations (Table 1).

Although most $S$. Typhimurium cells seem to be more sensitive to ampicillin than E. coli 6925 , individual bacterial colonies were observed growing at 4 times the concentration that the original observed to be inhibitory, indicating ampicillin sensitivity was not homogenous within the population. While only a few cells were able to persist as these concentrations, few cells are needed to colonize a mouse gut.

\begin{tabular}{|l|c|c|}
\hline & Hektoen & LB \\
\hline E. coli 6925 & 12.5 & 12.5 \\
\hline E. coli 6925 (pBR322) & $>400$ & $>400$ \\
\hline E. coli 6925 (pSAR) & $>400$ & $>400$ \\
\hline E. coli 6925 (pSLAR) & $>400$ & $>400$ \\
\hline S. Typhimurium 14028S & $6.25-25$ & $6.25-25$ \\
\hline
\end{tabular}

Table 1: Minimum inhibitory concentrations of ampicillin for all five bacteria strains used expressed as $\mu \mathrm{g} / \mathrm{mL}$. A range is presented for $S$. Typhimurium. At 6.25 $\mu \mathrm{g} / \mathrm{mL}$ the majority of the drop of bacterial suspension showed no signs of growth but a few colonies could be seen growing within the ring. This was true up to 25 $\mu \mathrm{g} / \mathrm{mL}$.

\subsection{S. Typhimurium is ampicillin sensitive at low levels when grown in culture}

When given a single lethal dosage of ampicillin in culture, $S$. Typhimurium demonstrates the same sensitivity as a known ampicillin sensitive strain of E. coli. 
Despite the detectable presence of both $E$. coli 6925 and $S$. Typhimurium upon inoculation, within 12 hours, the presence of ampicillin had rendered both undetectable by either spectophometric measures or plating (Figure $5 a$ and $5 b$ ). Conversely, E. coli 6925 ( $p$ BR322) detectable at a comparable level at inoculation grew to mid-logarithmic phase within 12 hours (Figure 5c).

When grown in culture, $S$. Typhimurium does not demonstrate the ability to survive in the presence of lethal dosages of ampicillin and demonstrates sensitivity similar to that of a non-plasmid bearing strain of E. coli 6925 . Unlike observations in the host system, a single dosage was sufficient to eliminate a population of $S$. Typhimurium while prolonged dosing with ampicillin could not eliminate the bacteria from the mouse.

\subsection{Attempts to clear $S$. Typhimurium from mouse gut were unsuccessful}

The $S$. Typhimurium model was attempted in DBA/2J mice. However, many of the mice died from infection within a few days despite treatment with ampicillin. More notably, the last surviving mouse from this group was one from the cohort receiving the lowest level of treatment. The most important information gathered from this group was the inability to predict the course of infection in this strain of mouse known to be more susceptible to $S$. Typhimurium than the $129 \mathrm{xl} / \mathrm{svJ}$ strain of mice. There is the possibility that some mice were injured during gavage. However, there is greater possibility that these mice developed systemic infections that ampicillin was not capable of effectively treating. Because these animals quickly succumb to systemic infections, they are not a good organism in which to model the progress of $S$. Typhimurium infection. 
a)

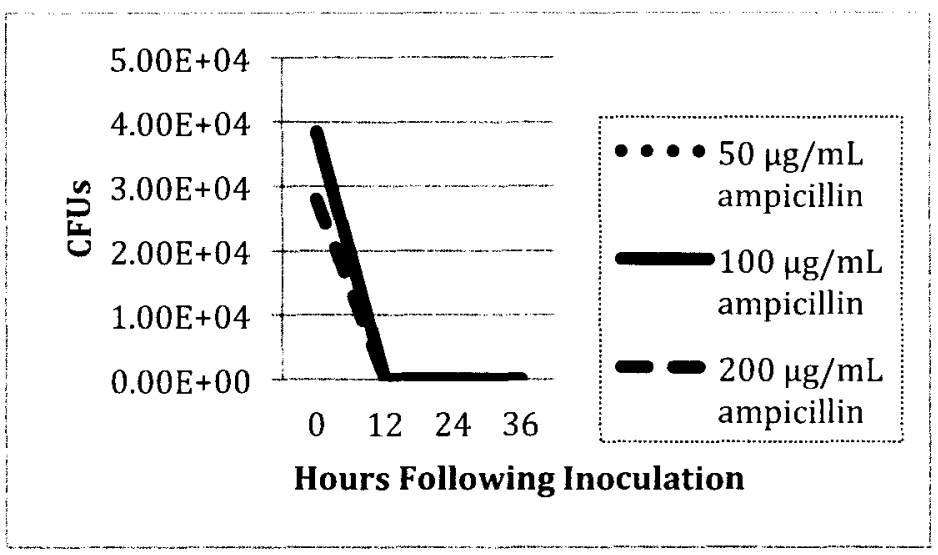

b)

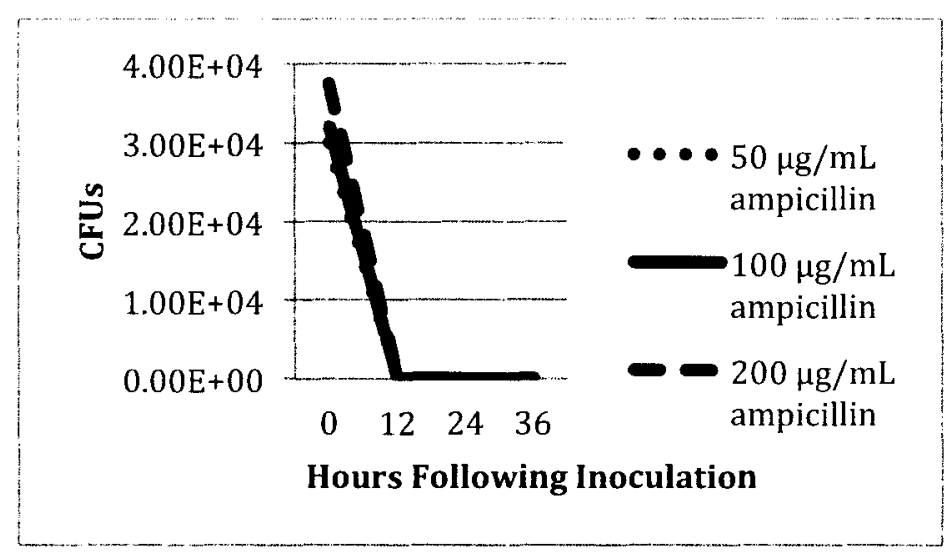

c)

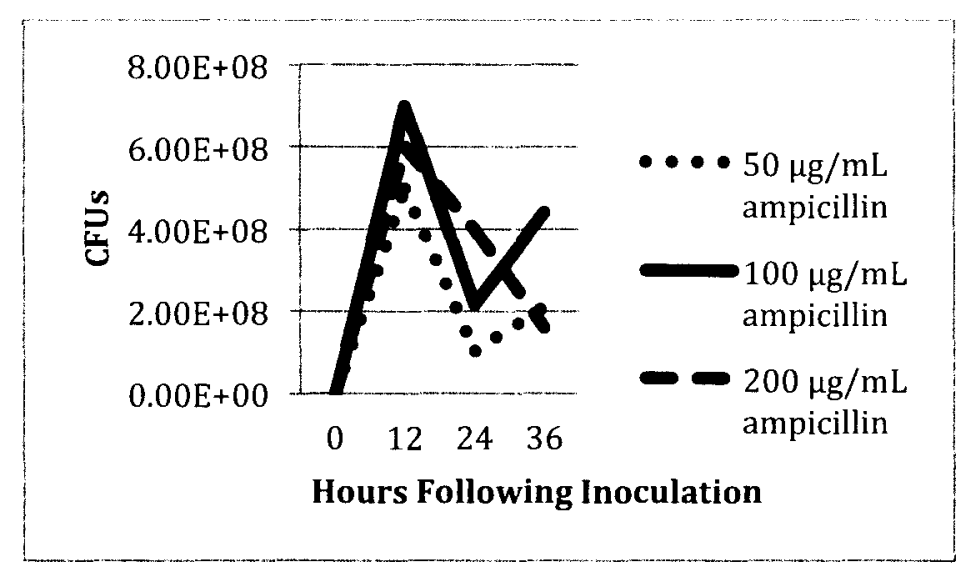

Figure 5: CFUs of a) E. coli 6925, b) S. Typhimurium, and c) E. coli 6925 (pBR322) over the course of 36 hours following inoculation into LB broth containing lethal dosages of ampicillin. For $\mathrm{c}$ ), the CFUs at 0 hours following inoculation was approximately $3 \times 10^{4}$, similar to the other two strains. 
In the more resistant mice, the model was more successful. Five cohorts of two $129 \mathrm{xl} / \mathrm{svJ}$ mice each were inoculated with $S$. Typhimurium $14028 \mathrm{~S}$ and then administered different dosages of ampicillin by bolus or drinking water: 200 $\mu \mathrm{g} / \mathrm{mL}, 400 \mu \mathrm{g} / \mathrm{mL}, 600 \mu \mathrm{g} / \mathrm{mL}$, a single bolus of $100 \mu \mathrm{L}$ of $500 \mu \mathrm{g} / \mathrm{mL}$ ampicillin, and a single bolus of $500 \mu \mathrm{g} / \mathrm{mL}$ ampicillin followed by $200 \mu \mathrm{g} / \mathrm{mL}$ ampicillin in drinking water. Ampicillin was administered for 12 days.

Cohort 4 received a single bolus of $100 \mu \mathrm{L}$ of $500 \mu \mathrm{g} / \mathrm{mL}$ ampicillin by gavage. Prior to treatment, the detected bacterial load was $18.2 \mathrm{CFUs}$ per milligram fecal sample. 24 hours after dosage, the bacterial load increased and continue to remain high, reaching a maximum of $2.38 \times 10^{5}$ during measuring (Figure 6). It appears that whether by the nature of the infection or the nature of detection, the bacterial load measured in fecal samples does not remain constant but can fluctuate quite dramatically. While it began fairly low, it had increased by a factor of 1000 within a few days and dropped back down to toward the end of measurement. This may be a product of the animal becoming sicker as the bacterial load increased, eating and drinking less, and therefore defecating less so that the fecal sample is not representative of the current state of the colon environment.

Cohort 1 received a constant dosage of $200 \mu \mathrm{g} / \mathrm{mL}$ ampicillin in drinking water. When treatment began, the measured bacterial load was $2.65 \times 10^{4} \mathrm{CFUs}$ per milligram fecal sample. After 24 hours of ampicillin treatment, $S$. Typhimurium CFUs remained high, $2.76 \times 10^{3} \mathrm{CFUs}$ per milligram fecal sample. After 48 hours, bacterial load had decreased and remained low through the remainder of treatment. Samples would be clear of $S$. Typhimurium for a few days and then would return a very low 


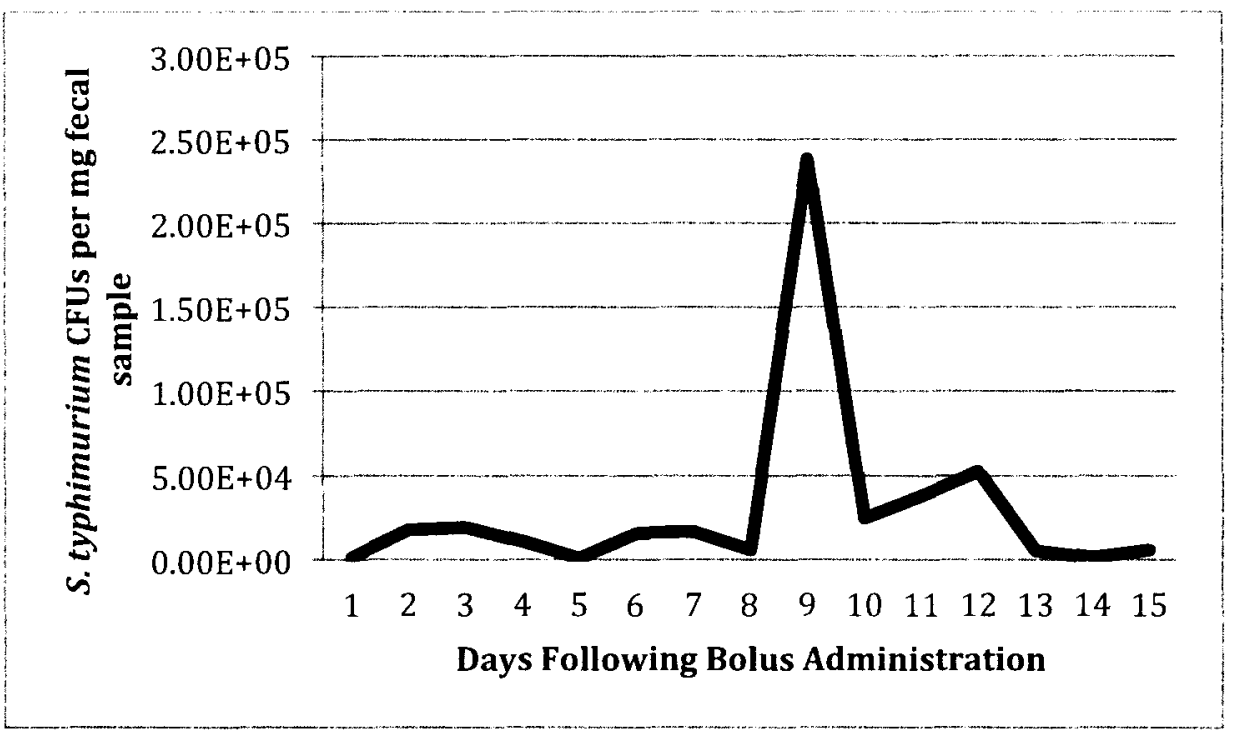

Figure 6: CFUs of $S$. Typhimurium from samples in Cohort 4 following bolus administration.

levels without the readministration of the bacteria (Figure 7a). After 12 days of ampicillin treatment, treatment was removed. Within 24 hours detectable bacterial load returned to the same level observed before treatment, $3.28 \times 10^{3} \mathrm{CFUs}$ per milligram fecal sample (Figure $7 \mathrm{~b}$ ).

Cohort 2 received a dosage of $400 \mu \mathrm{g} / \mathrm{mL}$ ampicillin in drinking water. When treatment began, the measured bacterial load was $8.87 \times 10^{2}$ CFUs per milligram fecal sample. After 24 hours of ampicillin treatment, the bacterial load remained high. After 48 hours of treatment, CFUs in fecal samples decreased dramatically, remaining undetectable for the last 5 days of treatment (Figure 8a). However when ampicillin treatment was removed, within 24 hours, the detectable CFU level in fecal samples became even higher than it had been prior to treatment, 9.07 $10^{3}$ (Figure 8b). Unlike Cohort 1, this high level of bacterial infection was not sustained, although $S$. Typhimurium remained detectable for 4 days after removal of ampicillin. 
Cohort 3 received a dosage of $600 \mu \mathrm{g} / \mathrm{mL}$ ampicillin in drinking water. When treatment began, the measurable bacterial load was 38.4 CFUs per milligram fecal sample, much lower than the established bacterial load in the first two cohorts. After 24 hours of treatment, as with the previous two cohorts, the bacterial load remained close to the pretreatment level. After 48 hours of treatment with ampicillin, the bacterial load dropped to undetectable; however, there were two spikes when CFUs of $S$. Typhimurium were identifiable within the 12 days of ampicillin treatment (Figure 9a). After the removal of ampicillin, the bacterial load returned, at an even higher level than prior to treatment, $2.53 \times 10^{3}$ CFUs per milligram fecal sample (Figure 9b). Unlike the first two cohorts, bacterial level return did not happen within the first 24 hours but instead took 3 days.

Cohort 5 received the single bolus of $100 \mu \mathrm{L}$ of $500 \mu \mathrm{g} / \mathrm{mL}$ ampicillin followed by $200 \mu \mathrm{g} / \mathrm{mL}$ ampicillin administered in drinking water. Prior to treatment, the bacterial load was detected at $2.61 \mathrm{Ex} 10^{3} \mathrm{CFUs}$ per milligram fecal sample. 24 hours after the administration of the bolus, the bacterial level had decreased but returned to pretreatment levels 72 hours following the bolus administration despite administration of ampicillin (Figure 10a). Unlike Cohort 1, which also received $200 \mu \mathrm{g} / \mathrm{mL}$ ampicillin in drinking water, the detectable level of $S$. Typhimurium remained higher in Cohort 5 throughout the course of ampicillin treatment. Potentially, the original bolus of ampicillin had killed the extremely sensitive $S$. Typhimurium cells, leaving the more resistant ones to persist. After the removal of ampicillin, bacterial load increased to a level much higher than pretreatment level, $2.51 \times 10^{4} \mathrm{CFUs}$ per milligram fecal sample (Figure $10 \mathrm{~b}$ ). 
a)

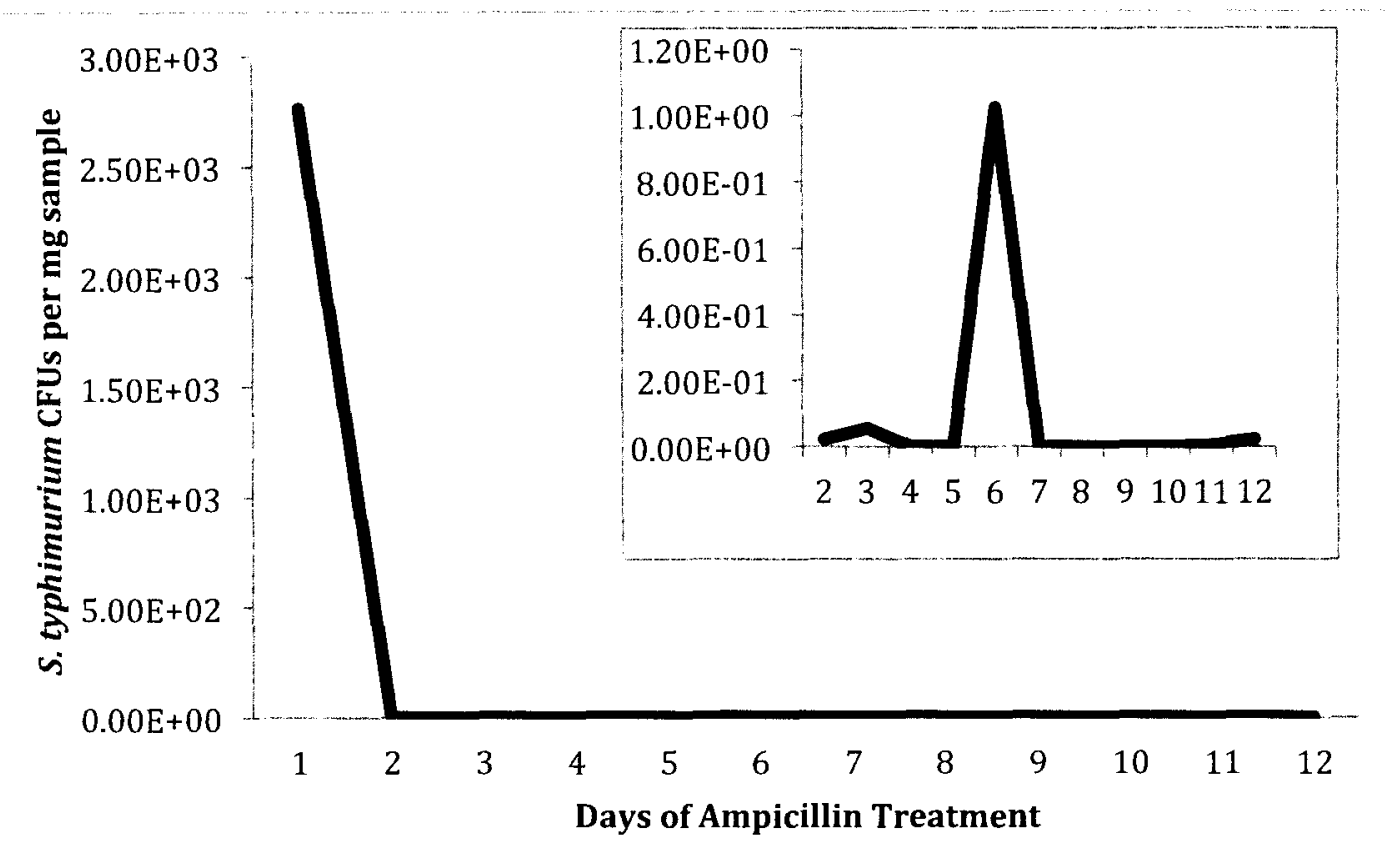

b)

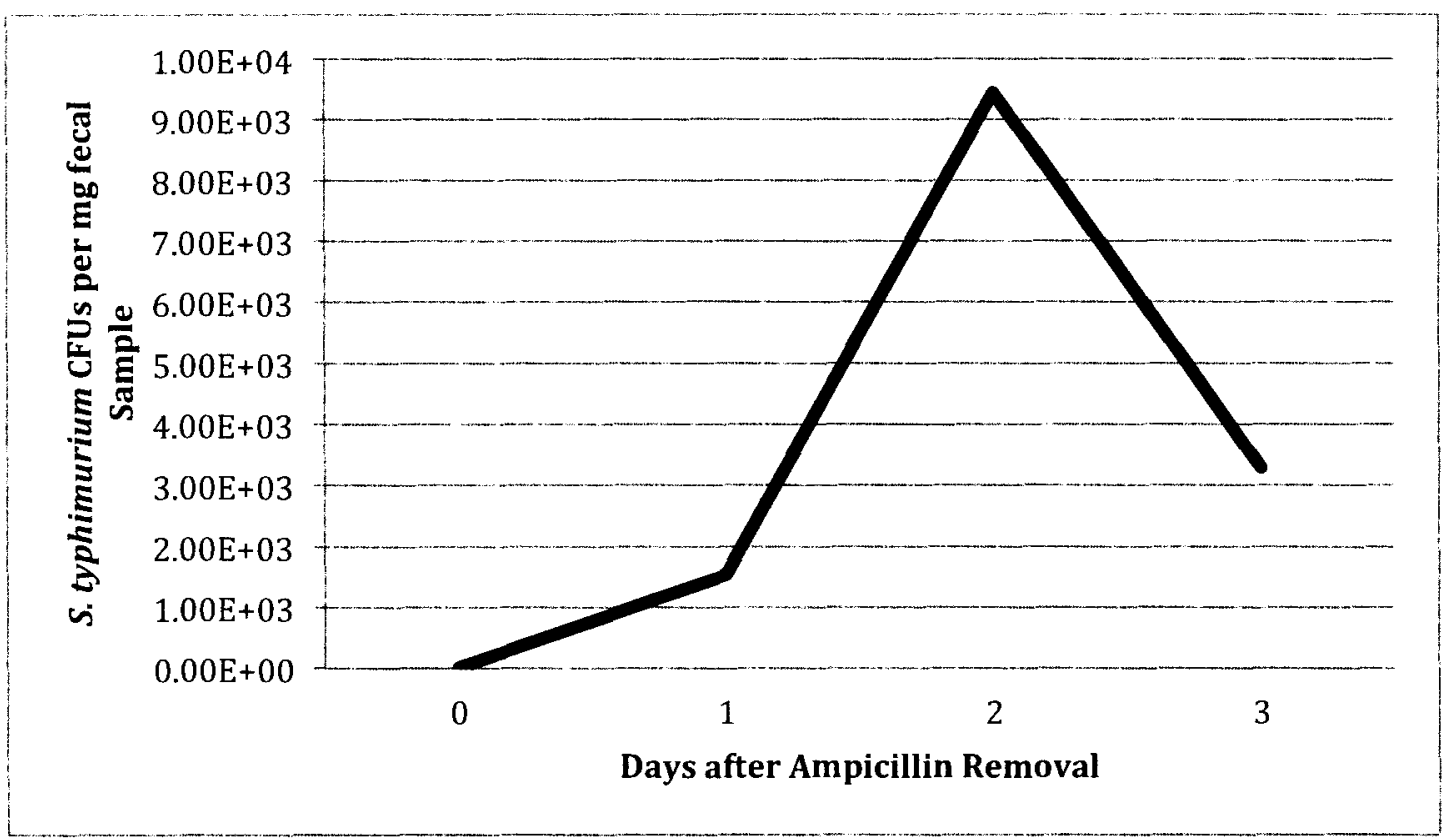

Figure 7: CFUs of $S$. Typhimurium from samples in Cohort 1 a) during ampicillin treatment (The inset graph is an enlargement of days 2 through 12 where it is apparent that the detectable level of $S$. Typhimurium did not stay at zero.) and b) following removal of ampicillin. 
a)

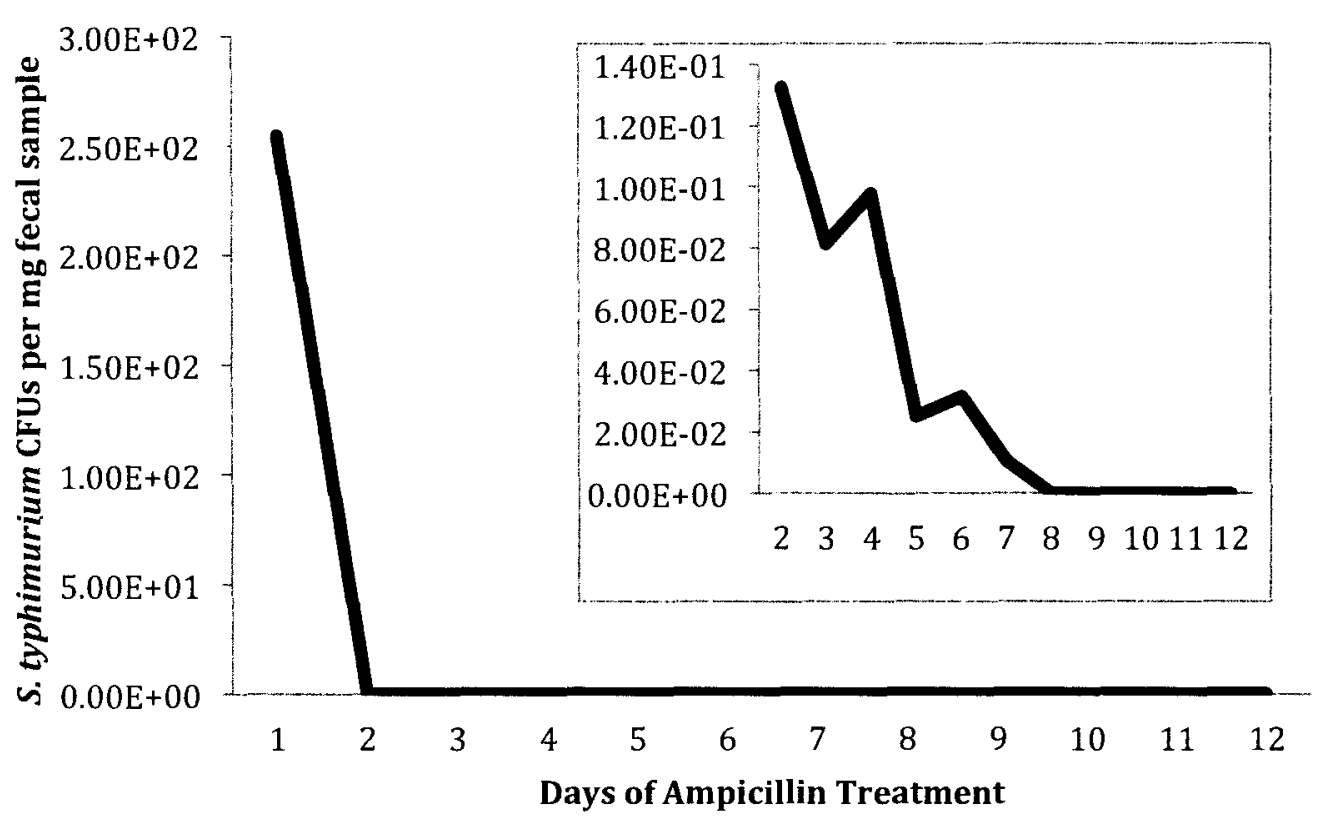

b)

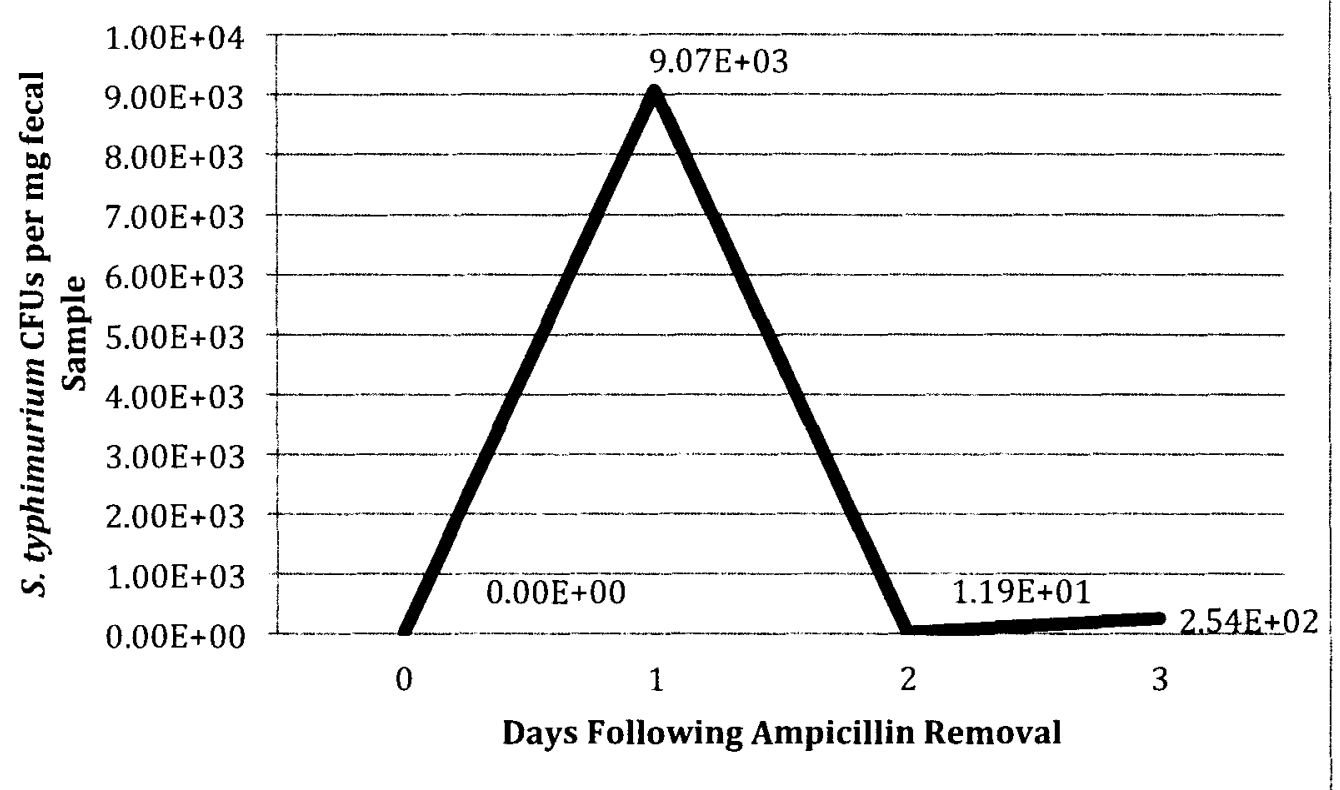

Figure 8: CFUs of $S$. Typhimurium from samples in Cohort 2 a) during ampicillin treatment (The inset graph is an enlargement of days 2 through 12. Bacterial load dropped dramatically and then decreased gradually to 0 for the last five days of treatment.) and b) following removal of ampicillin. 
a)

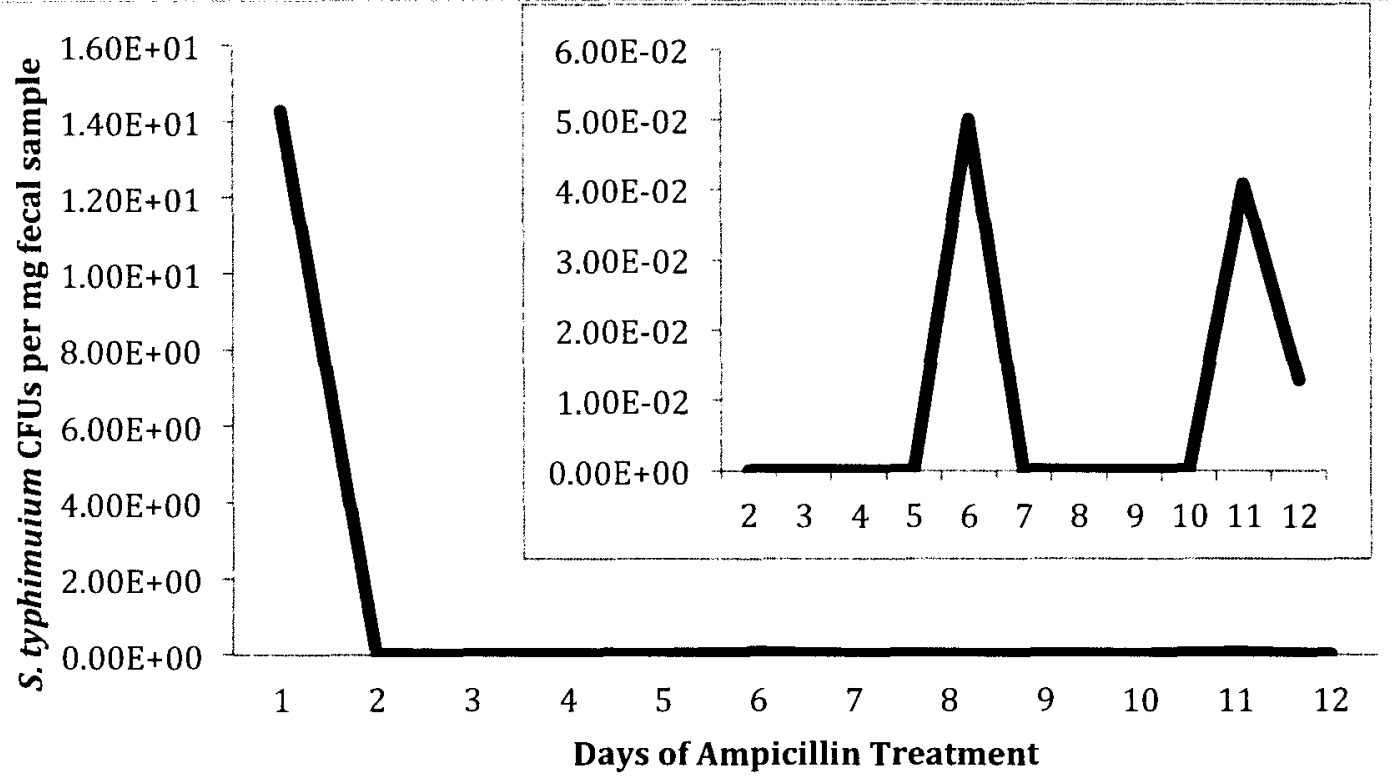

b)

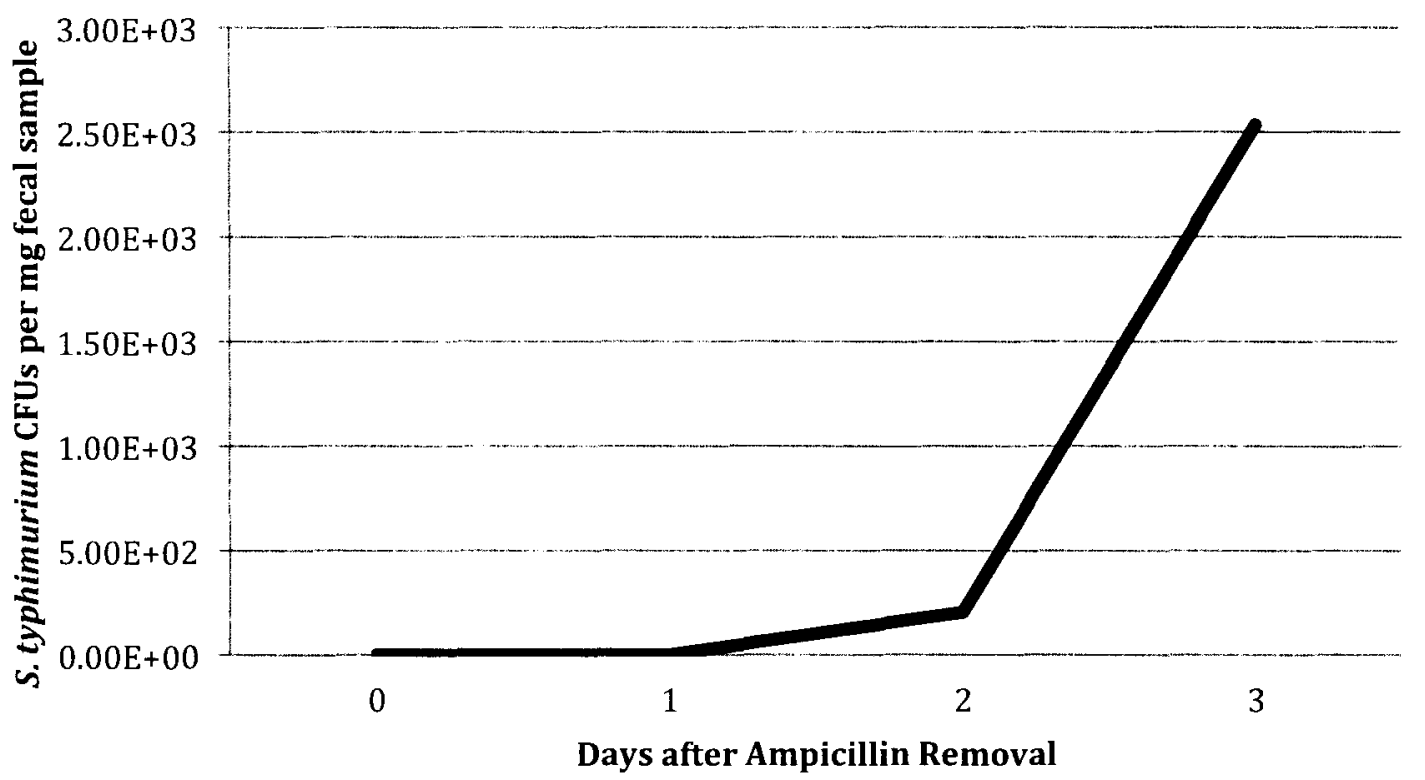

Figure 9: CFUs of $S$. Typhimurium from samples in Cohort 3 a) during ampicillin treatment (The inset graph is an enlargement of days 2 through 12. Bacterial load dropped decreased to undetectable with a few spikes of detectability during treatment.) and b) following removal of ampicillin. 
a)

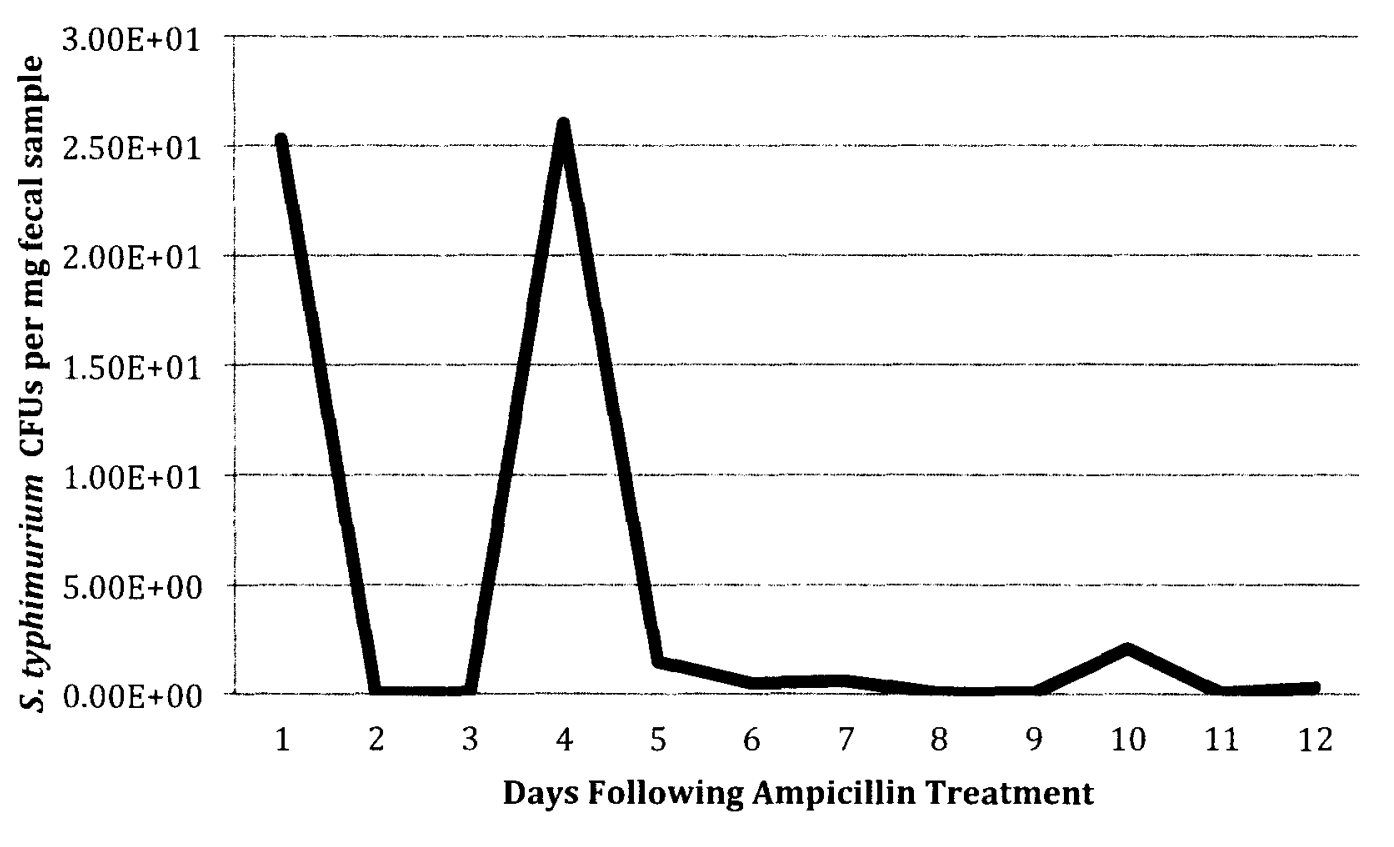

b)

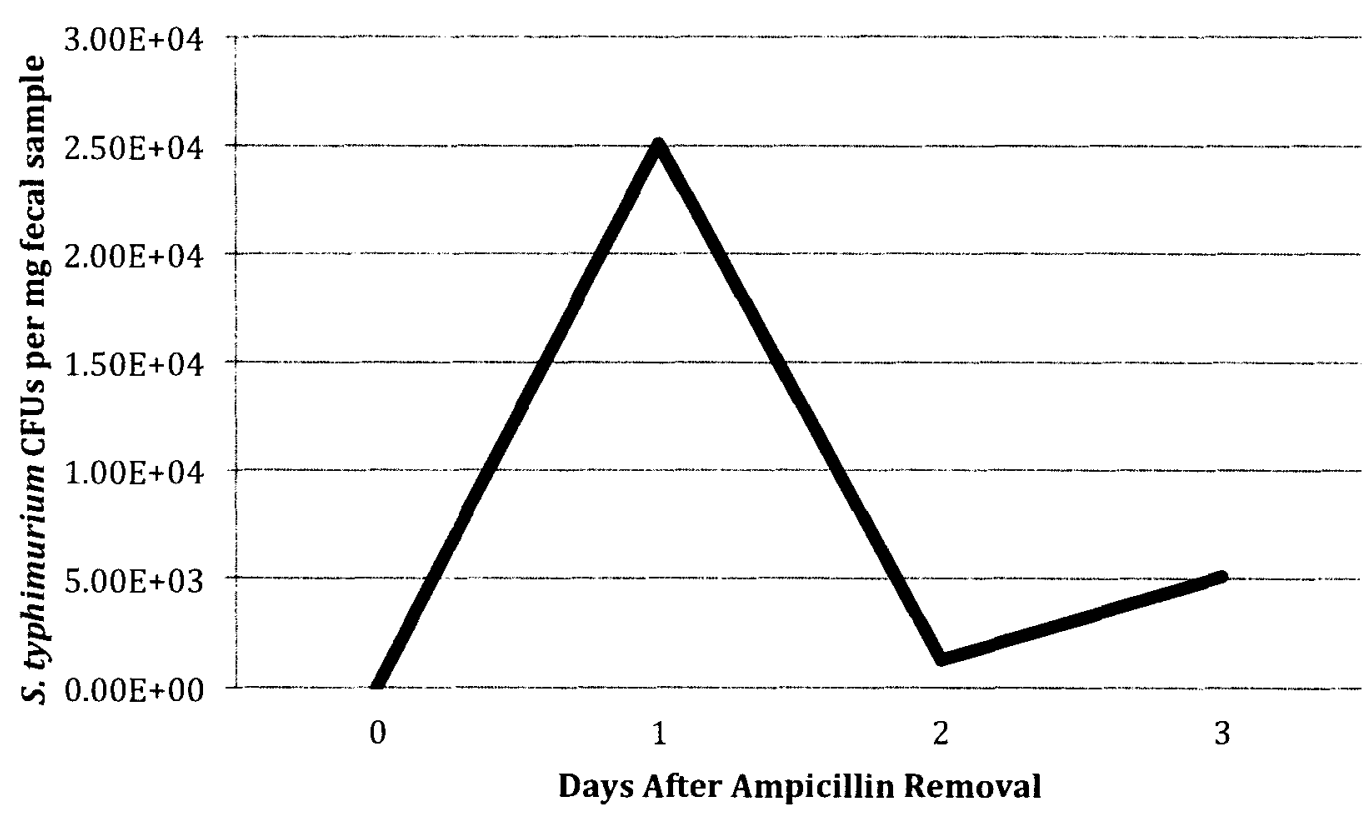

Figure 10: CFUs of $S$. Typhimurium from samples in Cohort 5 a) during ampicillin treatment and b) following removal of ampicillin treatment. 


\section{Discussion}

Despite the sensitivity that $S$. Typhimurium demonstrated in vitro, based on the return of the infection to detectable levels once the ampicillin treatment was removed, the infection was not completely cleared in the murine model. While there was no additional inoculation provided to the mice, it is not impossible that they were contaminated in other ways. While mice with infections were separated from those receiving treatment and their fecal samples processed separately, a possibility is that animal technicans coming into the mouse room unknowingly cross-contaminated cohorts. However, it may be more likely that the bioavailability of ampicillin is so low that even at higher doses, it was not an effectively lethal dosage to $S$. Typhimurium at physiological conditions.

It is also unclear whether a measurement of bacterial load through fecal samples is an accurate impression of the internal state of the mouse infection. Even in resistant strains of mice, $S$. Typhimurium may be able to grow within the epithelial cells of the intestine [15]. While they may not be able to establish a systemic infection from this point, due to the genotype of the host as related to Nramp1+vs. Nramp1- and the resistance of their macrophages to harboring $S$. Typhimurium and carrying them to other organs, the bacteria may impervious to ampicillin treatment. Ampicillin has difficulty surviving the $\mathrm{pH}$ of the stomach and similar difficulty crossing into host tissue, where it must travel to reach its target.

Moreover, if $S$. Typhimurium are moving inside epithelial cells, the bacteria may not be detectable in fecal shedding, which was the measure of data collection for this study. Removing the ampicillin may create a different environment that 
either allows for more pathogenic bacteria to grow actively or allows the recolonization of the gut within the luminal space by bacteria that have been hiding from antibiotic treatment.

Because $E$. coli 6925 is very sensitive to ampicillin in vitro and is easily cleared in the murine model, it is likely that the protective effect observed of resistant $E$. coli for sensitive $E$. coli in the presence of ampicillin was supportive of previous observations made in vitro, not the product of a nonlethal dose being administered. E. coli 6925 ( $p B R 322$ ) provided no detectable protection for sensitive $E$. coli while $E$. coli 6925 ( $p S A R$ ) provided almost complete protection for sensitive $E$. coli. E. coli 6925 (pSLAR) protected sensitive E. coli at an intermediate rate.

In vivo, by the methods used in these studies, it was not possible to demonstrate the complete clearance of $S$. Typhimurium infection, even with high dosages of ampicillin treatment. As such, it is uncertain that the protective effects observed were actually protection but are more likely the product of a nonlethal dose of ampicillin being administered.

Within the $S$. Typhimurium population, each bacterial cell may be more or less susceptible to the mechanism by which ampicillin works. This was particularly obvious in Cohort 5 , which received a large single dosage of ampicillin followed by a continuously available dose at a lower concentration of ampicillin. During the continued ampicillin treatment, $S$. Typhimurium was able to persist at higher levels than in the other three cohorts receiving continuous ampicillin treatment, potentially this was due to the high one time dose, where a larger proportion of cells within the $S$. Typhimurium population had lower levels of susceptibility. 
While the infection was never cleared, it was demonstrated that increasing the ampicillin dosage was more effective at reducing the $S$. Typhimurium numbers. In the case of Cohort 3 receiving the highest dosage of ampicillin within this study, $S$. Typhimurium was not able to recolonize as quickly, either due to the longer time needed for the mouse to metabolize ampicillin out of its system but more likely fewer living cells were left to recolonize.

In vitro work with ampicillin also demonstrated that over time at room temperature and at physiological temperature and $\mathrm{pH}$ the bactericidal properties of ampicillin were reduced, indicating a degradation of the $\beta$-lactam antibiotic over time under these conditions. Potentially in murine experiments, the dosage of ampicillin did not remain at a constant level, and at lower effective ampicillin levels, the $S$. Typhimurium cells were able to persist in the gut.

Because ampicillin was administered in drinking water, it was not possible to control the intake of each individual mouse. Even if most $S$. Typhimurium cells can be eliminated at low ampicillin doses in vitro, no measures were taken to determine the serum level of ampicillin in the mice during treatment. Because there was a delay of 48 hours in all cases before a dramatic decrease in bacterial load was observed, it is likely that the mice have to build a certain level of ampicillin before treatment becomes effective. However, the level of dosage appears to have been too low to allow the mice to build a sufficient level to eliminate $S$. Typhimurium infection. If an effective dosage of ampicillin is $60 \mathrm{mg} / \mathrm{kg}$ for mice (Anton 1982), each mouse would have to consume $16.4 \mathrm{~mL}$ of water per day of $200 \mu \mathrm{g} / \mathrm{mL}$, which is much higher than the mice consumed. Moreover, mice do not constantly drink. 
Potentially during periods of sleep or inactivity, the decrease in their levels of ampicillin was sufficient to allow $S$. Typhimurium to persist. Patterns of eating and the movement of food through the gastrointestinal tract may change the bioavailability and therefore bactericidal properties of ampicillin. While subcutaneous administrations of ampicillin have been the norm in previous studies, oral administration may more quickly reach the site of infection but cannot be controlled if administered in drinking water and may not produce an effective dosage. 


\section{CONCLUSIONS FROM IN VIVO MODELING}

The purpose of the current research was to develop a protocol to model in mice phenomena that had been observed in an in vitro setting. The nature of the interaction between $S$. Typhimurium and its host proved to heavily influence the ability to model within the mouse. $S$. Typhimurium behaves predictably in vitro. The bacteria demonstrates sensitivity to ampicillin at low levels. However, within a live host, the bacteria demonstrate an ability to evade both the attempts of the immune system to eliminate it and the antibiotics delivered to the host. Much of this survival may be mediated by the evolutionary history between host and pathogen.

The protocol that was used to administer the bacteria to the mice may also have provided a better model for human gastroenteritis but it may have inadvertently created a selective advantage for $S$. Typhimurium. Resistant strains of mice like $129 \mathrm{xl} / \mathrm{svj}$ typically do not develop inflammation within the intestinal tract in response to $S$. Typhimurium infection as is seen in humans [14]. Pretreatment with streptomycin, as used in the current protocol, induces inflammation in the intestinal tract that mimics that seen in humans [14]. However, this inflammation allows $S$. Typhimurium to have selective advantage over the other bacteria that may be growing in the gut, including any more that may be introduced purposefully. For example, in the inflamed gut, $S$. Typhimurium is able to use alternate carbon sources that other microbiota are not able to utilize [15]. 
Moreover, there is evidence that $S$. Typhimurium can grow within epithelial cells of the small intestine, even in resistant strains of mice that do not develop systemic infections [16]. This subpopulation of the infecting bacteria are found within epithelial cells, in a state of hyperreplication, ready to re-enter the intestinal tract from inside the epithelial cells [16]. Even in the instance of antibiotic treatment, these bacterial subpopulations may be able to survive inside the epithelial cells given the low bioavailability of ampicillin and its difficulty getting inside host cells as well as bacterial cells. Upon removal of the ampicillin, these bacteria may leave the epithelial cells, return to the intestinal lumen, and may be able to recolonize the host. Despite the fact that based on fecal samples, the infection had apparently cleared, upon removal of the antibiotics these bacteria were able to recolonize the gut, which is why the return of infection was observed. Clearly, some of these bacteria will be released from epithelial cells while treatment with antibiotics is occurring. However, because so few are needed to colonize the gut, if only a handful survive inside epithelial cells during antibiotic treatment, the return of infection will be observed. The same return to recolonize is not observed in an in vitro setting because there are no epithelial cells in which to evade ampicillin activity. $S$. Typhimurium as a pathogenic bacterium, has evolved inside of and along with its host and as such developed means to persist. The fact that it is able to survive inside epithelial cells even in those mice that do not develop systemic infections speaks to the bacteria's ability to evade the immune system as well as maintain infection by constantly inserting new pathogens into the intestinal tract. 
In order to develop a murine model for the protection of ampicillin-sensitive $S$. Typhimurium by ampicillin-resistant strains of $E$. coli, the adaptive measures that $S$. Typhimurium takes to avoid the host immune system must also be considered in attempting to treat the infection with oral antibiotics. Dosage of ampicillin is one consideration to the approach taken. Because the bioavailability of ampicillin is low, even at dosages that eliminate the bacteria in the lab, $S$. Typhimurium is able to survive inside the mouse, potentially because the effective dosage that the mouse is receiving is significantly less than the concentration in the drinking water. However, this would have to be carefully watched, because at some point high dosages of ampicillin may be toxic to the mouse or, be too high for protection to be afforded by the resistant $E$. coli.

Instead of streptomycin, another antibiotic may need to be used initially to clear the gut of innate microbiota. Because streptomycin induces inflammation that allows $S$. Typhimurium a selective advantage not normally found in the murine model of $S$. Typhimurium infection, a different antibiotic may provide a more even playing field for the two strains of bacteria introduced. Unfortunately, eliminating the inflammation also eliminates the similarity with the human gastroenteritis but it may allow more dissection of the interaction between a resistant strain of $E$. coli and S. Typhimurium during treatment with ampicillin.

Ultimately, because many of the properties of $S$. Typhimurium are only observed within a live host, they cannot be replicated in vitro. As such, it may never be possible to develop a protocol for this model inside a host because $S$. Typhimurium is able to persist with and without the presence of the resistant strain. 


\section{CHAPTER 4}

THE BEST OF TIMES AND THE WORST OF TIMES

How Salmonella uses Alternate Sigma Factors to Survive

\section{Introduction}

Salmonella enterica are rod-shaped, facultative anaerobic, Gram-negative members of the Enterobacteriacae family [17]. Most people have heard of the bacteria and generally associate it with food-borne illness. Despite general public knowledge of the health risks associated and precautions taken to prevent spread, Salmonella continues to cause many problems internationally. One approach toward curbing this spread and reducing the negative impact of $S$. enterica could be genetic analysis, with an ultimate goal of understanding why the bacteria are able to survive host immune responses capable of eliminating most bacteria.

It has been suggested that the Salmonella genus diverged from Escherichia coli somewhere between 100 and 150 million years ago [17]. While there is evoluntionary distance between the two genera, much of the genetic information has been conserved, and as a result, the study of one organism has provided insight into the study of the other. Salmonella spp. are generally considered to be pathogenic and can have both warm- and cold-blooded hosts [17]. More recent evolution has occurred within the Salmonella genus itself. Salmonella enterica has evolved into many different subspecies and serovars who manifest is dramatically 
different ways across a variety of hosts despite sharing $95 \%$ of the same genetic information [18]. From a medical and sanitation viewpoint, the genetics of Salmonella are particularly important to study. Although a single-celled organism, due to its long evolutionary history with humans and other host organisms, these bacteria have developed several sophisticated mechanisms to survive immune systems of its hosts, and evade sanitation efforts to kill it. Understanding this survival at the most fundamental of levels may help to more specifically combat the bacteria.

Salmonella typically reach their hosts through the consumption of contaminated food or water. Once inside its host, the bacteria must persist through various levels of $\mathrm{pH}$, temperature, osmolarity, and nutrient availability [19]. The pathogen must also face various attempts by the host's immune system to eliminate it. The organism must address each different environment and assault on the bacteria's integrity in order to survive. The ability of the organism to thrive in a multitude of different environments and establish infection is mediated by the regulated expression of different genes.

Because Salmonella is an important pathogen and can cause debilitating disease and even death, research typically focuses is on the properties of the organism that give it the ability to infect hosts. When studying virulence with respect to genetics, there are a multitude of approaches. Once a gene of interest has been discovered, the gene or gene product can be rendered nonfunctional and the resulting phenotype examined. Conversely, given a particular phenotype, researchers can examine genes present among strains sharing that characteristic. 
While there are a multitude of regulatory pathways within Salmonella that can influence gene expression, one of the most fundamental comes from the usage of alternate sigma factors by the cell's RNA polymerase. Sigma factors facilitate differential gene expression by reversibly binding to the RNA polymerase core enzyme and providing specificity for certain promoter regions. The various sigma factors have different affinities for particular promoters as well as for the core enzyme itself. Similar to other cellular proteins, sigma factors are regulated at a variety of levels. Transcription in Salmonella, as in all prokaryotes, requires a sigma factor, and ultimately all gene expression is affected by sigma factors activity.

Sigma factors were originally discovered as protein factors that stimulate RNA synthesis from DNA using DNA-dependent RNA polymerase [20]. It was later discovered that there were multiple sigma factors and that these alternate sigma factors allowed for differential gene expression through different affinity for the RNA polymerase core enzyme and for recognition of different promoter consensus sequences. It appears that the majority of sigma factors are evolutionarily related. These proteins all share four regions of similarity indicative of a common function [21]. For the group of closely related sigma factors, special regions within the protein recognize specific areas of the DNA as promoters versus non-promoter regions [22]. These DNA regions include conserved sequences centered around the 35 and -10 positions with respect to the transcription initiation site. By truncating the sigma protein at various locations, researchers have been able to determined that four conserved regions of the sigma factors were responsible for locating different areas of the promoter region. For example, region 4 of the sigma factor is 
found to recognize the consensus sequence around -35 , while regions 2 and 3 recognize the -10 consensus sequence [22]. Region 1 of the sigma factor, the amino terminus of the protein, blocks regions 2, 3, and 4 from interacting with the DNA [23]. Binding of the sigma factor to the core enzyme blocks region 1 and allows interaction of the other three regions with the DNA [6]. In this way, the sigma factor cannot interact with DNA without being bound by RNA polymerase. While it was understood that a sigma factor was necessary to facilitate transcription, their power to regulate gene expression was not fully understood.

\section{Early Virulence-Related Genetic Studies}

As with most pathogenic microorganisms, early genetic research focused on the disease-causing properties of Salmonella. Preliminary studies involving virulence properties of Samonella revealed that in the absence of a functional copy of several genes, the bacteria was unable to survive to cause infection inside its host. Further studies of each of these genes revealed that while all of the genes were required for optimal virulence, the gene expression was not under the same regulatory control. Baumler and his colleagues examined nearly 30 mutant strains of Salmonella Typhimurium that had shown attenuated ability to infect and survive inside mouse macrophages [24]. These strains had been created by the insertion of transposons in various locations of the genome and examining phenotype. By sequencing the areas around the transposable elements, researchers were able to identify that six of the regions disrupted by transposons corresponded to known genes. Baumler concluded that these genes all made contributions to the virulence properties of Salmonella. 
Some of the particular genes that Baumler concluded were disrupted in the attenuated strains were $\operatorname{purD}$, $p r c$, fliD, and nagA [24]. Other researchers have examined the transcriptional control of these genes to understand why they are so essential to the virulence capabilities of Salmonella. The dependence of these genes on different sigma factors for expression shed more light into not only the ability of Salmonella to survive in a variety of harsh conditions but also the virulence mechanism of the bacteria.

As many sigma factors are closely related, there is a high degree of homology between their structures and therefore promoter affinities. However, as few as one or two base pair change can dramatically change which sigma factor recognizes the promoter [25]. The purD gene encodes 5'-phosphoribosylglycinamide synthetase, which is involved in purine nucleotide synthesis [26]. While these genes have easily identifiable -10 consensus sequences, none appear to have the -35 region similar to those typically recognized by primary sigma factor, $\sigma^{70}[27]$. Further research revealed this gene and others related to purine synthesis were all proceeded by what researchers have called a PurBox that seems to be required for their transcription, as well as an area for regulation by purine levels in the cell [28]. These PurBoxes are bound by repressor proteins that must be removed in order for transcription of the pur genes to happen [28]. It stands to reason that purines would need to be synthesized regardless of environmental condition. If environmental conditions dictate the most dominant sigma factor and purines are an essential part of cellular function in all conditions, multiple sigma factors should be able to direct the transcription of their corresponding genes. Potentially, the 
ambiguity of the promoter region for these genes demonstrates the ability to be used by multiple sigma factors and PurBoxes allow for regulation in a concentration dependent manner.

A second gene, prc, encodes for a protease that in closely related organisms has been found to play a role in response to cell wall stress [29]. In these organisms, prc is preceded by a consensus sequence for a sigma factor showing a great deal of similarity to the sigma factor in E. coli and Salmonella that responds to a variety of global stresses, including damage to the cellular envelop [29].

The fliD gene encodes for part of the flagellar filament, needed for the motility of the bacteria [21], [30]. This gene is proceeded by a consensus sequence that can only be used by the flagella-specific sigma factor [21] and is part of a highly temporally and spatially regulated pathway that ensures flagella are expressed readily in times that motility is necessary and repressed when the bacteria has not formed the appropriate primary structures for the flagellar.

The nagA gene product is $\mathrm{N}$-acetylglucosamine-6- phosphate deacetylase in E. coli and has the same function in Salmonella Typhimurium [22]. These gene was found to have consensus sequence in the -10 region requiring the activating a magnesium sensitive regulator in the presence of the housekeeping sigma $\sigma^{70}[31]$. Based only on the extracellular availability of magnesium, the primary sigma factor is responsible for the transcription of the gene provided a secondary regulatory system is activated.

With the genes that Baumler examined, in combination with other research indicating that each of these types of genes was under different regulatory control 
by particular sigma factors, a pattern began to emerge. Genes responsible for the organism's response to particular threats to its integrity were under the transcriptional direction by particular sigma factors. The importance of sigma factors as transcriptional regulators is further revealed by their stability over time [32] and the high degree of homology among sigma factors responding to a particular stimuli between closely related species [33]. The use of alternate sigma factors by Salmonella like all prokaryotes allows for a coordinated expression of genes and an easily controlled process to promote survival even in the most harsh of conditions.

\section{A Tale of Six Sigmas...}

Individually, each type of sigma factor was purified, isolated, and determined to facilitate RNA transcription in the presence of RNA polymerase core enzyme and other appropriate molecules. To date, six different sigma factors have been discovered within the Salmonella genome that are responsible for transcription from a variety of promoters in response to different phases of the bacteria's lifestyle as well environmental conditions. Acting together in a complex, as an interconnected web of gene regulation, they enable Salmonella to withstand and thrive inside infected hosts.

Sigma factors were characterized as proteins before their functions as essential elements of the holoenzyme became clear. As such, each sigma factor is known by a variety of names. Designations with rpo or Rpo are used across species and refer to the particular stress to which a particular sigma factor responds. A more contemporary convention is to use a lower case Greek sigma with the 
molecular weight of the sigma factor as s superscript. In this text, all molecular weights refer to those found in Salmonella and E. coli.

Most sigma factors, $\sigma^{70}, \sigma^{\mathrm{E}}, \sigma^{\mathrm{H}}, \sigma^{\mathrm{S}}$, and $\sigma^{\mathrm{F}}$, belong to the same family of sigma factors, potentially all derived from some ancestral form or ancestral regulatory process. The other sigma factor, $\sigma^{N}$, belongs to a different family, although it is the only modern day example found, and may belong to a more ancient regulatory system that has become obsolete with current lifestyles of bacteria like Salmonella. While the housekeeping or primary sigma was found to facilitate most gene expression during exponential growth, each of the other sigma factors was found to help the organism address a number of different environmental stresses. Each sigma factor has a consensus sequence in the promoter region for which it has the greatest affinity. The relative affinities of multiple sigma factors for the same promoter region may determine which sigma factor recognizes it at a specific concentration of sigma factors within the cell. Much research related to sigma factors has focused on determining sigma regulons, the specific suite of genes under their transcriptional control.

\section{$\underline{3.1} \sigma^{\mathrm{N}}-$ Nitrogen Regulation}

$\sigma^{\mathbb{N}}, \sigma^{54}$, or RpoN seems to be more evolutionarily distant from the other alternate sigma factors than they are from each other, and it may be the remnants of a more ancient regulatory system that has since become less important to survival of Salmonella. In fact, some researchers believe that the processes governed by $\sigma^{\mathrm{N}}$ may not be essential or may be under transcriptional control of another sigma factor [34]. These processes include nitrogen fixation, dicarboxylic acid transport, and 
hydrogen oxidation [34]. Downregulating expression from RpoN-dependent genes provides increases resistance to killing by host cationic antimicrobial peptides [35], indicating that some of these processes may even be detrimental to the organism in certain conditions. In some related species $\sigma^{N}$ is related to pathogenicity, but that does not appear to be in Salmonella [36].

The differences between $\sigma^{N}$ and the rest of the sigma factors are profound. There is almost no sequence similarity between the $r p o N$ gene and genes for other known sigma factors, also suggesting a different origin [34]. $\sigma^{\mathrm{N}}$ promoters are unique in that they have conserved consensus sequences centered at -24 and -12 nucleotides from the transcription start site, as opposed to -35 and -10 conserved regions found in promoters recognized by other sigma factors [37]. A highly conserved RpoN-Box is involved in the recognition of the -24 and -12 DNA elements [37]. The distance between the -24 and -12 elements is more stringent than the analogous distance between the -35 and -10 elements for the $\sigma^{70}$ family of sigma factors, indicating a highly controlled regulation [37]. Moreover, the sequences at the -24 and -12 elements have highly conserved GG and GC regions respectively, also suggesting a high level of regulatory control [37].

While the $\sigma^{\mathrm{N}}$ protein is very different from other alternate sigma factors, the interaction between the sigma factor and template DNA is also distinct. The $\sigma^{70}$ family of sigma factors do not form stable closed complexes as part of the holoenzyme and transcription will start spontaneously [37]. Unlike other sigma factors, the $\sigma^{N}$ and core enzyme form a stable closed complex. In this way, $\sigma^{N}$ binding to the core enzyme actually blocks transcription because the open complex 
must be activated [38]. The binding of the RNA polymerase holoenzyme with $\sigma^{\mathrm{N}}$ as the sigma factor cannot induce DNA melting alone, similar to the RNA polymerase II system in eukaryotes [39], which is essential for the start of transcription. In fact, it has been hypothesized that $\sigma^{N}$ may bind to DNA first rather than binding to the core enzyme first [39]. This is supported by the fact that $\sigma^{N}$ binds to a different location on the core enzyme than $\sigma^{70}$ and in doing so may be able to assist in DNA melting once activated [39].

Because it forms a stable closed complex, the RNA polymerase with $\sigma^{N}$ as the sigma factor requires enhancer proteins for activation. Each enhancer protein is under the regulation of its own signal transduction pathway, allowing response to various environmental conditions [38]. All the enhancer proteins have in common hidden ATPase activity that allows for the DNA melting necessary to initiate transcription [38].

\subsection{The Housekeeping Sigma $\sigma^{70}$}

The other five sigma factors appear to be evolutionary related, developing from the original or primary sigma factor. RpoD or $\sigma^{70}$ is the housekeeping sigma factor and is responsible for the transcription of most of the genes in bacterial cells growing exponentially [40]. When $r p o D$ was found in the genome for $E$. coli, it was determined that the gene sequence had a high degree of homology between other $r p o D$ genes from closely related species [41]. Further genomic analysis determined that $r p o D$ is found in an transcript with the 30S ribosomal protein S21 and DNA primase [42]. This operon was the first discovered operon containing proteins involved in transcription, translation, and replication [42]. E $\sigma^{70}$ (the holoenzyme 
containing the core enzyme associated with $\sigma^{70}$ ) does not form a stable closed complex and transcription begins spontaneously [37]. Moreover, the $\sigma^{70}$ concentration found inside a cell undergoing exponential growth is less than concentration of core enzymes, indicating the level of the sigma factor present may regulate the level of transcription [42].

\section{$\underline{3.3} \sigma^{\mathrm{E}}-$ Response to Extracytoplasmic Stress}

When the bacteria faces stressors, other sigma factors are involved in the expression of genes necessary to survive the stress, such as $\sigma^{E}, \sigma^{24}$, or RpoE, which results in transcription of genes to combat envelop stress [43]. RpoE is constitutively expressed in the bacteria, held inactive by interaction with various binding proteins. The $r p o E$ gene seems to be the most highly conserved of alternate sigma factors across several species, as are the genes under its transcriptional control, suggesting an high level of importance of these functions to the survival of the multiple bacterial species.

RpoE must be able to respond to a signal coming from outside of the cell, while the protein itself exists within the bacterium. It appears a transmembrane protein, RseA, interacts with RseB on the periplasmic side and with $\sigma^{\mathrm{E}}$ on the cytoplasmic side. An area of the DegS protein on the periplasmic side recognizes unfolded proteins resulting in proteolysis of the periplasmic side of RseA. Cleaved RseA is a target for RseP, which then cleaves the transmembrane portion of RseA, releasing the RseA/ $\sigma^{\mathrm{E}}$ complex from the membrane and the unstable cytoplasmic portion of RseA is quickly degraded by cytoplasmic proteases [44]. RseB also interacts on the periplasmic side with both DegS and RseP to control the activity of 
these proteases in the absence of a stress response [44]. Upon perception of the extracytoplasmic stress in the form of misfolded proteins, $\sigma^{\mathrm{E}}$ is then able to interact with the core enzyme of RNA polymerase. The strength of the signal is directly proportional to the number of misfolded outer membrane proteins, which is a reflection of the extracytoplasmic stress.

While response to envelop stress is typically the signal necessary to release RpoE from RseA, research has shown that acid stress may also result in the same. It was found that mutants deficient in RpoE activity showed increased susceptibility to acid and reduced ability to survive inside macrophages. The RseP domain was required for this response to the acid shock, but its proteolytic activity was not dependent on DegS [44]. It is proposed that the acidic milieu affects the interaction between RseB and RseP, which normally keeps RseP inactive, so that RseP is released to act on RseA to discontinue negative control over $\sigma^{\mathrm{E}}[44]$. Both DegS and RseP have cytoplasmic and periplasmic domains, and the acid response appears to be independent of the envelop stress response. Again, the strength of the response is dependent on how much RseB is removed from RseP which in turn depends on strength and length of exposure.

Once $\sigma^{\mathrm{E}}$ is released to interact with RNA polymerase, not all $\sigma^{\mathrm{E}}$ - dependent genes are transcribed equally. Within the set of genes transcribed by RpoE, there are different promoters with varying levels of affinity for the sigma factor. Within the approximately 60 promoters examined that required $\sigma^{\mathrm{E}}$ for transcription, there were few very strong promoters (showing high affinity) but many relatively weak promoters. The strong promoters were conserved across both E. coli and S. enterica, 
and were typically involved in maintaining porin homeostasis [45]. Varying strength of promoters allow quick and efficient adaptation to different environments by being able to transcribe different genes in response to various signal [45]. If the stress signal is strong, the cellular concentration of $\sigma^{\mathrm{E}}$ will increase enough to transcribe at high rates from weak promoters.

In order to prevent wasted energy and further damage to the cell, the activation of $\sigma^{\mathrm{E}}$ also results in the downregulation of omp (outer membrane protein) mRNA [46]. In this way the cell also prevents these nascent mRNAs from also producing misfolded proteins while avoiding destruction by the exocytoplasmic stress. Two small non-coding RNAs, RybB and MicA, not under the control of RpoE, collectively expedite the destruction of omp mRNAs. Under normal conditions, the cellular machinery making outer membrane proteins is still not perfect and some misfolded proteins are generated. In this case, the same two sRNAs are involved in the response to clear the problem by inducing the $\sigma^{\mathrm{E}}$ response, but at a much lower level that would be found in a bacteria responding to prolonged stress [46]. As such, the two sRNAs are most likely under the transcriptional control of the primary sigma factor and their increased activity helps to induce $\sigma^{\mathrm{E}}$-mediated responses. As far as specific genes governed by $\sigma^{\mathrm{E}}$, the parts of the $\sigma^{\mathrm{E}}$ regulon that are highly conserved across species are involved in making the cell wall and outer membrane of Gram negative bacteria [47]. The variable portion may be involved in the alternative lifestyles that the studied species utilize. A genome wide search was done for $\sigma^{\mathrm{E}}$-dependent genes in several species including $E$. coli and $S$. Typhimurium, determining that several genes were at the core of the $\sigma^{\mathrm{E}}$ regulon. 
Some genes were involved in making lipoproteins, such as $y f i O$, yeaY, and yraP.

Others were involved in outer membrane protein synthesis and modification, like yeaT, skp, fkpA, and $\operatorname{deg} P$. And still others were involved in cell envelope structure, such as $p l s B, b a c A, a h p F$, and $y g i M$. Interestingly, both $r p o E$ and $r p o H$ were both under regulatory control of $\sigma^{\mathrm{E}}$, indicating that $\sigma^{\mathrm{E}}$ promotes its own transcription and the transcription of other sigma factors [47]. By autoregulation, $\sigma^{\mathrm{E}}$ can create a multi-fold increase in gene product from its regulon as the extracytoplasmic stress sigma factor. All of the genes found to be under the control of $\sigma^{\mathrm{E}}$ are related to making proteins for cellular structure.

\section{$3.4 \sigma^{H}-$ Response to Heat Shock}

One of the genes under the transcriptional control of RpoE is another sigma factor, $\mathrm{RpoH}$ or $\sigma^{32}$ [47]. This sigma factor has been found to be involved in the transcription of genes that help Salmonella withstand high temperatures, potentially as a result of fever response within the host. Whereas $\sigma^{\mathrm{E}}$ appears to mediate the response to misfolded outer membrane proteins, $\sigma^{\mathrm{H}}$ seems to be involved with proteins within the cytoplasm that are not correct [48]. Concomitant with increased heat exposure, cell wall and membrane proteins begin to misfold and denature. As the concentration of $\sigma^{\mathrm{E}}$ increases in response to the proteins that are misfolded in the outer membrane, $\sigma^{\mathrm{H}}$ also accumulates to respond to a sustained stressor. This is supported by the finding that $r p o H$ expression is directly proportional to $\sigma^{\mathrm{E}}$ activity at temperatures higher than $42^{\circ} \mathrm{C}[49]$, a temperature at which protein denaturing will reach inside the cell. 
RpoH governs the transcription of genes incudling those encoding proteases that allow for the removal and recycling of misfolding proteins within the cytoplasm to prevent damage to the cell. For example, an operon composed of opdA and yhiQ was found to be immediately proceeded by a consensus sequence for the RpoH promoter [50]. While the function of these two proteins is has not been directly studied in the heat shock response, $\mathrm{OpdA}$ is metalloprotease oligopeptidase $\mathrm{A}$, a protease that would be helpful in degrading misfolded proteins.

Some researchers have also hypothesized that $\sigma^{\mathrm{H}}$ is related to RNA thermometers, which are other regulatory means for activating and utilizing heat shock genes. RNA thermometers are areas of 5'-untranslated region that fold and complementary pair in such a way as to block the Shine-Dalgarno (SD) sequence of downstream genes [51]. When heated to sufficient temperatures, these areas unpair to allow the ribosome access to the SD sequence. A previously undescribed RNA thermometer was found within the 5'-UTR of the agsA gene in Salmonella. This gene is known to be involved in response to heat shock and has a promoter region containing a consensus sequence for RpoH utilization [51]. Within the agsA mRNA appear to be RNA thermometer sequences [51].

In $E$. coli , a closely related species to $S$. Typhimurium, the rpoH mRNA itself contains RNA thermometers. It appears in this species, the cellular level of the sigma factor is controlled by complementary base pairing in the mRNA. Unlike other RNA thermometers, the SD sequence in this case is not blocked but the start codon is inaccessible to the ribosome and two halves of the ribosome-binding site complementary pair at low temperatures [51]. Because of the importance of heat 
shock in bacteria as a whole, a similar mechanism is most likely at play in Salmonella.

While responding to heat shock is vitally important for survival of the bacteria, perhaps $\sigma^{\mathrm{H}}$ most important function is to mediate $\sigma^{\mathrm{E}}$ regulation of $\sigma^{\mathrm{S}}$ through $h f q$ gene expression. In $E$. coli, the promoter sequence found upstream of the $h f q$ gene was found to be $\sigma^{\mathrm{H}}$-dependent. The same promoter was found in $S$. Typhimurium [48]. When nutrients are scarce, $\sigma^{\mathrm{E}}$ appears to upregulate $\sigma^{\mathrm{S}}$ through the increase of $\sigma^{\mathrm{H}}[48]$.

The product of the $h f q$ gene, HF-I, is important for translation of RpoS. This small protein is heat stable and binds to RNA to facilitate translation [52] by associating with the ribosome [53]. Several possible mechanisms for the manner in which the protein encoded by $h f q$ regulated $\sigma^{S}$ translation have been suggested, including by preventing the interaction of some sort of antisense mRNA or by being directly involved in the transcription of rpoS [54]. Most evidence supports the assertion that the function of HF-I is as a RNA chaperone after it was demonstrate to bring the mRNA and ribosome in correct association for translation [55].

\section{$3.5 \sigma^{\mathrm{S}}$-Stationary Phase Growth, Response to Stress and Starvation}

The role of this sigma factor, also called $\sigma^{38}$, is slightly more difficult to define than that of RpoE or RpoH. However, it is clear that the function of RpoS is essential. The conserved sequence of $r p o S$ across multiple species and within the same species found in different geographical areas speaks to its importance. When rpoS genes are characterized in clinical isolates, the mutations found are not clonal but rather novel, implying that there is some selection against mutants. Even when strains 
demonstrated different abilities to survive certain stresses like exposure to hydrogen peroxide, it did not appear to be related to different rpoS genes [56].

The number and types of genes that seem to be under transcriptional control of $\sigma^{S}$ have a variety of functions and respond to a wide variety of lifestyle requirements and threats to survival. The only known constant about the genes transcriptionally governed by RpoS is their dependence on growth phase [57]. Previously, work has determined that during logarithmic growth, any activity from $\sigma^{\text {S }}$ promoters is repressed by cyclic-AMP receptor activity [58]. Stationary phase growth is characterized by a lack of cellular multiplication and decreasing cell density. The transition from exponential growth to stationary phase growth is the result of the concentration of a regulatory protein [59]. The concentration of Fis (factor for inversion stimulation) a DNA binding protein, is high during exponential growth and low in stationary phase. Fis binds to a region of DNA upstream of the rpoS promoter and with decreasing amount, allows a switch to stationary phase [59].

A genome-wide search has been done for genes under the transcriptional control of RpoS. The project found that like RpoE, the $\sigma^{S}$ regulon includes promoters of various strengths. Despite the assumed similarities between the $E$. coli and $S$. Typhimurium genome and therefore the $\sigma^{S}$ regulon, there were several genes within the Salmonella genome that were not homologous with any genes of E. coli, which may speak to different lifestyles. Several genes of unknown function were found under the control of $\sigma^{S}$ as well as ogt, which encodes for the enzyme $0^{6}$ methylguanine DNA methyltransferase [58]. This enzyme is responsible for 
repairing DNA damaged by alkylation. These results supported previous findings that bacteria lacking a functional rpoS gene also cannot withstand DNA damage by alkylating agents [60].

$\sigma^{\mathrm{S}}$ also seems to play a role in a wide variety of other functions that ensure the survival of the bacteria, such as protection from acid shock and nutrient depletion. Decreased pH unfolds the secondary structure stem and loops of the rpoS mRNA, allowing availability for translation [61]. With increasing $\mathrm{pH}, \mathrm{RpoS}$ was not degraded by proteolytic activity typical of protein turnover, but rather held inactive by complementary basepairing rendering the mRNA inaccessible to the ribosome when the acid threat had subsided. Constitutive degradation of the sigma factor coupled with the lack of more protein being translated resulted in the system reset after the acid threat had passed [61]. This is in contrast to previous work which concluded that the protein MviA was responsible for responding to the acid shock by increasing $\sigma^{S}$ level by preventing its degradation. In this work, lacking a functional mviA gene resulted in overproduction of $\sigma^{\mathrm{S}}$ and $\sigma^{\mathrm{S}}$ - dependent transcriptional units and increased tolerance to acid [62]. These two studies examined bacteria in different stages of growth, one in logarithmic and one in stationary, and potentially two different regulatory pathways are at play dependent on growth phase.

The RpoS sigma factor also seems to be involved in survival of the bacteria in nutrient depleted conditions. $\sigma^{\text {S }}$ has been found to act as both a positive regulator for stiA and stiC and a negative regulator for stiB. These three genes are part of the multiple-nutrient starving inducing loci. $\sigma^{\text {s }}$ was required for phosphate, carbon, and 
nitrogen starvation survival through induction of stiA and stiC. $\sigma^{\mathrm{S}}$ also acted as a negative regulator of $s t i B$ during starvation-induced stationary growth [63].

\section{$\underline{3.6 \sigma^{F}-\text { Flagellar Formation and Chemotaxis }}$}

Flagellar assembly was originally assumed to be under the control of $\sigma^{70}$ because it seemed essential to survival. However, examining promoters of known flagellar genes found no consensus sequences for $\sigma^{70}$ [64]. Instead, researchers found promoter sequences in Salmonella known to be used by alternative sigma factors in closely related species [64]. $\sigma^{\mathrm{F}}$, more commonly called FliA or $\sigma^{28}$, has the most specific function of all the alternate sigma factors. FliA is involved in the transcription of genes related to the formation of flagella, specifically the formation of the flagellar filament [40]. Operons of flagellar assembly are proceeded by one of three classes of promoters, class 1, 2, or 3 [65], [66], [67], which allow for a temporal regulation of expression of gene products. From these operons, more than 50 flagellar genes are transcribed [21].

There is only one class 1 operon which encodes the $f l h D$ and $f l h C$ genes [66].

Class 1 is the master opeon, with FlhD and FlhC acting as a global regulator of flagellar assembly [67]. FlhD and FlhC form a heterotetrameric complex that is a positive transcriptional activator of class 2 promoters through $\sigma^{70}$ by interacting with the $\alpha$ subunit of the core enzyme [65], [68], [69]. Class 2 operons include genes for the assembly of the hook and basal body complex (HBB), $\sigma^{F}$, and FlgM [65]. The basal body, including the motor, penetrates the cell membrane and includes the hook element on the extracellular side of the cell [69]. The filament protrudes from the hook into the extracellular matrix and turns to provide motility. 
The third class of flagellar operons requires FliA for transcription [49]. Proteins generated from these operons are for the flagellar filament, the generation of motor force, and chemotaxis [67]. FlgM which is also transcribed from class 2 operons along with FliA acts as an anti-sigma factor, keeping FliA inactive until the completion of the HBB. The C-terminal of FliA has a binding site for FlgM [21]. By binding to FliA, FlgM prevents RNA polymerase core enzyme from interacting with FliA to transcribe class 3 flagellar operons [71]. The FlgM protein is able to assess the functionality and completion of the HBB because the protein itself is an exported substrate [72]. Decreasing cellular concentrations of FlgM release FliA to interact with the RNA polymerase core enzyme and transcribe class 3 operons for completion of the flagellar filament [72]. The relative concentration of FliA to FlgM determines the number of flagella that a single cell will have [73]. Additionally, the FlhD/FlhC complex may assist FliA in associated with the RNA polymerase [73]. FlhD is involved in assessing nutrient state [74], which may make it necessary to more or less mobile. Flagellar formation happens at a specific time during the cell cycle, particularly right before the cell divides when the cell is at its largest and the intracellular concentration of FlgM before exportation is at its lowest [73].

The intracellular concentration of FliA and FlgM is governed by other regulatory mechanisms as well. The genes from both of these proteins can be transcribed from either class 2 or class 3 promoters [75]. In this way, FliA can positively and negatively regulate its own intracellular concentration dependent upon the concentration of FlgM within the cell [76]. Over production of flagella is a waste of valuable resources [77]. Mutants lacking FlgM make too many flagella and 
overexpress from class 3 operons [77]. Multiple promoters for genes needed in the same cellular process allow for response to environmental conditions as well as temporal regulation to avoid excess expenditure of energy by the bacteria [65].

\section{Changing Sigma Factors}

The presence of alternate sigma factors has been well studied, but how do the alternate sigma factors displace the housekeeping sigma or each other to govern gene transcription? Most of the answer points to concentration dependence; that is, the concentration of a particular sigma factor changes in response to different environmental conditions. For example, RpoE is expressed constitutively but held inactive by various other proteins until an extracellular signal is received. This signal activates a series of proteolytic activity that gradually increases the intracellular concentration of RpoE. Once RpoE is released, it is free to interact with the core enzyme. RpoE is positively autoregulated and as genes are transcribed from RpoE promoters, the intracellular concentration increases exponentially so that RpoE can outcompete other sigma factors for binding access to the core enzyme. RpoE in turn allows for transcription of $r p o H$, which summarily mediates rpoS expression, so that the intracellular level of all three alternative sigma factors is increased. Fine tuning of these concentrations allows for precise control of gene expression. If a finite amount of RNA polymerase is available, increasing the presence of one sigma factor can repress expression of genes requiring a different sigma factor [78].

Growth phase also appears to play a role in the intracellular concentration of certain sigma factors. During exponential growth, intracellular concentrations of $\sigma^{70}$ 
remain relatively constant and $\sigma^{\mathrm{S}}$ is basically absent [79]. During stationary phase growth, the intracellular concentration of $\sigma^{5}$ increases to nearly $30 \%$ of $\sigma^{70}$ concentration [79]. Moreover, the concentration of the core enzyme decreases during stationary phase growth [79], meaning that a $30 \%$ increase in concentration is more than a $30 \%$ increase in competitive advantage. RpoS activity is repressed by $u s p A$ and $u s p B$, which are both under the transcriptional control of $\sigma^{70}$ [78]. During exponential growth, $\sigma^{S}$ is highly unstable [79]. In stationary phase growth, $\sigma^{S}$ is released and free to interact with RNA polymerase core enzyme. Researchers have hypothesized that there may be a $\sigma^{70}$ anti-sigma factor under transcriptional control of $\sigma^{S}$ or that a change in the cytoplasm may favor $\sigma^{S}$ - mediated transcription [78], allowing the intracellular concentration of $\sigma^{5}$ to increase and guarantee more interactions with RNA polymerase core enzyme. Most genes expressed during exponential growth are not expressed during stationary phase growth, so $\sigma^{70}$ proteins need to be rendered inactive [79]. Interestingly, the intracellular levels of $\sigma^{5}$ reach those of $\sigma^{70}$ during osmotic shock [63], indicating that the concentration of a sigma factor can be a gradual or dramatic depending on the gene expression required to survive a particular situation.

Environmental conditions can also play a role in the stability of the proteins which can affect transcriptional efficiency. For example, RpoH, the heat shock sigma factor, is high unstable at low temperatures but above $42^{\circ} \mathrm{C}$ intracellular concentrations will transiently increase [79]. Higher temperatures may provide increased efficiency of $\sigma^{\mathrm{H}}$ - mediated transcription or they may stabilize the protein itself so that it is able to interact with the core enzyme [79]. 
With the idea of differential gene expression through alternate sigma factors in mind, it is possible to see how Salmonella is able to respond quickly and efficiently to a wide array of environmental conditions inside its host and elsewhere. But the picture is not complete without an understanding of the lifestyle of Salmonella to provide insight into the phenotype resulting from the differential gene expression.

\section{Salmonella as a Pathogenic Bacteria}

In determining how alternate sigma factors are able to promote survival and spread of Salmonella, it is important to understand how Salmonella infects its hosts and how it avoids attempts by the host to eliminate its threat. Typically, genes are discovered that are related in some way to the survival of the pathogen and then later research is required to reveal how the transcription of the particular gene is controlled. Research involving Salmonella has found that transcription control through alternate sigma factors provides an elegant means of balancing gene expression and energy usage with pathogenic requirements. By examining phenotype and then determining the underlying genotype, researchers have been able to determine how Salmonella is able to lead a pathogenic lifestyle.

Salmonella typically enters its host through the oral route. If sufficient numbers are ingested, some organisms will survive the low $\mathrm{pH}$ conditions of the stomach to reach the small intestine [17]. Sometimes the bacterial infection is halted here. For a systemic infection to occur, the bacteria must invade the gut epithelium [80]. Salmonella preferentially invade epithelial cells in the distal ileum of the small intestine by adhering to and then injecting effector proteins into the 
host cell [81]. The small intestine provides an environment of near-neutral $\mathrm{pH}$ and high osmolarity, condusive to bacterial invasion not found in the large intestine [82]. Within the small intestines, Salmonella specifically invades Peyer's patches through M cells. Peyer's patches are specialized lymphoid tissues that are designed to sample intestinal antigens and lead to immune responses [83]. Salmonella exclusively enter M cells which are found within the follicle-associated epithelium of Peyer's patches [84]. M cells are epithelial cells responsible for the uptake of luminal antigens [83] and can engulf large particles, making them ideal for target by Salmonella [68]. When one bacterium makes entry into the host epithelial cell, it recruits other pathogens to its location [85].

Not all Salmonella infections spread from the gastrointestinal tract into the rest of the host's body, causing a systemic infection. However, if the infection is to become systemic, the bacteria must be able to spread and colonize beyond the small intestine. The presence of the pathogen in M cells causes damage to the integrity of the epithelial cells allowing for dissemination. Salmonella presence in the M cells becomes cytotoxic within an hour of infection [84]. In this way, Salmonella is able to disrupt barriers between cells to allow for migration [86]. The death of these $M$ cells causes gaps to form in the surrounding epithelial tissue, allowing the bacteria to spread laterally along the basal lamina or deeper into the follicle [84]. From this point, the bacteria can spread through the bloodstream and lymphatic system to mesenteric lymph nodes and other deeper tissues [17]. Eventually through the web of pathways in the vascular and lymphatic system, the bacteria is transported to other organs in the body where it can lay dormant or undergo further replication 
[17]. It most commonly reaches the lymph nodes, liver, or spleen [87]. Induction of inflammation around the initial site of infection results in the recruitment of more immune cells and causes diarrhea which can allow the spread of the bacteria to other hosts and other environments [82].

The travel of Salmonella through different cell types is governed by the bacteria's ability to induce it's own internalization into non-phagocytic cells [88], [83]. This process is contact mediated and begins when the bacteria touches epithelial cells of the small intestine. Salmonella contact with host cells causes changes in the host cells' plasma membrane [89]. The bacteria are able to induce degradation of microvilli and the formation of cytoplasmic projections from the host cell to surround and enclose the bacteria in membrane-bound vesicle [84]. The host cells responses to the bacteria appear to be localized, limited to the areas of contact between the bacteria and the host cell [88]. The complete internalization of the bacteria seems to require the adherence of the bacteria cell to the host cell.

Salmonella has evolved a mechanism that uses components of the host cell's cellular machinery to result in its internalization into the cell, specifically the epidermal growth factor receptors [88].

This induced internalization by host cells is not limited to a specific cell type but has been found to occur in all types of eukaryotic cells [89]. Because the invasion mechanism is not cell specific, a candidate process would have to be present in all eukaryotic cell types. Fimbrial genes are transcribed from several operons, each with different fimbrial types [90]. Fimbrial proteins may guide the bacteria to the epithelial cells based on certain molecules present on the surface of 
the eukaryotic cells and different fimbrial types may target bacterial cells to different cell lines [90].

The ability to be internalized by nonphagocytic cell is one distinct characteristic of Salmonella. The other hallmark of a Salmonella infection is the ability to survive and replicate inside phagocytic cells like dendritic cells and macrophages [80], both of which are present in large quantities in the Peyer's patches [91]. In fact these cell types seem to rapidly migrate to the area of invasion as soon as the bacteria attaches to the epithelial cells [86], a phenomenon not observed with commensal E. coli. Some researchers suspect that the bacteria stimulates the host cell to release transcellular chemical signals that cause the mass migration [86]. Because of the necessity these bacteria have to evade the immune system by surviving in phagocytic cells, this mechanism may have evolved to allow the bacteria to gain access to macrophages and dendrites before an immune system response can be mounted.

While both dendritic cells and macrophages are important components of the host immune system, the lifestyle of Salmonella inside each is different. While inside macrophages the number of bacterial cells increases dramatically, there is no change in the number of bacterial cells inside dendritic cells [92]. Logically, this difference may be based on the different functions of dendritic cells and the macrophages within the host immune system. In fact, the ability of Salmonella to colonize a particular species may be mediated by the ability to survive within dendritic cells of that host [93]. 


\section{The Immune System Response}

At each step in colonization of different cell types, Salmonella are faced with an onslaught of attempts by the host's immune system to eliminate the bacteria. Host immune systems are able to mount two types of immune responses against bacterial invasion: constitutive and inducible [94]. Constitutive defenses include barriers like the mucosal epithelium. They are typically present only at the area of exposure and the destruction is direct only at the invading pathogen [94]. Also included in constitutive immune responses is gastric acidity, which has long been considered as a way to prevent ingested microorganisms from migrating out into the rest of the body [95]. Typically, the pathogen is ingested along with food or water which is by comparison to the conditions inside the host body, lower temperature, more neutral $\mathrm{pH}$, and lower nutrient content [83]. As it travels throughout the host, the pathogen faces reduced $\mathrm{pH}$ in the stomach then higher $\mathrm{pH}$ in the small intestine and higher concentration of bile salts than in the stomach [83].

Other immune responses are induced upon infection. Major targets of the innate immune system are pathogen-associated molecular patterns (PAMPs). The recognition of these PAMPs result in uptake by dendritic and phagocytic cells [94]. Just as Salmonella has evolved a mechanism to get inside nonphagocytic cells, these bacteria have also acquired the ability to survive inside phagocytic cells that help the innate immune system eliminate them from the host body.

Dendritic cells transfer information about the bacterial pathogen to the adaptive immune system by recognizing PAMPs and capturing and degrading bacteria to be presented to T cells [81]. As such, inference with this mechanism 
promotes bacterial survival [81]. Bacteria bypass the typical processes within dendritic cells to prevent presentation of antigens to T cells. Adaptive immunity to Salmonella requires B cells and $\mathrm{T}$ cells primed by mature dendritic cells [96]. The bacteria is enclosed inside a vacuole within the dendritic cell called a Salmonella containing vacuole (SCV). Usually, the dendritic lysosomes fuse with vesicles containing engulfed pathogens inside the cell, degrade the bacteria, and present various pieces to T cells [81]. Inside the dendritic cells, Salmonella restricts expression of genes that produce proteins recognized as PAMPs to the inside of the cell, preventing dendritic cell maturation, and antigen presentation [96].

\section{Islands of Pathogenicity}

Virulence factors are properties of the pathogen that allow it to invade and infect a host [83]. These include genes encoding products that would allow Salmonella to enter epithelial cells and survive in macrophages and dendritic cells. An estimated 5-10\% of genes within the Salmonella genome can be considered virulence genes [83]. Some of these genes have been found arranged in clusters within the Salmonella chromosome, called Salmonella Pathogenicity Islands (SPIs). It has been theorized that these gene clusters were acquired by horizontal transfer due to the higher G-C content that in other parts of the Salmonella chromosome [83] and similar regions are not found in closely related commensal species such as $E$. coli [89]. There are at least five known SPIs, but SPI- 1 and SPI-2 are known to play a role in the initial phases of infection. Both SPI- 1 and SPI- 2 encode type III secretion systems (TTSS), although they perform different functions [97]. Additionally, genes within the SPIs encode both effector proteins and regulatory proteins [80]. These 
two secretion systems allow the insertion of effector proteins into both the extracellular environment and the host cell.

In general, SPI-1 appears to contain genes involved in bacterial uptake by the host cell, while SPI-2 genes contribute to survival inside cells [98]. However, there is some evidence that SPI-1 may also be important for life inside the vacuole for intracellular replication [99]. Some gene products of SPI-1 physically link the TTSS to eukaryotic cells by being injected into the plasma membrane, and recruiting other host cell factors to allow internalization [100]. Secreted proteins from genes transcribed from SPI-1 leads to actin cytoskeleton rearrangements of the host cell that bring the bacteria into the cell in a membrane bound vesicle [101]. SPI-1 genes include those for effector proteins that trigger signal transduction pathways within the host cell to promote the internalization of the bacterial cell. A variety of host functions can be hijacked to serve the bacteria's purpose, including cytoskeleton arrangement, vesicular trafficking, cell cycle progression, and programmed cell death [98]. SPI-1 effector proteins activate GTP-binding proteins such as Cdc42, Rac-1, and Rho, which coordinate intracellular activities in the host cell [101]. Once the bacteria has been brought inside the cell, the actin rearrangement must be reversed to enclose them. This is done through other effector proteins that downregulate actin rearrangement [102].

An important series of proteins called Salmonella invasion proteins (Sips) are intimately involved in the ability of the bacteria to induce the host cell to internalize it and are found in the SPI-1 gene clusters. These proteins are translocases required for the intimate association of bacteria with host cells [98]. SipD is found on the 
bacterial surface prior to contact with the host cell, and may act as a sensor of appropriate host cells to invade [98]. SipA does not cause the membrane ruffles in the epithelial cells associated with the internalization [103], but mutants with deficient $\operatorname{sip} A$ genes create ruffles that are not preferentially located at the site of bacterial contact [104]. Evidence is mounting that SipA mediates the actin rearrangement that allows for the internalization bacteria [104]. SipB and SipC are found on both host cell and bacteria after contact has been made [98]. SipC, works independently of host cell function, by bundling actin filaments into cables to allow for rearrangement favorable to the entry of bacteria [105]. SipC performs functions similar to those found within eukaryotic cells, but show no primary similarity with eurkaryotic proteins with similar function [105].

Another group of important Salmonella proteins are the invasion proteins. When delivered orally, bacteria with missing or incomplete invasion regulons are unable to colonize the small intestine or the spleen [106]. However, when delivery is through a method other than oral, these strains are able to establish infections in both of these organs, indicating that these gene products may be essential for the establishment of infection after oral exposure to the bacteria [106].

Transcription of all SPI-1 operons is activated by a regulatory loop beginning with HilA [107]. Through other regulator proteins like HilC, HilD, and InvF, expression of invasion genes is modulated by HilA [87]. Interestingly, a rising concentration of acetate in the distal intestine can activate the expression of HilA by bypassing normal positive regulators of expression [82]. The bacteria has evolved a mechanism to increase expression of its invasion proteins when in the right place. 
While SPI-1 may play a role in the procession of the infection past the initial invasion of epithelial cells, SPI- 2 is vital for the migration of bacteria to other parts of the host [108]. SPI-2 was the second pathogenicity island discovered and is required for survival after bacteria has entered epithelial cells [97]. Mutants without SPI-2 genes can enter Peyer's patches but were unable to spread to mesenteric lymph nodes [109]. It also appears evolutionarily speaking that SPI-2 was acquired after SPI-1. The ability to spread and survive past the epithelial tissue of the small intestines allowed the expansion of the ecological niche of Salmonella [109]. Not all members of the SPI-2 pathogenicity island are equally vital for the ability of the pathogen to establish systemic infection. Mutants with various genes knocked out show a varying level of attenuation [109], [110]. However, the genes within the SPI-2 are responsible for avoiding destruction by lysosomes within dendritic cells and macrophages [111]. Expression of SPI-2 genes seems to be induced by the slightly acidic conditions inside the initial vacuole formed when the bacteria is internalized by the host cell [108].

\section{Regulation of Salmonella Pathogenicity Islands by Sigma Factors}

Regulatory control of SPIs can be exerted by sigma factors. SPI-1 genes are typically transcribed using E $\sigma^{70}, \sigma^{\mathrm{H}}$ mediates SPI-1 expression by regulating activators of SPI-1. Systems mediated by RpoH negatively relate HilD posttranslationally and HilA transcriptionally [108]. HilD is responsible for activating HilA transcription, and HilA in turn activates all the genes within SPI-1. $\sigma^{\mathrm{H}}$ directs the production of Lon protease which specifically degrades HilD [108]. Through modulating the activating of $\sigma^{\mathrm{H}}$, the bacterial cell can control SPI-1 
expression. This ensures that SPI-1 expression can be restricted to specific regions within the cell [108]. Moreover, as $\sigma^{\mathrm{H}}$ is usually used for transcription in the event of some stress to the bacteria, the expression of genes from $\sigma^{\mathrm{H}}$, such as Lon protease, can restrict the expression of SPI-1 genes during stress. In this way, the cell can repress invasion genes long enough to replicate, escape, and invade a new macrophage before cell death [91].

Promoters for SPI-2 genes all have consensus sequences for $\sigma^{70}[112]$. However, upstream of some of the genes seemed to be consensus sequences for $\sigma^{\mathrm{E}}$ that researchers assume may be functional but non-canonical $\sigma^{\mathrm{E}}$ binding sites [96]. Researchers postulate that these $\sigma^{\mathrm{E}}$ binding sites may serve a couple of different purposes. The $\sigma^{\mathrm{E}}$ - recognized promoters may allow the bacteria to expression TTSS in response to host factors that compromise the bacterial cellular integrity [112]. Alternatively, $\sigma^{\mathrm{E}}$ may fine-tune the expression of SPI-2 genes through $\sigma^{70}[112]$ by preferentially overexpressing certain genes while all others are expressed at basal levels by $\sigma^{70}$.

Stationary phase Salmonella are unable to cause the actin rearrangement in host epithelial cells that is necessary for entry [85]. Invasion factors are either not functional or not expressed in stationary phase bacteria [85]. As growth phase has been demonstrated to change intracellular concentrations of different sigma factors and virulence genes do not appear to be under the transcriptional control of $\sigma^{\mathrm{s}}$,it stands to reason that these bacteria would not be able to invade as they are not able to expression invasion genes because the activity of the necessary sigma factors is repressed. 


\section{Other Genetic Sources of Virulence}

Virulence genes contained outside Salmonella Pathogenicity Islands contribute to host colonization and are regulated by sigma factors. Once outside the mammalian small intestine, invasion loci are not necessary for spread and nutrients are usually limited. For example, the location of the $\mathrm{Spv}$ regulon varies among Salmonella species from the chromosome to a plasmid, yet all species carry the genetic locus, which contributes to intracellular growth once bacteria has spread outside of the small intestine [33]. The dependence on the alternate sigma factors for the expression of these genes is illustrated by the inability of $\sigma^{\mathrm{S}}$ mutants to efficiently express the Spv regulon. Expression of one of the members of the Spv regulon, $s p v B$, was decreased by $86 \%$ when $\sigma^{s}$ was knocked out [50]. In a functional sense, the lethal dosage in mice for a strain without a functional $r p o S$ gene was 1000 fold greater than wild type [50].

The dependence of Spv regulon expression on growth phase also indicates a dependence on $\sigma^{s}$ for transcription. However, it seems to be nutrient availability, not cell density, that is most important in mediated Spv regulon expression [33]. $\sigma^{S}$ associated with RNA polymerase results in expression of genes that are essential to help the bacteria survive nutrient depleted conditions, such as those found in deeper tissues beyond the small intestine [33].

$\sigma^{\mathrm{S}}$ increases expression of $s p v$ virulence genes by interacting with SpvR, a repressor protein for the virulence plasmid [97]. Competition for RNA polymerase between $\sigma^{\mathrm{S}}$ and $\sigma^{70}$ led to less efficient transcription of $\operatorname{spv} R$ from its promoter as $\sigma^{S}$ has a greater affinity for RNA polymerase than $\sigma^{70}$ but a lower affinity for the 
promoter for $\operatorname{spv} R$ [113]. $\sigma^{\mathrm{s}}$ affinity for RNA polymerase is enhanced by its interaction with $\mathrm{Crl}$, giving it the ability to displace $\sigma^{70}$ as the preferred promoter [114]. The presence of SpvR regulates its own transcription [113] so the lack of efficient transcription leads to decreasing cellular levels which lead to the derepression of $s p v$ plasmid virulence genes. $\sigma^{S}$ ensures that enough SpvR is present to activate transcription from the spvA promoter, the first gene in the regulon [33].

\section{A Sigma Factor Cascade Contributes to Survival in Phagocytic Cells}

While Salmonella Pathogenicity Islands allow bacteria to invade host cells, the pathogen must also survive the hostile environment within. While differential gene expression through various sigma factors ensures the appropriate expression of SPIs during access to the intracellular milieu, the use of sigma factors also permits subsequent survival. Ferric Fang describes a cascade of transcription and translational events that involve sigma factors associating with the core enzyme to transcribe genes for each other and those necessary to respond to a variety of assaults in the intracellular environment [115]. The first step in the cascade is activation of $\sigma^{\mathrm{E}}$, which is constitutively expressed through $\sigma^{70}$ promoters but held inactive by a pair of negative regulators, RseA and RseB [116]. RseA interacts with $\sigma^{\mathrm{E}}$ in such a way to block the binding site for RNA polymerase [44]. When an extracytoplasmic stress is perceived, $\sigma^{\mathrm{E}}$ is released by RseA and freed to bind to RNA polymerase. Interaction of $\sigma^{\mathrm{E}}$ with the core enzyme allows for transcription from other promoters. These promoters include those before the $\sigma^{\mathrm{E}}$ regulon of genes but also before the $r p o H$ gene, which encodes the alternative sigma factor, $\sigma^{H} . \sigma^{H}$ provides specificity for RNA polymerase to transcribe genes in the $\sigma^{\mathrm{H}}$ regulon, which 
respond to cytoplasmic stress. Additionally, $\sigma^{\mathrm{H}}$ allows transcription of $h f q$. The Hfq protein interacts with the $r p o S$ mRNA to facilitate its translation. The $\sigma^{\text {s }}$ then allows transcription of genes under its transcriptional control, which allow for a starvation response [115]. This overall cascade allows for coordinated response by the pathogen. To ensure that sigma factors help transcribe genes needed to respond to stress only as long as it exists, there must be some mechanism of turnover [115]. In this way, the use of an interconnected web of sigma factors allows the Salmonella to gain access to various cell types and then survive within the cells to be able to spread to other areas of the host.

This cascade's vital importance to survival in particular within macrophages is illustrated by the increased levels of $\sigma^{\mathrm{s}}$ inside the macrophage following infection. Some aspect of being inside a macrophage results in increased transcription of the $r p o S$ gene. While levels of the housekeeping sigma $\sigma^{70}$ decreased, levels of $\sigma^{S}$ increased about 10 fold a few hours after infection [117]. The conditions inside the macrophage induce the stress response and restrict nutrient availability, which induces the sigma cascade of gene expression to help the bacteria survive, not necessary become virulent.

\section{Sigma Factors Coordinate Gene Expression Together}

Rarely is gene expression controlled in a strictly linear manner. That is, multiple sigma factors may work together to fine tune expression of a group of genes to provide the bacteria with the high probability of survival. The cascade of sigma factors to be able to survive inside phagocytic cells described above is just one example. There are many other instances of sigma factors working 
simultaneously to express a certain suite of genes to allow response to a particular stimulus.

One way to determine if one sigma factor plays a role in the efficient transcription by the other is to knock out one of them and see how the function of gene products mediated by the other are effected. In this way, researchers determined a relation between RpoE and FliA. Mutants without rpoE showed defective or limited mobility [118]. In these mutants, expression from class 1 flagellar promoters remained unaffected while some class 2 and most class 3 promoters showed decreased activity as compared to wild type [118]. Researchers concluded that RpoE may promote expression from class 3 promoters by mediating expression of FliA during osmotic stress, such as the hyperosmotic conditions found in the small intestine [118].

$\mathrm{RpoH}$ and RpoN also appear to be related in their ability to control the same genes as well as the dependence of one on the other. Expression of some heat shock operons appear to be under the control of RpoN in certain conditions, as expression from $\sigma^{\mathrm{H}}$ operons is downregulated in mutants with $r p o N$ knockout [36]. In this way, RpoN may be responsible for fine tuning some gene expression during heat shock response. The expression of topoisomerases also appears to be governed by both $\sigma^{\mathrm{N}}$ and $\sigma^{\mathrm{H}}[36]$, which may also indicate an interdependence of the two sigma factors on the activity of the other.

Insufficient expression of one sigma factor can be compensated for by overexpression of other sigma factors. For example, inside macrophages while RpoS only moderately increased following infection, $\mathrm{RpoH}$ and $\mathrm{RpoE}$ showed dramatic 
increases in intracellular concentration [119]. While RpoS is typically associated with virulence inside phagocytic cells, it may be possible for other sigma factors to express a suite of genes by working together to achieve the same end result. Research has also demonstrated that RpoN can compensate for insufficient RpoS in the formation of certain lipopolysaccharides [120]. RpoE is able to mediate RpoS levels during stationary phase growth through $\mathrm{RpoH}$ and the RNA chaperone Hfq to ensure appropriate gene expression to respond to diverse stressors [48].

\section{Survival Outside of a Host}

While Salmonella is an important enteric pathogen as it infects many hosts and can be transmitted from species to species, it also is able to survive outside any host. Because of this characteristic, it has been an important target of sanitation processes to eliminate possible sources of transmission. Unfortunately for food service personnel, Salmonella have also evolved a variety of strategies to withstand attempts to eliminate them from food sources, some of which have been found to be modulated by the use of alternate sigma factors. There are basically three strategies to eliminate bacteria in food service: high temperatures, low temperatures, and washing. Salmonella has evolved mechanisms to unfortunately survive many of the attempts to eliminate it.

Because Salmonella can infect a variety of hosts, one means of transmission to human hosts is through food products that are infected themselves, such as poultry. The same mechanisms of alternate sigma factor used to survive acid challenges in a mammal gut are also utilized in surviving the fowl gastrointestinal tract and can lead to transmission of the pathogen to a new host [121]. 
Other studies specific to food handling procedures and alternate sigma factors have determined that RpoS, for example, is essential to Salmonella's ability to withstand normal sanitation procedures common in the food service industry and that early induction of RpoS can cause the cells to enter stationary growth phase prematurely, negating the protective nature of stationary growth to the pathogen's ability to survive [122]. Other studies have demonstrated that certain food handling processes, such as washing in various antimicrobial agents, can induce RpoS to protect the bacteria from destruction [123]. Significant drops in temperature have also been found to activate transcription from $\sigma^{\text {s }}$ dependent promoters rather than from the $\sigma^{70}$ promoters from which genes are normally transcribed, indicating that $\sigma^{\mathrm{S}}$ may help the organism survive in cold temperatures [124].

Sometimes multiple alternate sigma factors contribute to survival through food processing. For example, $\sigma^{\mathrm{S}}$ and $\sigma^{\mathrm{E}}$ were both found to be important in surviving refrigeration and changes in osmotic pressure. Depending on the nature of the stress, either $\sigma^{S}$ or $\sigma^{\mathrm{E}}$ may be more important and their relative concentration dictated the type of response [125]. In short, Salmonella employs the same strategies to survive food processing as it does to survive changing environmental conditions inside its host.

\section{Regulation of Sigma Factors}

Because sigma factors are capable of dramatic changes in cellular protein composition and energy use, their effects must be closely guarded to ensure that the pathogen is responding to the stress without exhausting cellular resources. Some alternate sigma factors are constitutively expressed but held inactive until they are 
needed by regulatory proteins that change conformation or leave the cell in response to a particular signal. For example, RpoE is held inactive until an extracellular signal of extracytoplasmic stress is received and FliA is held inactive by FlgM until the FlgM is exported out of the cell by the completed hook and basal body structure. Some regulation of sigma factors is accomplished by the optimal conditions under which they can influence gene expression. For example, rpoH can not be translated below a certain temperature because at lower temperatures the mRNA folds back on itself blocking the start codon. And RpoS shows increased efficiency at stationary phase growth and is almost nonexistent during exponential growth, potentially due to a change in the intracellular milieu caused by a different growth stage.

Because much of the efficiency of sigma factors to influence transcription is influenced by their relative concentrations within the cells, many mechanisms to regulate them change the available concentration of these proteins. Different proteases target specific sigma factors and depending on the relative concentration of these proteases, the relative availability of the sigma factors can be adjusted. As the concentration of core enzyme is constant, this can dramatically effect gene expression.

Because of the wide variety of genes under its transcriptional control and the ability of RpoS to elicit a strong response, its activity must be closely monitored by the bacteria. Several novel pathways of regulation have been discovered, and it is almost certain that others exist. DksA is required for efficient translation of rpoS but not at the same location as the protein product of $h f q[126]$. Another protein, RstA, 
decreases the expression of RpoS controlled genes and appears to decrease cellular levels of RpoS independently of proteolytic activity [127]. Translation of the rpoS mRNA is elevated in the presence of appropriate carbon sources, indicating a growth rate dependent control of sigma factor availability [38]. In response to increased glucose levels, StpA prevents overactivation of $\sigma^{S}$ indirectly enhancing its turnover [128]. Some small mRNAs such as DsrA and RprA, are highly conserved as are their antisense elements within the rpoS mRNA but only have small effects on RpoS availability [129]. DsrA interaction with rpoS mRNA disrupts the stem and loop base pairing of rpoS mRNA to allow high levels of translation [130]. The same study discovered another small RNA, RprA, that interacts in a similar way to positively regulate RpoS translation [130]. The high number of complex regulation systems that operate independently of each other speak to the need to be able to quickly change RpoS activity as well as to the functions that RpoS helps to mediate.

\section{Sigma Factors and Other Regulatory Mechanisms}

Differential gene expression through alternate sigma factors is far from the only regulatory mechanism with Salmonella and there are points in the response to environmental stimuli that these other regulatory pathways are influenced by or influence alternate sigma factors. Two important regulators that intersect differential gene expression with sigma factors are the PhoP/PhoQ regulatory system and the Fis global regulator.

The PhoP/PhoQ regulatory system influences the expression of many genes and is functionally a sensor of extracellular magnesium concentration. It has been found to have evolved differently in closely related species like $E$. coli and 
Salmonella as a result of different lifestyles [131]. The relation between the PhoP/PhoQ regulatory system and $\sigma^{\mathrm{S}}$ appears to be essential. Even in cells with functional copies of rpoS, mutants lacking PhoP cannot form functional phagosomes within phagocytic cells [132]. Mutants with a double knockout of the RpoS and PhoP/PhoQ show decreased virulence and decreased invasion of host cells [133]. It has even been suggested that because of their inability to cause lasting infections, these double knockouts should be used to make a Salmonella vaccine [133].

PhoP controls the level of available RpoS by controlling proteins which enable its degradation by ClpXP. PhoP acts as a transcriptional activator for iraP, which encodes for a protein that interacts with RssB. RssB facilitates ClpXP degradation of $\sigma^{S}$ [134]. By blocking RssB activity, the level of $\sigma^{S}$ accumulates during PhoP/PhoQ activation, which includes low levels of magnesium as found inside macrophages. This is very different than the type of regulation seen in the commensal E. coli [134], indicating that while there is some similarity in the genes expressed between the two, the regulation of the alternative sigma pathways is not the same.

Interestingly, RpoE seems to be involved in the regulation of $\mathrm{PhoP} / \mathrm{PhoQ}$ activity through Hfq, the same RNA chaperone through which it mediates RpoS expression [135]. As RpoE is at the top of a cascade that leads to increased RpoS concentration, it stands to reason that there would be a multitude of ways through which RpoE regulates RpoS level.

Fis (factor for inversion stimulation) is a global transcription regulator and facilitates site-specific DNA recombination [136]. The intracellular concentrations 
of Fis are high during exponential growth and low in late exponential and stationary phase growth [137]. The fis promoter itself is of some interest into how these concentration differences are maintained. It is $\sigma^{70}$ dependent and growth-phase dependent regulation from this promoter is achieved through a weak - 35 sequence, a second RNA polymerase binding site, and the relative concentration of nucleotides within the cell [138]. The fis promoter is somewhat unique among $\sigma^{70}$-dependent promoters in that transcription begins with a cysteine [137]. This residue is normally a poor initiator of transcription and as a result the RNA polymerase holoenzyme binds very weakly with the fis promoter [137]. When cellular concentrations of cysteine are low, there is very little transcription from the promoter but as CTPs increase in the cell, so does gene expression from the fis promoter [137].

As expected from the pattern of Fis concentration in the cell, there is a negative relationship between the intracellular level of RpoS and Fis during stationary phase growth [140]. Fis in fact is able to mediate expression from $\sigma^{S}-$ dependent genes by binding to a Fis-specific site upstream of $\sigma^{S}$ promoter regions and blocking RpoS activity during exponential growth [59].

Fis, as its name suggests, is also essential for the ability of Salmonella to switch flagellar types. There are two types of flagellar filaments, FljB and FliC, which are both transcribed from class 3 promoters. Flagellar switching is achieved by inversion of a promoter region. When expression occurs from this promoter, a type B filament is produced and a repressor of type $C$ is created. When the inversion occurs, the repressor of type $C$ is not produced and type $C$ filaments are made [140]. 
Hin (for $\mathrm{H}$ invertase) and Fis are both required for proper inversion [141]. Hin seems to mediate the inversion while Fis ensures the appropriate alignment of the piece of DNA that is being inverted [141].

In having two different types of filaments available for use, Salmonella is able to evade the host immune system. FliC is a well-studied target of the immune system [91]. As bacteria migrate through the small intestines and into the rest of the host, FliC expression is suppressed or switched for FljB expression to avoid detection by $\mathrm{T}$ cells [91]. Once past the initial site of infection, $\mathrm{T}$ cells are no longer able to recognize the pathogen [91]. Fis allows for the switching of promoter availability to FliA and due to its pattern of concentration in the cell, ensures that the bacteria is not wasting cellular energy making flagella while in stationary growth.

Finally, the relatedness of alternate sigma factors and pathogenicity can ensure that certain genes are not expressed at the wrong time. The gene hilA which is responsible for the regulation of SPI- 1 genes is found in the same operon as FliA, the alternate sigma factor for flagellar filament assembly [87]. This proximity within the genome allows for the simultaneous control of both mobility and invasion properties.

\section{From Theory to Practice}

Differential gene expression through the use of alternate sigma factors is one of numerous regulatory methods available to Salmonella to avoid destruction by its host's immune system or sanitation processes and to thrive in a variety of 
environments. Control through sigma factors intersects control exerted by other regulatory pathways to ensure a highly controllable pattern of gene expression.

There is yet much more work to be done in this area. The full capacity of Salmonella to change rapidly and accurately to respond to environmental conditions is still not well understood. Genes that are central to virulence are often under the most types of regulatory control. For example, sigma factor expression is itself is highly controlled at the level of transcription and translation, but they are interconnected in a complex web, regulating and fine tuning the gene expression from each type of promoter.

The use of alternate sigma factors seems to be a specific evolutionary tactic for Salmonella to survive in the environment and inside a host. The differential gene expression that Salmonella demonstrates is induced by environmental conditions that the pathogen encounters within its hosts. Moreover, these environmental conditions are in a constant state of flux, as a product of the bacteria's movement through its host as well as the changing state of the host itself. It is not clear the extent of signals that induce the differential gene expression in Salmonella. Sensitivities and properties that Salmonella demonstrates outside of a host may be quite different from what happens inside another organism. While there is no evidence that differential gene expression through alternate sigma factors confers antibiotic resistance, it is likely that the adaptive manner in which Salmonella is able to survive within its host will affect its interaction with other bacteria grown in the same system and the ability of the antibiotic to act on the bacteria by allowing it to change phases of growth rapidly as a population. 


\section{REFERENCES}

1. Petrosino, J., C. Cantu, 3rd, and T. Palzkill, beta-Lactamases: protein evolution in real time. Trends Microbiol, 1998. 6(8): p. 323-7.

2. Dugatkin, L.A., M. Perlin, J.S. Lucas, and R. Atlas, Group-beneficial traits, frequency-dependent selection and genotypic diversity: an antibiotic resistance paradigm. Proc Biol Sci, 2005. 272(1558): p. 79-83.

3. Clark, D.R., T.M. Alton, A. Bajorek, P. Holden, L.A. Dugatkin, R.M. Atlas, and M.H. Perlin, Evolution of altruists and cheaters in near-isogenic populations of Escherichia coli. Front Biosci, 2009. 14: p. 4815-24.

4. Perlin, M.H., D.R. Clark, C. McKenzie, H. Patel, N. Jackson, C. Kormanik, C. Powell, A. Bajorek, D.A. Myers, L.A. Dugatkin, and R.M. Atlas, Protection of Salmonella by ampicillin-resistant Escherichia coli in the presence of otherwise lethal drug concentrations. Proc Biol Sci, 2009. 276(1674): p. 3759-68.

5. Bolivar, F., R.L. Rodriguez, M.C. Betlach, and H.W. Boyer, Construction and characterization of new cloning vehicles. I. Ampicillin-resistant derivatives of the plasmid pMB9. Gene, 1977. 2(2): p. 75-93.

6. Valdez, Y., G.E. Diehl, B.A. Vallance, G.A. Grassl, J.A. Guttman, N.F. Brown, C.M. Rosenberger, D.R. Littman, P. Gros, and B.B. Finlay, Nramp1 expression by dendritic cells modulates inflammatory responses during Salmonella Typhimurium infection. Cell Microbiol, 2008. 10(8): p. 1646-61.

7. Mastroeni, P. and M. Sheppard, Salmonella infections in the mouse model: host resistance factors and in vivo dynamics of bacterial spread and distribution in the tissues. Microbes Infect, 2004. 6(4): p. 398-405.

8. Kimman, T.G., Genetics of infectious disease susceptibility2001, Boston: Kluwer Academic Publishers. 247 p.

9. Shaoping, W., Lu, R., and J. Sun, Chronic Salmonella Infected Mouse Model. JoVE 2010. 39 http://www.jove.com/index/Details.stp?!D=1947.doc.

10. Hunter, P.A., G.N. Rolinson, and D.A. Witting, Comparative activity of amoxycillin and ampicillin in an experimental bacterial infection in mice. Antimicrob Agents Chemother, 1973. 4(3): p. 285-93.

11. Lafforgue, G., C. Arellano, C. Vachoux, J. Woodley, C. Philibert, V. Dupouy, A. Bousquet-Melou, P. Gandia, and G. Houin, Oral absorption of ampicillin: role of paracellular route vs. PepT1 transporter. Fundam Clin Pharmacol, 2008. 22(2): p. 189-201.

12. Anton, P.A., J.A. Kemp, T. Butler, and M.R. Jacobs, Comparative efficacies of 
ceftriaxone, moxalactam, and ampicillin in experimental Salmonella typhimurium infection. Antimicrob Agents Chemother, 1982. 22(2): p. 312-5.

13. Kumar, A., E. Hajjar, P. Ruggerone, and M. Ceccarelli, Molecular simulations reveal the mechanism and the determinants for ampicillin translocation through OmpF. J Phys Chem B, 2010. 114(29): p. 9608-16.

14. Hapfelmeier, S. and W.D. Hardt, A mouse model for S. typhimurium-induced enterocolitis. Trends Microbiol, 2005. 13(10): p. 497-503.

15. Thiennimitr, P., S.E. Winter, M.G. Winter, M.N. Xavier, V. Tolstikov, D.L. Huseby, T. Sterzenbach, R.M. Tsolis, J.R. Roth, and A.J. Baumler, Intestinal inflammation allows Salmonella to use ethanolamine to compete with the microbiota. Proc Natl Acad Sci U S A, 2011. 108(42): p. 17480-5.

16. Knodler, L.A., B.A. Vallance, J. Celli, S. Winfree, B. Hansen, M. Montero, and O. Steele-Mortimer, Dissemination of invasive Salmonella via bacterial-induced extrusion of mucosal epithelia. Proc Natl Acad Sci U S A, 2010. 107(41): p. 17733-8.

17. Dougan, G., V. John, S. Palmer, and P. Mastroeni, Immunity to salmonellosis. Immunol Rev, 2011. 240(1): p. 196-210.

18. McDermott, J.E., H. Yoon, E.S. Nakayasu, T.O. Metz, D.R. Hyduke, A.S. Kidwai, B.O. Palsson, J.N. Adkins, and F. Heffron, Technologies and approaches to elucidate and model the virulence program of salmonella. Front Microbiol, 2011. 2: p. 121.

19. Ohl, M.E. and S.I. Miller, Salmonella: a model for bacterial pathogenesis. Annu Rev Med, 2001. 52: p. 259-74.

20. Burgess, R.R., A.A. Travers, J.J. Dunn, and E.K. Bautz, Factor stimulating transcription by RNA polymerase. Nature, 1969. 221(5175): p. 43-6.

21. Kutsukake, K., S. Iyoda, K. Ohnishi, and T. Iino, Genetic and molecular analyses of the interaction between the flagellum-specific sigma and anti-sigma factors in Salmonella typhimurium. EMBO J, 1994. 13(19): p. 4568-76.

22. Dombroski, A.J., W.A. Walter, M.T. Record, Jr., D.A. Siegele, and C.A. Gross, Polypeptides containing highly conserved regions of transcription initiation factor sigma 70 exhibit specificity of binding to promoter DNA. Cell, 1992. 70(3): p. 501-12.

23. Dombroski, A.J., W.A. Walter, and C.A. Gross, Amino-terminal amino acids modulate sigma-factor DNA-binding activity. Genes Dev, 1993. 7(12A): p. 2446-55.

24. Baumler, A.J., J.G. Kusters, I. Stojiljkovic, and F. Heffron, Salmonella typhimurium loci involved in survival within macrophages. Infect Immun, 1994. 62(5): p. 1623-30.

25. Romling, U., W.D. Sierralta, K. Eriksson, and S. Normark, Multicellular and aggregative behaviour of Salmonella typhimurium strains is controlled by 
mutations in the agfD promoter. Mol Microbiol, 1998. 28(2): p. 249-64.

26. Aiba, A. and K. Mizobuchi, Nucleotide sequence analysis of genes purH and purD involved in the de novo purine nucleotide biosynthesis of Escherichia coli. J Biol Chem, 1989. 264(35): p. 21239-46.

27. Kilstrup, M., S.G. Jessing, S.B. Wichmand-Jorgensen, M. Madsen, and D. Nilsson, Activation control of pur gene expression in Lactococcus lactis: proposal for a consensus activator binding sequence based on deletion analysis and sitedirected mutagenesis of purC and purD promoter regions. J Bacteriol, 1998. 180(15): p. 3900-6.

28. Mongodin, E., J. Finan, M.W. Climo, A. Rosato, S. Gill, and G.L. Archer, Microarray transcription analysis of clinical Staphylococcus aureus isolates resistant to vancomycin. J Bacteriol, 2003. 185(15): p. 4638-43.

29. Wood, L.F., A.J. Leech, and D.E. Ohman, Cell wall-inhibitory antibiotics activate the alginate biosynthesis operon in Pseudomonas aeruginosa: Roles of sigma (AlgT) and the AlgW and Prc proteases. Mol Microbiol, 2006. 62(2): p. 412-26.

30. Weir, E.K., L.C. Martin, C. Poppe, B.K. Coombes, and P. Boerlin, Subinhibitory concentrations of tetracycline affect virulence gene expression in a multiresistant Salmonella enterica subsp. enterica serovar Typhimurium DT104. Microbes Infect, 2008. 10(8): p. 901-7.

31. Minagawa, S., H. Ogasawara, A. Kato, K. Yamamoto, Y. Eguchi, T. Oshima, H. Mori, A. Ishihama, and R. Utsumi, Identification and molecular characterization of the $\mathrm{Mg} 2+$ stimulon of Escherichia coli. J Bacteriol, 2003. 185(13): p. 3696-702.

32. Sutton, A., R. Buencamino, and A. Eisenstark, rpoS mutants in archival cultures of Salmonella enterica serovar typhimurium. J Bacteriol, 2000. 182(16): p. 4375-9.

33. Guiney, D.G., S. Libby, F.C. Fang, M. Krause, and J. Fierer, Growth-phase regulation of plasmid virulence genes in Salmonella. Trends Microbiol, 1995. 3(7): p. 275-9.

34. Morett, E. and L. Segovia, The sigma 54 bacterial enhancer-binding protein family: mechanism of action and phylogenetic relationship of their functional domains. J Bacteriol, 1993. 175(19): p. 6067-74.

35. Barchiesi, J., M. Espariz, S.K. Checa, and F.C. Soncini, Downregulation of RpoNcontrolled genes protects Salmonella cells from killing by the cationic antimicrobial peptide polymyxin B. FEMS Microbiol Lett, 2009. 291(1): p. 739.

36. Studholme, D.J., Enhancer-dependent transcription in Salmonella enterica Typhimurium: new members of the sigmaN regulon inferred from protein sequence homology and predicted promoter sites. J Mol Microbiol Biotechnol, 2002. 4(4): p. 367-74. 
37. Barrios, H., B. Valderrama, and E. Morett, Compilation and analysis of sigma(54)-dependent promoter sequences. Nucleic Acids Res, 1999. 27(22): $\mathrm{p}$. 4305-13.

38. Buck, M., M.T. Gallegos, D.J. Studholme, Y. Guo, and J.D. Gralla, The bacterial enhancer-dependent sigma(54) (sigma(N)) transcription factor. J Bacteriol, 2000. 182(15): p. 4129-36.

39. Buck, M. and W. Cannon, Specific binding of the transcription factor sigma-54 to promoter DNA. Nature, 1992. 358(6385): p. 422-4.

40. Ohnishi, K., K. Kutsukake, H. Suzuki, and T. Iino, Gene fliA encodes an alternative sigma factor specific for flagellar operons in Salmonella typhimurium. Mol Gen Genet, 1990. 221(2): p. 139-47.

41. Scaife, J.G., J.S. Heilig, L. Rowen, and R. Calendar, Gene for the RNA polymerase sigma subunit mapped in Salmonella typhimurium and Escherichia coli by cloning and deletion. Proc Natl Acad Sci U S A, 1979. 76(12): p. 6510-4.

42. Burton, Z.F., C.A. Gross, K.K. Watanabe, and R.R. Burgess, The operon that encodes the sigma subunit of RNA polymerase also encodes ribosomal protein S21 and DNA primase in E. coli K12. Cell, 1983. 32(2): p. 335-49.

43. Kenyon, W.J., S.M. Thomas, E. Johnson, M.J. Pallen, and M.P. Spector, Shifts from glucose to certain secondary carbon-sources result in activation of the extracytoplasmic function sigma factor sigmaE in Salmonella enterica serovar Typhimurium. Microbiology, 2005. 151(Pt 7): p. 2373-83.

44. Muller, C., I.S. Bang, J. Velayudhan, J. Karlinsey, K. Papenfort, J. Vogel, and F.C. Fang, Acid stress activation of the sigma(E) stress response in Salmonella enterica serovar Typhimurium. Mol Microbiol, 2009. 71(5): p. 1228-38.

45. Mutalik, V.K., G. Nonaka, S.E. Ades, V.A. Rhodius, and C.A. Gross, Promoter strength properties of the complete sigma E regulon of Escherichia coli and Salmonella enterica. J Bacteriol, 2009. 191(23): p. 7279-87.

46. Papenfort, K., V. Pfeiffer, F. Mika, S. Lucchini, J.C. Hinton, and J. Vogel, SigmaEdependent small RNAs of Salmonella respond to membrane stress by accelerating global omp $m R N A$ decay. Mol Microbiol, 2006. 62(6): p. 1674-88.

47. Rhodius, V.A., W.C. Suh, G. Nonaka, J. West, and C.A. Gross, Conserved and variable functions of the sigmaE stress response in related genomes. PLoS Biol, 2006. 4(1): p. e2.

48. Bang, I.S., J.G. Frye, M. McClelland, J. Velayudhan, and F.C. Fang, Alternative sigma factor interactions in Salmonella: sigma and sigma promote antioxidant defences by enhancing sigma levels. Mol Microbiol, 2005. 56(3): p. 811-23.

49. Testerman, T.L., A. Vazquez-Torres, Y. Xu, J. Jones-Carson, S.J. Libby, and F.C. Fang, The alternative sigma factor sigmaE controls antioxidant defences required for Salmonella virulence and stationary-phase survival. Mol Microbiol, 2002. 43(3): p. 771-82. 
50. Conlin, C.A. and C.G. Miller, opdA, a Salmonella enterica serovar Typhimurium gene encoding a protease, is part of an operon regulated by heat shock. J Bacteriol, 2000. 182(2): p. 518-21.

51. Waldminghaus, T., N. Heidrich, S. Brantl, and F. Narberhaus, FourU: a novel type of RNA thermometer in Salmonella. Mol Microbiol, 2007. 65(2): p. 413-24.

52. Brown, L. and T. Elliott, Efficient translation of the RpoS sigma factor in Salmonella typhimurium requires host factor I, an RNA-binding protein encoded by the hfq gene. J Bacteriol, 1996. 178(13): p. 3763-70.

53. Brown, L. and T. Elliott, Mutations that increase expression of the rpoS gene and decrease its dependence on hfq function in Salmonella typhimurium. J Bacteriol, 1997. 179(3): p. 656-62.

54. Cunning, C. and T. Elliott, RpoS synthesis is growth rate regulated in Salmonella typhimurium, but its turnover is not dependent on acetyl phosphate synthesis or PTS function. J Bacteriol, 1999. 181(16): p. 4853-62.

55. Sittka, A., V. Pfeiffer, K. Tedin, and J. Vogel, The RNA chaperone Hfq is essential for the virulence of Salmonella typhimurium. Mol Microbiol, 2007.63(1): p. 193-217.

56. Robbe-Saule, V., G. Algorta, I. Rouilhac, and F. Norel, Characterization of the RpoS status of clinical isolates of Salmonella enterica. Appl Environ Microbiol, 2003. 69(8): p. 4352-8.

57. Ibanez-Ruiz, M., V. Robbe-Saule, D. Hermant, S. Labrude, and F. Norel, Identification of RpoS (sigma(S))-regulated genes in Salmonella enterica serovar typhimurium. J Bacteriol, 2000. 182(20): p. 5749-56.

58. Fang, F.C., C.Y. Chen, D.G. Guiney, and Y. Xu, Identification of sigma S-regulated genes in Salmonella typhimurium: complementary regulatory interactions between sigma S and cyclic AMP receptor protein. J Bacteriol, 1996. 178(17): p. 5112-20.

59. Hirsch, M. and T. Elliott, Fis regulates transcriptional induction of RpoS in Salmonella enterica. J Bacteriol, 2005. 187(5): p. 1568-80.

60. Fang, F.C., S.J. Libby, N.A. Buchmeier, P.C. Loewen, J. Switala, J. Harwood, and D.G. Guiney, The alternative sigma factor katF (rpoS) regulates Salmonella virulence. Proc Natl Acad Sci U S A, 1992. 89(24): p. 11978-82.

61. Audia, J.P. and J.W. Foster, Acid shock accumulation of sigma S in Salmonella enterica involves increased translation, not regulated degradation. J Mol Microbiol Biotechnol, 2003. 5(1): p. 17-28.

62. Bearson, S.M., W.H. Benjamin, Jr., W.E. Swords, and J.W. Foster, Acid shock induction of RpoS is mediated by the mouse virulence gene mviA of Salmonella typhimurium. J Bacteriol, 1996. 178(9): p. 2572-9.

63. O'Neal, C.R., W.M. Gabriel, A.K. Turk, S.J. Libby, F.C. Fang, and M.P. Spector, RpoS is necessary for both the positive and negative regulation of starvation 
survival genes during phosphate, carbon, and nitrogen starvation in Salmonella typhimurium. J Bacteriol, 1994. 176(15): p. 4610-6.

64. Helmann, J.D. and M.J. Chamberlin, DNA sequence analysis suggests that expression of flagellar and chemotaxis genes in Escherichia coli and Salmonella typhimurium is controlled by an alternative sigma factor. Proc Natl Acad Sci U S A, 1987. 84(18): p. 6422-4.

65. Bonifield, H.R. and K.T. Hughes, Flagellar phase variation in Salmonella enterica is mediated by a posttranscriptional control mechanism. J Bacteriol, 2003. 185(12): p. 3567-74.

66. Karlinsey, J.E., S. Tanaka, V. Bettenworth, S. Yamaguchi, W. Boos, S.I. Aizawa, and K.T. Hughes, Completion of the hook-basal body complex of the Salmonella typhimurium flagellum is coupled to FlgM secretion and fliC transcription. Mol Microbiol, 2000. 37(5): p. 1220-31.

67. Karlinsey, J.E. and K.T. Hughes, Genetic transplantation: Salmonella enterica serovar Typhimurium as a host to study sigma factor and anti-sigma factor interactions in genetically intractable systems. J Bacteriol, 2006. 188(1): $\mathrm{p}$. 103-14.

68. Liu, X., N. Fujita, A. Ishihama, and P. Matsumura, The C-terminal region of the alpha subunit of Escherichia coli RNA polymerase is required for transcriptional activation of the flagellar level II operons by the FlhD/FIhC complex. J Bacteriol, 1995. 177(17): p. 5186-8.

69. Liu, X. and P. Matsumura, The FlhD/FlhC complex, a transcriptional activator of the Escherichia coli flagellar class II operons. J Bacteriol, 1994. 176(23): p. 7345-51.

70. Brown, K.L. and K.T. Hughes, The role of anti-sigma factors in gene regulation. Mol Microbiol, 1995. 16(3): p. 397-404.

71. Chadsey, M.S., J.E. Karlinsey, and K.T. Hughes, The flagellar anti-sigma factor FlgM actively dissociates Salmonella typhimurium sigma28 RNA polymerase holoenzyme. Genes Dev, 1998. 12(19): p. 3123-36.

72. Hughes, K.T., K.L. Gillen, M.J. Semon, and J.E. Karlinsey, Sensing structural intermediates in bacterial flagellar assembly by export of a negative regulator. Science, 1993. 262(5137): p. 1277-80.

73. Kutsukake, K. and T. Iino, Role of the FliA-FlgM regulatory system on the transcriptional control of the flagellar regulon and flagellar formation in Salmonella typhimurium. J Bacteriol, 1994. 176(12): p. 3598-605.

74. Chilcott, G.S. and K.T. Hughes, Coupling of flagellar gene expression to flagellar assembly in Salmonella enterica serovar typhimurium and Escherichia coli. Microbiol Mol Biol Rev, 2000. 64(4): p. 694-708.

75. Wozniak, C.E., F.F. Chevance, and K.T. Hughes, Multiple promoters contribute to swarming and the coordination of transcription with flagellar assembly in 
Salmonella. J Bacteriol, 2010. 192(18): p. 4752-62.

76. Ikebe, T., S. Iyoda, and K. Kutsukake, Structure and expression of the fliA operon of Salmonella typhimurium. Microbiology, 1999. 145 ( Pt 6): p. 1389-96.

77. Yokoseki, T., T. Iino, and K. Kutsukake, Negative regulation by fliD, fliS, and fliT of the export of the flagellum-specific anti-sigma factor, FlgM, in Salmonella typhimurium. J Bacteriol, 1996. 178(3): p. 899-901.

78. Farewell, A., K. Kvint, and T. Nystrom, Negative regulation by RpoS: a case of sigma factor competition. Mol Microbiol, 1998. 29(4): p. 1039-51.

79. Jishage, M. and A. Ishihama, Regulation of RNA polymerase sigma subunit synthesis in Escherichia coli: intracellular levels of sigma 70 and sigma 38. J Bacteriol, 1995. 177(23): p. 6832-5.

80. Hansen-Wester, I. and M. Hensel, Salmonella pathogenicity islands encoding type III secretion systems. Microbes Infect, 2001. 3(7): p. 549-59.

81. Bueno, S.M., C.A. Riedel, L.J. Carreno, and A.M. Kalergis, Virulence mechanisms displayed by Salmonella to impair dendritic cell function. Curr Med Chem, 2010. 17(12): p. 1156-66.

82. Lawhon, S.D., R. Maurer, M. Suyemoto, and C. Altier, Intestinal short-chain fatty acids alter Salmonella typhimurium invasion gene expression and virulence through BarA/SirA. Mol Microbiol, 2002. 46(5): p. 1451-64.

83. Slauch, J., R. Taylor, and S. Maloy, Survival in a cruel world: how Vibrio cholerae and Salmonella respond to an unwilling host. Genes Dev, 1997. 11(14): p. 1761-74.

84. Jones, B.D. and S. Falkow, Identification and characterization of a Salmonella typhimurium oxygen-regulated gene required for bacterial internalization. Infect Immun, 1994. 62(9): p. 3745-52.

85. Francis, C.L., M.N. Starnbach, and S. Falkow, Morphological and cytoskeletal changes in epithelial cells occur immediately upon interaction with Salmonella typhimurium grown under low-oxygen conditions. Mol Microbiol, 1992. 6(21): p. 3077-87.

86. McCormick, B.A., S.P. Colgan, C. Delp-Archer, S.I. Miller, and J.L. Madara, Salmonella typhimurium attachment to human intestinal epithelial monolayers: transcellular signalling to subepithelial neutrophils. J Cell Biol, 1993. 123(4): p. 895-907.

87. Lucas, R.L., C.P. Lostroh, C.C. DiRusso, M.P. Spector, B.L. Wanner, and C.A. Lee, Multiple factors independently regulate hilA and invasion gene expression in Salmonella enterica serovar typhimurium. J Bacteriol, 2000. 182(7): p. 187282.

88. Pace, J., M.J. Hayman, and J.E. Galan, Signal transduction and invasion of epithelial cells by S. typhimurium. Cell, 1993. 72(4): p. 505-14.

89. Galan, J.E., Molecular and cellular bases of Salmonella entry into host cells. Curr 
Top Microbiol Immunol, 1996. 209: p. 43-60.

90. Baumler, A.J., R.M. Tsolis, and F. Heffron, Contribution of fimbrial operons to attachment to and invasion of epithelial cell lines by Salmonella typhimurium. Infect Immun, 1996. 64(5): p. 1862-5.

91. Cummings, L.A., S.L. Barrett, W.D. Wilkerson, I. Fellnerova, and B.T. Cookson, FliC-specific $C D 4+T$ cell responses are restricted by bacterial regulation of antigen expression. J Immunol, 2005. 174(12): p. 7929-38.

92. Jantsch, J., C. Cheminay, D. Chakravortty, T. Lindig, J. Hein, and M. Hensel, Intracellular activities of Salmonella enterica in murine dendritic cells. Cell Microbiol, 2003. 5(12): p. 933-45.

93. Bueno, S.M., P.A. Gonzalez, L.J. Carreno, J.A. Tobar, G.C. Mora, C.J. Pereda, F. Salazar-Onfray, and A.M. Kalergis, The capacity of Salmonella to survive inside dendritic cells and prevent antigen presentation to $T$ cells is host specific. Immunology, 2008. 124(4): p. 522-33.

94. Medzhitov, R. and C. Janeway, Jr., Innate immune recognition: mechanisms and pathways. Immunol Rev, 2000. 173: p. 89-97.

95. Giannella, R.A., S.A. Broitman, and N. Zamcheck, Gastric acid barrier to ingested microorganisms in man: studies in vivo and in vitro. Gut, 1972. 13(4): p. 251-6.

96. Alaniz, R.C., L.A. Cummings, M.A. Bergman, S.L. Rassoulian-Barrett, and B.T. Cookson, Salmonella typhimurium coordinately regulates FliC location and reduces dendritic cell activation and antigen presentation to $C D 4+T$ cells. $\mathrm{J}$ Immunol, 2006. 177(6): p. 3983-93.

97. Shea, J.E., M. Hensel, C. Gleeson, and D.W. Holden, Identification of a virulence locus encoding a second type III secretion system in Salmonella typhimurium. Proc Natl Acad Sci U S A, 1996. 93(6): p. 2593-7.

98. Lara-Tejero, M. and J.E. Galan, Salmonella enterica serovar typhimurium pathogenicity island 1-encoded type III secretion system translocases mediate intimate attachment to nonphagocytic cells. Infect Immun, 2009. 77(7): p. $2635-42$.

99. Steele-Mortimer, O., J.H. Brumell, L.A. Knodler, S. Meresse, A. Lopez, and B.B. Finlay, The invasion-associated type III secretion system of Salmonella enterica serovar Typhimurium is necessary for intracellular proliferation and vacuole biogenesis in epithelial cells. Cell Microbiol, 2002. 4(1): p. 43-54.

100. Scherer, C.A., E. Cooper, and S.I. Miller, The Salmonella type III secretion translocon protein SspC is inserted into the epithelial cell plasma membrane upon infection. Mol Microbiol, 2000. 37(5): p. 1133-45.

101. Chen, L.M., S. Hobbie, and J.E. Galan, Requirement of CDC42 for Salmonellainduced cytoskeletal and nuclear responses. Science, 1996. 274(5295): p. 2115-8.

102. Fu, Y. and J.E. Galan, A salmonella protein antagonizes Rac-1 and Cdc42 to 
mediate host-cell recovery after bacterial invasion. Nature, 1999.401(6750): p. 293-7.

103. Jepson, M.A., B. Kenny, and A.D. Leard, Role of sipA in the early stages of Salmonella typhimurium entry into epithelial cells. Cell Microbiol, 2001. 3(6): p. 417-26.

104. Higashide, W., S. Dai, V.P. Hombs, and D. Zhou, Involvement of SipA in modulating actin dynamics during Salmonella invasion into cultured epithelial cells. Cell Microbiol, 2002. 4(6): p. 357-65.

105. Hayward, R.D. and V. Koronakis, Direct nucleation and bundling of actin by the SipC protein of invasive Salmonella. EMBO J, 1999. 18(18): p. 4926-34.

106. Galan, J.E. and R. Curtiss, 3rd, Cloning and molecular characterization of genes whose products allow Salmonella typhimurium to penetrate tissue culture cells. Proc Natl Acad Sci U S A, 1989. 86(16): p. 6383-7.

107. Matsui, M., A. Takaya, and T. Yamamoto, Sigma32-mediated negative regulation of Salmonella pathogenicity island 1 expression. J Bacteriol, 2008. 190(20): p. 6636-45.

108. Lober, S., D. Jackel, N. Kaiser, and M. Hensel, Regulation of Salmonella pathogenicity island 2 genes by independent environmental signals. Int J Med Microbiol, 2006. 296(7): p. 435-47.

109. Cirillo, D.M., R.H. Valdivia, D.M. Monack, and S. Falkow, Macrophagedependent induction of the Salmonella pathogenicity island 2 type III secretion system and its role in intracellular survival. Mol Microbiol, 1998. 30(1): p. 175-88.

110. Hensel, M., J.E. Shea, S.R. Waterman, R. Mundy, T. Nikolaus, G. Banks, A. Vazquez-Torres, C. Gleeson, F.C. Fang, and D.W. Holden, Genes encoding putative effector proteins of the type III secretion system of Salmonella pathogenicity island 2 are required for bacterial virulence and proliferation in macrophages. Mol Microbiol, 1998. 30(1): p. 163-74.

111. Tobar, J.A., L.J. Carreno, S.M. Bueno, P.A. Gonzalez, J.E. Mora, S.A. Quezada, and A.M. Kalergis, Virulent Salmonella enterica serovar typhimurium evades adaptive immunity by preventing dendritic cells from activating $T$ cells. Infect Immun, 2006. 74(11): p. 6438-48.

112. Osborne, S.E. and B.K. Coombes, RpoE fine tunes expression of a subset of SsrBregulated virulence factors in Salmonella enterica serovar Typhimurium. BMC Microbiol, 2009. 9: p. 45.

113. Kowarz, L., C. Coynault, V. Robbe-Saule, and F. Norel, The Salmonella typhimurium katF (rpoS) gene: cloning, nucleotide sequence, and regulation of spvR and spvABCD virulence plasmid genes. J Bacteriol, 1994. 176(22): $\mathrm{p}$. 6852-60.

114. Robbe-Saule, V., M.D. Lopes, A. Kolb, and F. Norel, Physiological effects of Crl in 
Salmonella are modulated by sigmaS level and promoter specificity. J Bacteriol, 2007. 189(8): p. 2976-87.

115. Fang, F.C., Sigma cascades in prokaryotic regulatory networks. Proc Natl Acad Sci U S A, 2005. 102(14): p. 4933-4.

116. De Las Penas, A., L. Connolly, and C.A. Gross, The sigmaE-mediated response to extracytoplasmic stress in Escherichia coli is transduced by RseA and RseB, two negative regulators of sigmaE. Mol Microbiol, 1997. 24(2): p. 373-85.

117. Khan, A.Q., L. Zhao, K. Hirose, M. Miyake, T. Li, Y. Hashimoto, Y. Kawamura, and T. Ezaki, Salmonella typhi rpoS mutant is less cytotoxic than the parent strain but survives inside resting THP-1 macrophages. FEMS Microbiol Lett, 1998. 161(1): p. 201-8.

118. Du, H., X. Sheng, H. Zhang, X. Zou, B. Ni, S. Xu, X. Zhu, H. Xu, and X. Huang, RpoE may promote flagellar gene expression in Salmonella enterica serovar typhi under hyperosmotic stress. Curr Microbiol, 2011. 62(2): p. 492-500.

119. Eriksson, S., S. Lucchini, A. Thompson, M. Rhen, and J.C. Hinton, Unravelling the biology of macrophage infection by gene expression profiling of intracellular Salmonella enterica. Mol Microbiol, 2003. 47(1): p. 103-18.

120. Bittner, M., S. Saldias, F. Altamirano, M.A. Valvano, and I. Contreras, RpoS and $R p o N$ are involved in the growth-dependent regulation of rfaH transcription and $O$ antigen expression in Salmonella enterica serovar Typhi. Microb Pathog, 2004. 36(1): p. 19-24.

121. Dunkley, K.D., T.R. Callaway, V.I. Chalova, R.C. Anderson, M.M. Kundinger, C.S. Dunkley, D.J. Nisbet, and S.C. Ricke, Growth and genetic responses of Salmonella Typhimurium to $\mathrm{pH}$-shifts in an anaerobic continuous culture. Anaerobe, 2008. 14(1): p. 35-42.

122. Komitopoulou, E., N.J. Bainton, and M.R. Adams, Oxidation-reduction potential regulates RpoS levels in Salmonella Typhimurium. J Appl Microbiol, 2004. 96(2): p. 271-8.

123. Dodd, C.E. and T.G. Aldsworth, The importance of RpoS in the survival of bacteria through food processing. Int J Food Microbiol, 2002. 74(3): p. 189-94.

124. Rajkumari, K. and J. Gowrishankar, In vivo expression from the RpoSdependent $P 1$ promoter of the osmotically regulated proU operon in Escherichia coli and Salmonella enterica serovar Typhimurium: activation by rho and hns mutations and by cold stress. J Bacteriol, 2001. 183(22): p. 654350.

125. McMeechan, A., M. Roberts, T.A. Cogan, F. Jorgensen, A. Stevenson, C. Lewis, G. Rowley, and T.J. Humphrey, Role of the alternative sigma factors sigmaE and sigmaS in survival of Salmonella enterica serovar Typhimurium during starvation, refrigeration and osmotic shock. Microbiology, 2007. 153(Pt 1): p. 263-9. 
126. Webb, C., M. Moreno, M. Wilmes-Riesenberg, R. Curtiss, 3rd, and J.W. Foster, Effects of DksA and ClpP protease on sigma $S$ production and virulence in Salmonella typhimurium. Mol Microbiol, 1999. 34(1): p. 112-23.

127. Cabeza, M.L., A. Aguirre, F.C. Soncini, and E.G. Vescovi, Induction of RpoS degradation by the two-component system regulator RstA in Salmonella enterica. J Bacteriol, 2007. 189(20): p. 7335-42.

128. Lucchini, S., P. McDermott, A. Thompson, and J.C. Hinton, The H-NS-like protein StpA represses the RpoS (sigma 38) regulon during exponential growth of Salmonella Typhimurium. Mol Microbiol, 2009. 74(5): p. 1169-86.

129. Jones, A.M., A. Goodwill, and T. Elliott, Limited role for the DsrA and RprA regulatory RNAs in rpoS regulation in Salmonella enterica. J Bacteriol, 2006. 188(14): p. 5077-88.

130. Majdalani, N., S. Chen, J. Murrow, K. St John, and S. Gottesman, Regulation of RpoS by a novel small RNA: the characterization of RprA. Mol Microbiol, 2001. 39(5): p. 1382-94.

131. Monsieurs, P., S. De Keersmaecker, W.W. Navarre, M.W. Bader, F. De Smet, M. McClelland, F.C. Fang, B. De Moor, J. Vanderleyden, and K. Marchal, Comparison of the PhoPQ regulon in Escherichia coli and Salmonella typhimurium. J Mol Evol, 2005. 60(4): p. 462-74.

132. Alpuche-Aranda, C.M., E.L. Racoosin, J.A. Swanson, and S.I. Miller, Salmonella stimulate macrophage macropinocytosis and persist within spacious phagosomes. J Exp Med, 1994. 179(2): p. 601-8.

133. Lee, H.Y., S.A. Cho, I.S. Lee, J.H. Park, S.H. Seok, M.W. Baek, D.J. Kim, S.H. Lee, S.J. Hur, S.J. Ban, Y.K. Lee, Y.K. Han, Y.K. Cho, and J.H. Park, Evaluation of phoP and rpoS mutants of Salmonella enterica serovar Typhi as attenuated typhoid vaccine candidates: virulence and protective immune responses in intranasally immunized mice. FEMS Immunol Med Microbiol, 2007. 51(2): p. 310-8.

134. Tu, X., T. Latifi, A. Bougdour, S. Gottesman, and E.A. Groisman, The PhoP/PhoQ two-component system stabilizes the alternative sigma factor RpoS in Salmonella enterica. Proc Natl Acad Sci U S A, 2006. 103(36): p. 13503-8.

135. Coornaert, A., A. Lu, P. Mandin, M. Springer, S. Gottesman, and M. Guillier, MicA sRNA links the PhoP regulon to cell envelope stress. Mol Microbiol, 2010. 76(2): p. 467-79.

136. Mallik, P., T.S. Pratt, M.B. Beach, M.D. Bradley, J. Undamatla, and R. Osuna, Growth phase-dependent regulation and stringent control of fis are conserved processes in enteric bacteria and involve a single promoter (fis $P$ ) in Escherichia coli. J Bacteriol, 2004. 186(1): p. 122-35.

137. Walker, K.A., P. Mallik, T.S. Pratt, and R. Osuna, The Escherichia coli Fis promoter is regulated by changes in the levels of its transcription initiation nucleotide CTP. J Biol Chem, 2004. 279(49): p. 50818-28. 
138. Walker, K.A., C.L. Atkins, and R. Osuna, Functional determinants of the Escherichia coli fis promoter: roles of $-35,-10$, and transcription initiation regions in the response to stringent control and growth phase-dependent regulation. J Bacteriol, 1999. 181(4): p. 1269-80.

139. T, O.C. and C.J. Dorman, Expression of the Fis protein is sustained in lateexponential-and stationary-phase cultures of Salmonella enterica serovar Typhimurium grown in the absence of aeration. Mol Microbiol, 2007. 66(1): $\mathrm{p}$. 237-51.

140. Aldridge, P.D., C. Wu, J. Gnerer, J.E. Karlinsey, K.T. Hughes, and M.S. Sachs, Regulatory protein that inhibits both synthesis and use of the target protein controls flagellar phase variation in Salmonella enterica. Proc Natl Acad Sci U S A, 2006. 103(30): p. 11340-5.

141. Bruist, M.F., A.C. Glasgow, R.C. Johnson, and M.I. Simon, Fis binding to the recombinational enhancer of the Hin DNA inversion system. Genes Dev, 1987. 1(8): p. 762-72. 


\section{CURRICULUM VITAE}

NAME: $\quad$ Rena Margaret Wallen

ADDRESS: Department of Biology

University of Louisville

Louisville, KY 40292

DOB: $\quad$ Lexington, Kentucky - July 20, 1981

EDUCATION: $\quad$ B.Sc, Biology

B.Sc., Psychology

University of Louisville

$2005-2009$

PUBLICATIONS: $\quad$ A Tale of 6 Sigmas: How changing partners allows Salmonella to thrive in the best of times and survive the worst of times Written with Dr. Michael Perlin

Awaiting publication in Salmonella Book 2, InTech Publications

VOLUNTEER

EXPERIENCE: $\quad$ Louisville Regional Science Fair Judge (March 10, 2012) 